\title{
Applications of U.S. Geological Survey Digital Cartographic Products, 1979-1983
}

\section{U.S. GEOLOGICAL SURVEY BULLETIN 1583}



Departinent of the Interior

U.S. Geological Survey

ERRATA

APPLICATIONS OF U.S. GEOLOGICAL SURVEY DIGITAL CARTOGRAPHIC PRODUCTS 1979-1983

U.S. GEOLOGICAL SURVEY BULLETIN 1583

Pages 13-17, Figures 4, 6-10

Illustrations were erroneously printed in reverse tones causing a reversal in figure tonal patterns. Light tones should appear dark and dark tones should appear light.

Pages 13-i4, Figures 4 and 6

Captions for figures 4 and 6 are reversed. Correct captions are:

Figure 4. The elevation data used in the study were from the Reward quadrangle 7.5-minute digital elevation model. In this image, the dark tones represent low elevations while the light areas identify high elevations.

Figure 6. This Landsat MSS band 7 (reflected infrared energy) subscene of the Reward quadrangle in Pennsylvania illustrates the variability of the oak forest spectral signature. Notice the changes caused by the topographic effect and compare it with figure 10. 



\section{Applications of U.S. Geological Survey Digital Cartographic Products, 1979-1983}

By T. R. LOVELAND and BEN RAMEY 


\section{DEPARTMENT OF THE INTERIOR DONALD PAUL HODEL, Secretary \\ U.S. GEOLOGICAL SURVEY \\ Dallas L. Peck, Director}

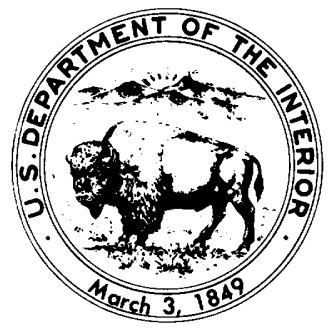

UNITED STATES GOVERNMENT PRINTING OFFICE: 1986

For sale by the Distribution Branch, U.S. Geological Survey, 604 South Pickett Street, Alexandria, VA 22304-4658

Library of Congress Cataloging-in-Publication Data

Loveland, Thomas R.

Applications of U.S. Geological Survey digital cartographic products, 1979-1983.

(U.S. Geological Survey bulletin ; 1583)

Bibliography : p.

Supt. of Docs. no.: I 19.3:1583

1. Digital mapping. 2. Cartography-United States. I.

Ramey, Benjamin S. II. Title. III. Series.

QE75.B9 no. 1583 [GA139] $557.3 \mathrm{~s}$ 


\section{CONTENTS}

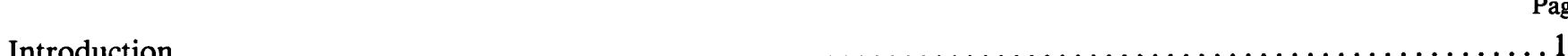

Data characteristics and availability

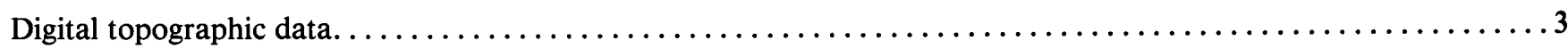

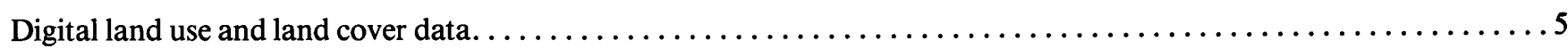

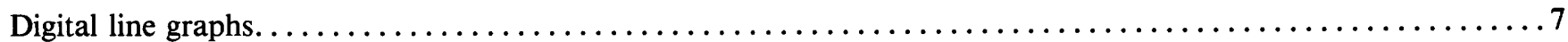

\section{Applications}

Reduction of the topographic effect on Landsat data. . . . . . . . . . . . . . . . . . . . .

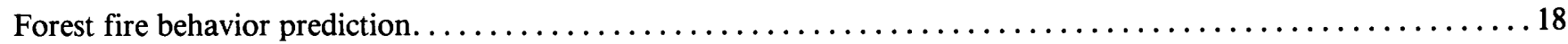

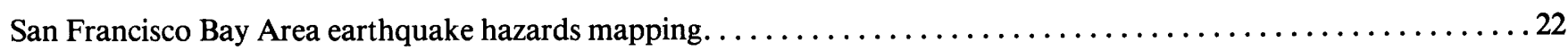

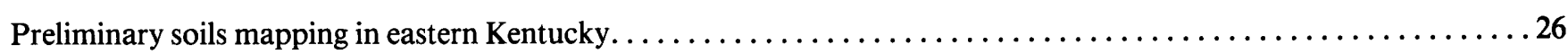

Survey of Oregon irrigation development potential. . . . . . . . . . . . . . . . . . . . . . . . . . . 29

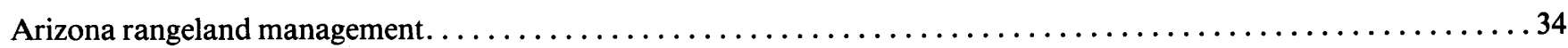

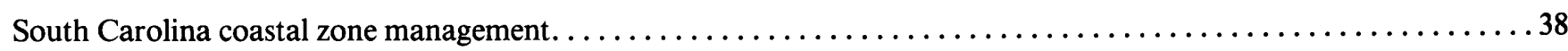

Environmental assessment of a nuclear power plant

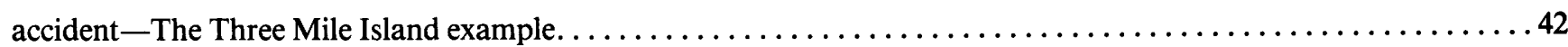




\section{FIGURES}

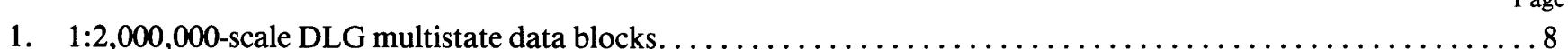

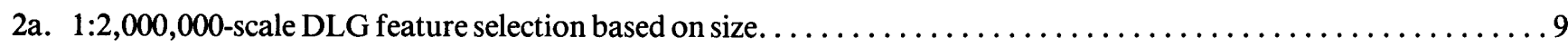

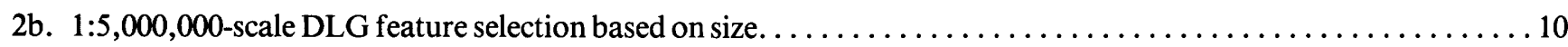

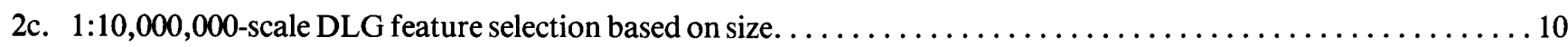

3a. 1:2,000,000-scale DLG feature groups, Florida - Interstate, and Federal and State limited access highways. . . . 11

3b. 1:2,000,000-scale DLG feature groups, Florida - Major U.S. and State primary non-limited-access highways. . . . 11

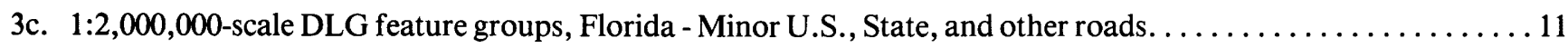

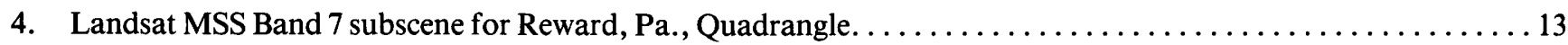

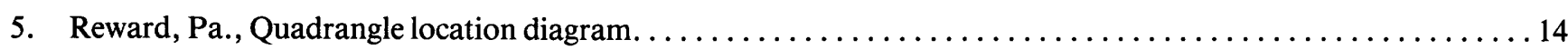

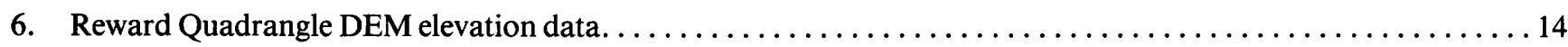

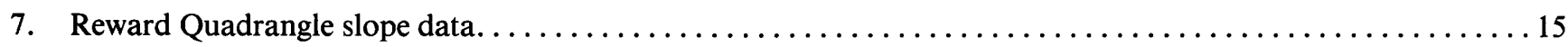

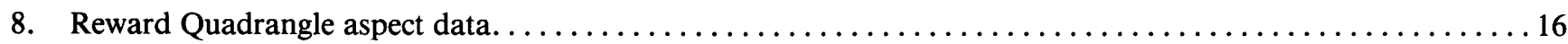

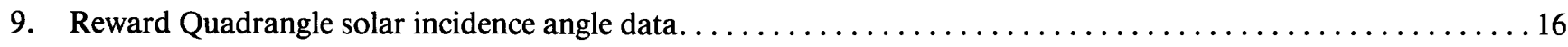

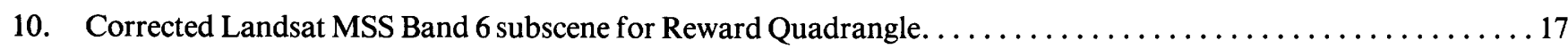

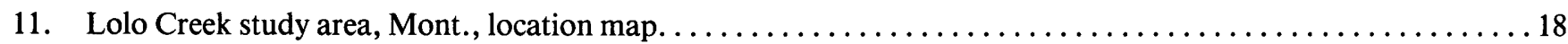

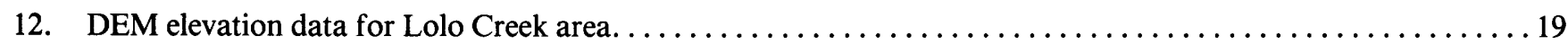

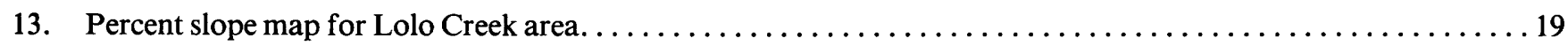

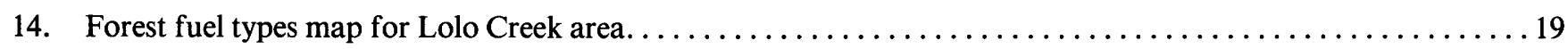

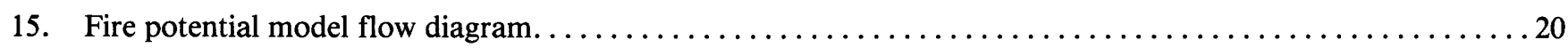

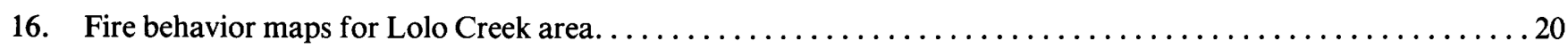

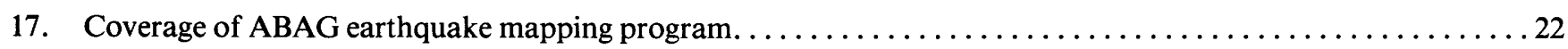

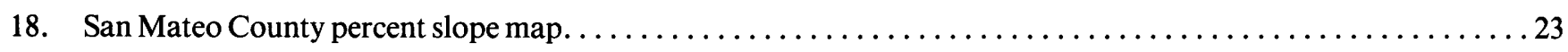

19. San Mateo County earthquake-induced landslide susceptibility map. $\ldots \ldots \ldots \ldots \ldots \ldots \ldots \ldots \ldots \ldots$

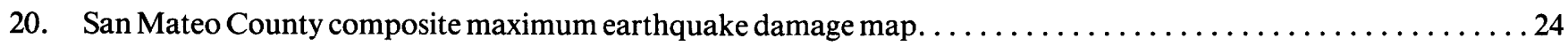

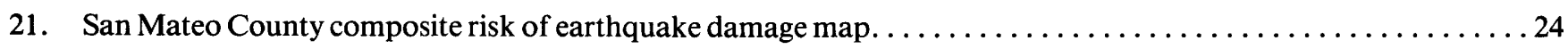

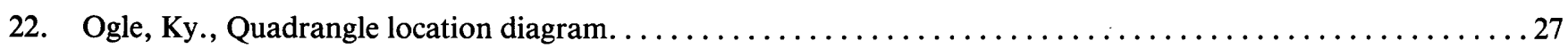

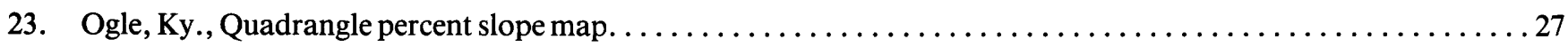

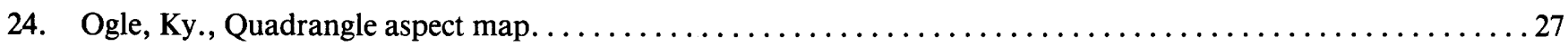

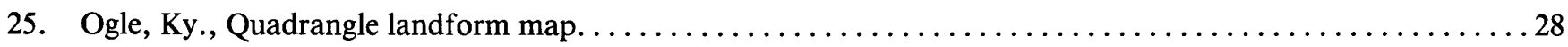

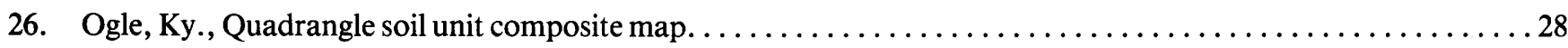

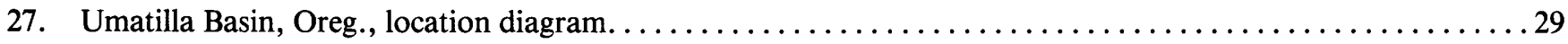

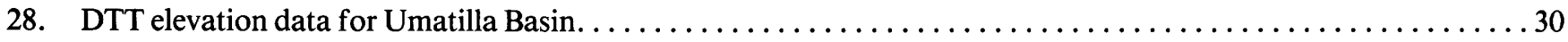

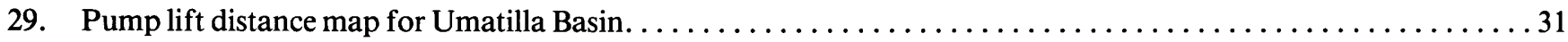

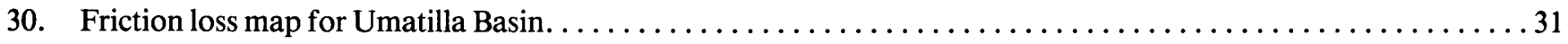

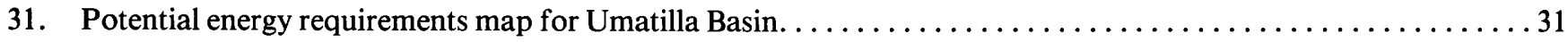




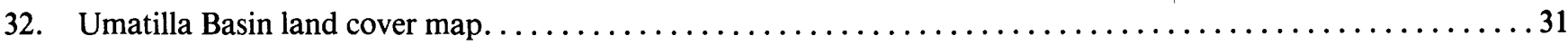

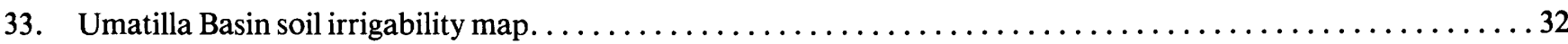

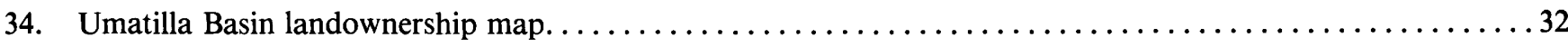

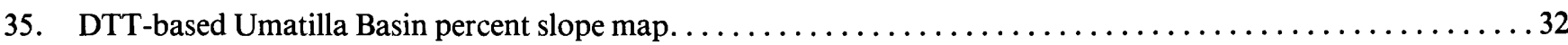

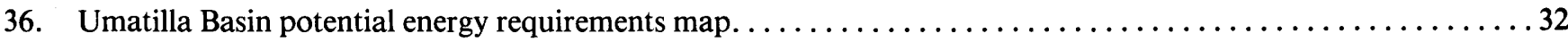

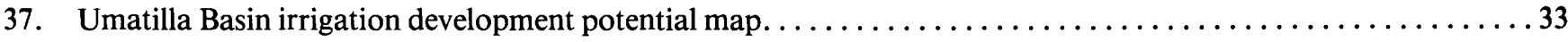

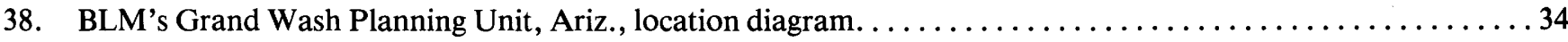

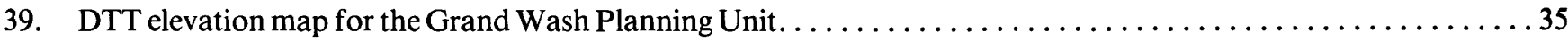

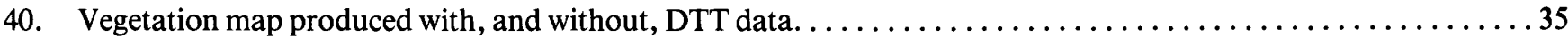

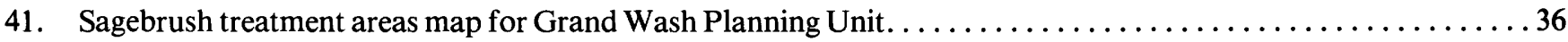

42. Pinyon-Juniper cutting areas map for Grand Wash Planning Unit......................... 36

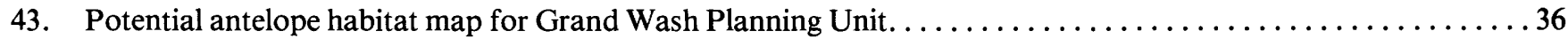

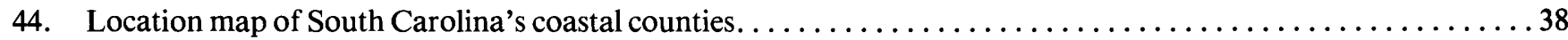

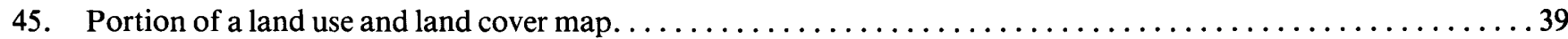

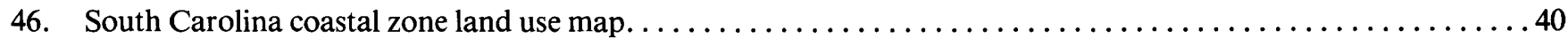

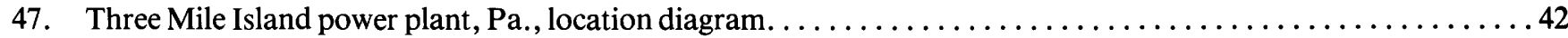

48. Land use and land cover and census tract map for Three Mile Island area $\ldots \ldots \ldots \ldots \ldots \ldots \ldots \ldots \ldots$

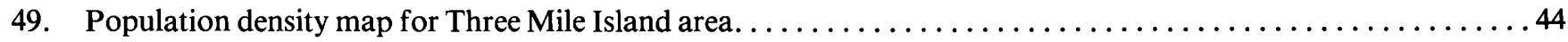





\section{Applications of U.S. Geological Survey Digital Cartographic Products 1}

\author{
By T. R. Loveland and Ben Ramey
}

\section{INTRODUCTION}

The U.S. Geological Survey prepares and distributes fundamental, multipurpose cartographic data to a wide range of users throughout the United States. Recognizing that traditional cartographic procedures will eventually be replaced by digital techniques, the USGS is now actively developing computer-based methods to produce digital cartographic products. The digital cartographic products currently being developed parallel the traditional map-based information but have the advantage that they can be used in a computer environment. The digital cartographic products include: 1) digital elevation models (DEM's), 2) digital land use and land cover data, and 3) digital line graphs (DLG's). In addition, digital terrain tapes (DTT's) that were developed by the Defense Mapping Agency are currently available through the USGS. As with conventional map products, the digital products are suitable for efficient application to a variety of problems.

The Survey's digital cartographic products offer several general advantages for resource studies. The products:

- cover extensive geographic areas and have relatively fine spatial resolution,

- permit the use of rapid, objective, and repeatable computer-based analysis techniques,

- permit the solving of complex resource problems when used in conjunction with other types of digital cartographic data,

- provide the user with the flexibility to address a variety of unrelated problems or alternative scenarios of the same problem, and

- are cost-effective due to the above factors, and because of their relatively low-cost per unit of cartographic information.

In addition, each individual product offers specific advantages based on both its unique attributes and the problems to which it may be applied.

The objective of this report is to briefly describe the characteristics and availability of each digital cartographic product, and then discuss applications or research studies that exemplify both the specific and general benefits gained through the use of digital terrain tapes, digital elevation

\footnotetext{
${ }^{1}$ The report was compiled, prepared, and edited by Thomas $\mathbf{R}$. Loveland, Technicolor Government Services, EROS Data Center, Sioux Falls, S.D., and Ben Ramey, National Mapping Division, Reston, Va.
}

models, and digital land use and land cover data in the mapping and analysis process. ${ }^{2}$ The studies collectively illustrate the variety of applications and the advantages and unique contributions that the digital data offer to resource investigations. The descriptions of the studies are not intended to provide technical details but rather to present typical applications and the capabilities the data offered to those studies. For readers with specific technical questions, a point of contact and references to published technical reports relating to each study are included in each example.

The documentation of these examples was made possible by assistance provided by representatives from several state, regional, and federal government agencies. The following people contributed to the production of this report: Peter Croswell, Kentucky Department for Natural Resources and Environmental Protection; David Cowen, University of South Carolina; Paul Wilson and Jeanne Perkins, Association of Bay Area Governments; S. W. Wharton and B. N. Holben, National Aeronautics and Space Administration (Goddard Space Flight Center); Lawrence Pettinger, Valerie Milazzo, and James Wray, U.S. Geological Survey; and Wayne Miller and Mark Shasby, Technicolor Government Services, Inc., and William Draeger and David Greenlee, U.S. Geological Survey, all from the EROS Data Center, Sioux Falls, South Dakota.

\section{SELECTED REFERENCES}

Anderson, K. E., 1978, Spatial analysis in a data base environment, in Dutton, G., ed., First International Advanced Study Symposium on Topological Data Structures for Geographic Information: Cambridge, Massachusetts, Harvard Papers on Geographic Information Systems, v. 2.

Guptill, S. C., 1980, The development and use of digital cartographic data bases, in Blaser, A., ed., Data Base Techniques for Pictorial Applications: Berlin, Heidelberg, Springer-Verlag, p. 65-77.

- 1981, Thematic map production from digital spatial data, in Computer Mapping of Natural Resources and the Environment and Satellite Derived Data Applications: Cambridge, Massachusetts, Harvard University, Laboratory for Computer Graphics and Spatial Analysis, v. 15, p. 121-124.

Hirsch, S. A., 1980, Cartographic considerations for merging digital spatial data files, in American Society of Photogrammetry, and American Congress on Surveying and Mapping Fall Technical Meeting, Niagara Falls, New York, 1980, Proceedings, p. DP2C1-DP2C16.

${ }^{2}$ Applications of digital line graphs will not be illustrated in this report. Due to their relatively recent availability, they have just begun to be applied to resource problems. 
McEwen, R. B., 1979, U.S. Geological Survey digital cartographic data acquisition, in Mapping Software and Cartographic Data Bases: Cambridge, Massachusetts, Harvard University, Laboratory for Computer Graphics and Spatial Analysis, v. 2, p. 136-142.

- 1980, USGS digital cartographic applications program: Journal of the Surveying and Mapping Division, American Society of Civil Engineers, v. 106, SUI, p. 13-22.

, 1981, Information potential of a digital cartographic data base, in American Society of Photogrammetry Annual Meeting, 47th, Washington, D.C., 1981, Proceedings, p. 150-153.

McEwen, R. B., and Calkins, H. W., 1982, Digital cartography in the USGS National Mapping Division: Cartographica, v. 19, no. 2, p. 11-26.

McEwen, R. B., and Jacknow, H. R., 1980, USGS digital cartographic data base, in International Symposium on Cartography and Computing, Applications in
Health and Environment, Auto-Carto IV, Reston, Virginia, 1979, Proceedings v. 1, p. 225-235.

McEwen, R. B., Witmer, R. E., and Ramey, B. S., Editor, 1983, USGS Digital Cartographic Data Standards, U.S. Geological Survey Circular 895-A through G.

McLaurin, J. D., 1980, U.S. Geological Survey digital mapping program, in Cartographic and Statistical Data Bases and Mapping Software: Harvard University, Laboratory for Computer Graphics and Spatial Analysis, v. 8, p. 53-59.

Milazzo, V. A., Hallam, C. A., and Anderson, K. E., 1978, An integrated system of graphic and digital data production: Paper presented at Association of American Geographers Annual Meeting, 74th, New Orleans, Louisiana, 1978.

Starr, L. E., and Anderson, K. E., 1982, Some thoughts on cartographic and geographic information systems for the 1980's, in William T. Pecora Symposium, 7th, Sioux Falls, SD, 1981, Proceedings: American Society of Photogrammetry, p. 41-55. 


\section{Digital Topographic Data- Characteristics and Availability}

\section{INTRODUCTION}

Digital topographic data, usually in magnetic tape form, consist of sampled arrays of elevations for a number of ground positions that are usually, but not always, at regularly spaced intervals. The USGS currently produces and distributes digital elevation models (DEM's) corresponding to standard USGS 7.5-minute quadrangles. The USGS also distributes digital terrain tapes (DTT's) and arc-second DEM's produced by the Defense Mapping Agency (DMA) from 1:250,000-scale maps. The 7.5-minute DEM's and the arc-second DEM's are distributed in the standard USGS DEM tape format, designed in the late 1970's. This format has become the standard for digital topographic data files. DTT files are distributed as produced by the DMA and do not conform to the standard USGS DEM tape format.

\section{CHARACTERISTICS}

\section{5-Minute DEM's}

Digital elevation models that correspond to standard USGS 7.5-minute quadrangles may be derived from a number of data sources, such as existing contour plates, profiles or terrain models scanned in stereo photogrammetric equipment, or from digitizing orthophoto or stereo-plotting equipment. Currently, the majority of 7.5-minute DEM's are created using digitizing orthophoto equipment and consist of elevation values spaced at regular 30-meter intervals, expressed in meters, and referenced in the Universal Transverse Mercator (UTM) coordinate system; however, the DEM tape format does provide for randomly scattered data values and a variety of coordinate referencing systems.

\section{Digital Terrain Tapes}

Digital terrain tapes (DTT's) were produced by the Army Map Service (now Defense Mapping Agency Hydrographic and Topographic Center) from the early 1960 's to the late 1970's. Initially, DTT's were produced to drive milling machines for production of threedimensional relief maps; however, the versatility of the data was soon recognized and DTT's were used in a variety of situations, including assessment and analysis of land resource problems.

The DTT's were created by digitizing the contours, ridgelines, and drains from 1:250,000-scale maps and subsequently interpolating elevations to the nearest foot at
.01 -inch intervals at map scale. The .01 -inch spacing corresponds to a ground distance of 63.5 meters between elevation values.

Each DTT file represents a 1-degree by 1-degree block that corresponds to the east or west half of the original 1:250,000-scale map. The elevation data are referenced in digitizer coordinates at increments of 0.01 inch.

Several factors must be considered if DTT's are to be effectively used for analysis:

- The 1:250,000-scale contours may have been mapped slightly differently from sheet to sheet, which may cause some discontinuity in the elevations in adjoining files.

- The data are only as accurate as the 1:250,000-scale contours.

- Because the interpolation was originally performed by a planar approximation method, which tends to be inadequate if contours are relatively far apart, a terracing or stepping effect can be noticed in the data. This is especially apparent when topographic slope is calculated from the elevations.

- Mosaicking between sheets can be a significant problem, unless a sophisticated resampling program is employed.

\section{Arc-Second DEM's}

Arc-second DEM's are produced by the Defense Mapping Agency by updating and reformatting existing DTT's and by scanning contours, ridgelines, and drains from 1:250,000-scale maps where DTT coverage is nonexistent or inadequate.

Existing DTT's are updated by adding control points, interpolating, and subsequently verifying the data by generating contour plots to compare to the original source materials. Arc-second DEM's are produced from 1:250,000-scale maps in much the same manner as DTT's were created; however, the digitizing equipment and processing methodology is significantly improved and more rigorous.

Like DTT's, arc-second DEM's cover 1-degree by 1-degree blocks corresponding to the east or west half of the 1:250,000-scale map, except in Alaska, where the blocks cover only one third of a 1:250,000-scale map. The spacing between data values is 3 seconds of arc and varies with latitude; at the Equator spacing is approximately 90 meters in each direction, and at 50 degrees latitude, is approximately 90 meters north-south by 60 meters east-west. The elevation values are recorded to the nearest meter and are referenced horizontally in latitude and longitude coordinates.

Arc-second DEM's represent an improvement in data reliability over the DTT's because of the use of additional control and modern verification techniques; however, the data are derived from information on the 1:250,000-scale 
map series and are consequently limited to the accuracy inherent therein. Arc-second DEM's provide useful data for analyzing land resource problems where general elevation estimates are needed.

\section{AVAILABILITY}

Completed 7.5-minute DEM's are being added to the data base daily. A status graphic depicting the current availability of 7.5-minute DEM's is produced every six months by the National Cartographic Information Center. Digital terrain tapes are available for all of the conterminous United States and Hawaii. Arc-second DEM's are available for nearly all of the United States (including Alaska and Hawaii). The few quadrangles for which arc-second DEM coverage is not complete are currently in preparation.

Descriptions of the technical specifications for 7.5-minute and arc-second DEM's, and DTT's are included in U.S. Geological Survey Circular 895-B entitled "Digital Elevation Models." Circular 895-B is available from NCIC.

Questions about availability and ordering of all forms of digital topographic data should be addressed to:
U.S. Geological Survey

EROS Data Center

User Services Section

Sioux Falls, SD 57198

(605) 594-6151/FTS 784-7151

\section{SELECTED REFERENCES}

Brunson, E. B., and Olsen, R. W., 1978, Digital data elevation model collection systems: American Society of Photogrammetry Digital Terrain Model Symposium, St. Louis, Missouri, 1978, Proceedings, p. 72-99.

Doyle, F. J., 1978, Digital terrain models-An overview: Photogrammetric Engineering and Remote Sensing, v. 44 , n. 12, p. 1481-1485.

Elassal, A. A., and Caruso, V. M., 1983, USGS Digital Cartographic Data Standards: Digital Elevation Models, U.S. Geological Survey Circular 895-B.

USGS National Mapping Division, 1980, Computer files for digital elevation models: Reston, Virginia, USGS National Mapping Division.

-, 1977, Digital terrain tapes-users guide ( $2 \mathrm{~d}$ ed.): Reston, Virginia, USGS. National Cartographic Information Center, $12 \mathrm{p}$. 


\section{Digital Land Use and Land Cover Data-Characteristics and Availability}

\section{INTRODUCTION}

Digital land use and land cover data are produced by the U.S. Geological Survey from 1:250,000-and 1:100,000-scale USGS land use and land cover maps. Four associated maps are also available in digital form: (1) political units, (2) census county subdivisions, (3) hydrologic units (watersheds), (4) federal land ownership. These digital files provide comprehensive, standardized cartographic and geographic data useful for a variety of planning problems.

\section{CHARACTERISTICS}

Each digital file represents one theme, such as land use and land cover or political units, for a specific 1:250,000- or 1:100,000-scale map. Each file consists of lines defining non-overlapping information within the map. Numeric codes are used to identify the category to which each area (or polygon) on the map belongs.

The technical specifications for the data are fully described in U.S. Geological Survey Circular 895-E (Feagas and others, 1983).

The digital data are stored in a topological file structure within the Geographic Information Retrieval and Analysis System (GIRAS). This structure allows the line segments (arcs) forming each polygon's perimeter to be connected to form areas (or polygons). Pointers are used to identify the specific line segments that must be connected in order to form unique polygons. In GIRAS format, the topological data sets can then be manipulated and used for many types of geographic analyses and applications. The topographical or line segment file structure is efficient for archiving map data and does preserve all mapped information. However, for some types of analysis, many users convert the data to a polygonal format which is simpler to process for area calculations, polygon overlay, and other spatial manipulations.

LAND USE AND LAND COVER - Files contain up to 37 categories of land use and land cover. Small-scale aerial photographs are the primary sources of the land use and land cover information. The minimum size of the land use and land cover polygons is 16 hectares ( 40 acres) for most rural categories and four hectares (10 acres) for all urban and built-up, and water classes. The classification system is fully described in USGS Professional Paper 964 (Anderson and others, 1976).

POLITICAL UNITS-State and county boundaries. CENSUS COUNTY SUBDIVISIONS-Boundary data for census tracts within Standard Metropolitan Statistical Areas (SMSA), and for minor civil divisions in non-SMSA's.

HYDROLOGIC UNITS-Watershed boundaries corresponding to USGS-defined drainage basins.

FEDERAL LAND OWNERSHIP-Federallyowned lands for 28 agencies. Parcels must be at least 16 hectares ( 40 acres) to be included.

\section{AVAILABILITY}

Digital land use and land cover data are currently available for approximately one third of the conterminous United States. Coverage is complete for most states east of the Mississippi and for all files on the Atlantic and Gulf coasts. Coverage is also complete for Hawaii, Kansas, Louisiana, and Missouri.

An index to available land use and land cover and associated map digital data is available from:

\section{U.S. Geological Survey}

EROS Data Center

User Services Section

Sioux Falls, SD 57198

(605) 594-6151/FTS 784-7151

Additional information may be obtained by contacting:

Office of Geographic and Cartographic Research

National Mapping Division

U.S. Geological Survey

521 National Center

Reston, Virginia 22092

(703) 860-6341

\section{SELECTED REFERENCES}

Anderson, J. R., Hardy, E. E., Roach, J. T., and Witmer, R. E., 1976, A land use and land cover classification system for use with remote sensor data: U.S. Geological Survey Professional Paper 964, 28 p.

Anderson, K. E., 1979, A geographic information system for land use data in the United States of America: Paper presented at U.N. Regional Cartographic Conference for the Americas, 2d, Mexico City, 1979, 16p.

Feagas, R. G., and others, 1983, USGS Digital Cartographic Data Standards: Land Use and Land Cover Digital Data, U.S. Geological Survey Circular 895-E.

Fitzpatrick-Lins, K. A., 1978, Accuracy and consistency comparisons of land use and land cover maps made from high-altitude photographs and Landsat multispectral imagery: U.S. Geological Survey Journal of Research, v. 6, n. 1, p. 23-40.

, 1980, Accuracy of selected land use and land cover maps at scales of $1: 250,000$ and 1:100,000: U.S. Geological Survey Circular 829, 24 p. 
Guptill, S. C., 1978, The impact of computer graphics, data manipulation software, and computing equipment on spatial data structures, in Dutton, G., ed., First International Advanced Study Symposium on Topological Data Structures for Geographic Information Systems: Cambridge, Massachusetts, Harvard Papers on Geographic Information Systems, v. 2.

, 1979, A digital cartographic data base for land use and land cover and associated maps, in Mapping Software and Cartographic Data Bases: Cambridge, Mass., Harvard University, Laboratory for Computer Graphics and Spatial Analysis, v. 2, p. 99-106.

Kleckner, R. L., 1981, A national program of land use and land cover mapping and data compilation, in Planning Future Land Uses: Madison, Wisconsin, Agronomy Society of America, p. 7-13.

Milazzo, V. A., 1980, A review and evaluation of alternatives for updating U.S. Geological Survey land use and land cover maps: U.S. Geological Survey Circular $826,19 \mathrm{p}$.

, 1982, The role of change data in a land use and land cover map updating program, in William $T$. Pecora Symposium, 7th, Sioux Falls, SD, 1981, Proceedings: American Society of Photogrammetry, $p$. 189-200.

Mitchell, W. B., Guptill, S. C., Anderson, K. E., Fegeas, R. G., and Hallam, C. A., 1977, GIRAS: A geographic information retrieval and analysis system for handling land use and land cover data: U.S. Geological Survey Professional Paper 1059, 16 p.

Wray, J. R., 1980, Examples of automated cartography in presenting land use and land cover maps and data, in International Symposium on Cartography and Computing, Applications in Health and Environment, Auto-Carto IV, Reston Va., 1979, Proceedings; v. 2, p. 156-157. 


\section{Digital Line Graphs- Characteristics and Availability}

\section{INTRODUCTION}

Digital line graphs (DLG's) consist of base-category line map information. The USGS currently produces and distributes tapes of two types of DLG's: (1) large-scale DLG's primarily digitized from 1:24,000-scale USGS topographic quadrangle maps (some large-scale DLG's have been digitized from 1:62,500-scale topographic quadrangle maps), and (2) small-scale DLG's digitized from the 1:2,000,000-scale National Atlas sectional maps.

\section{CHARACTERISTICS}

\section{General Structure}

The DLG file structure is designed to accommodate virtually all categories of planimetric data represented on a conventional line map. Point, line, and area data types are accepted. Each distinct data category (such as boundaries, hydrography, transportation) is stored as a separate file or subfile which is somewhat equivalent to the printing separates used in the conventional map production process.

The DLG data are classified at one of three levels depending on the editing, enhancing, and spatial structuring done to the files:

DLG-1: Line map information that has been coded to prescribed standards and edited to remove data acquisition blunders.

DLG-2: Line map information that has been interactively edited to add additional attribute codes and to remove visible errors and inconsistencies.

DLG-3: DLG-2 data that has been spatially structured to define all topological relationships.

Currently all DLG data distributed by the USGS are classified as DLG-3 except for the special graphics format available for smallscale DLG's.

The spatial structuring found in DLG-3 files explicitly maintains, in digital form, the spatial relationships among the various elements of the data. In graphic form, these relationships are implicitly conveyed and usually grasped by even the novice map user. Topology, as defined for cartography and automated spatial data analysis, requires that all lines be explicitly linked to nodes (ends of lines or line junctions), and that all areas be explicitly coded to the bounding lines. All nodes, lines, and areas are completely and unambiguously linked to permit computer interpretation without human assistance. Maintaining the topology of the data is especially important in applications using geographic information systems and spatial data analysis.

\section{Large-Scale DLG's}

The large-scale DLG's contain, in digital form, the planimetric data shown on the standard USGS 7.5-minute quadrangle maps. The coding scheme is designed to accommodate the base data categories defined by the National Mapping Program, as well as non-base categories such as the U.S. Public Land Survey System. The attribute coding scheme is open-ended and can be expanded as needs change.

Production of large-scale DLG's has been authorized only for geographic areas and data categories for which there has been an expressed need by another Federal agency. To date, these needs have centered on selected themes of the data base, especially boundaries and the U.S. Public Land Survey System. Large-scale DLG's are being produced at the DLG-3 level in order to maximize future utility.

The technical specifications for large-scale DLG's are available from the U.S. Geological Survey, EROS Data Center, User Services Section, Sioux Falls, SD 57198.

\section{Small-scale (1:2,000,000-scale) DLG's}

The small-scale DLG's digitized from the 1:2,000,000-scale National Atlas maps meet the needs of the USGS and other agencies for a small-scale national data base suited to practical combination, manipulation and analysis.

The small-scale DLG's are available in DLG-3 format and a special graphics format. The topologically structured DLG-3 files are suitable for graphics production and for use with geographic information and spatial data analysis systems. The special graphics format is a simplified data structure (information defining topological structure is omitted) designed especially for automated graphics production.

The data in the small-scale DLG data base are recorded in separate files (or multiple subfiles for large data volumes) according to three major categories: (1) boundaries (political and administrative), (2) hydrography (streams and water bodies), (3) transportation (roads and trails, railroads). Data are also available for selected cultural features, such as airports and the Alaska pipeline, and hypsography (continental divide only). The coverage is nationwide, with the data in 21 multistate regional blocks (fig. 1) to limit file size and to minimize edge-join problems in applications requiring adjacent blocks. 
Both the DLG-3 format and special graphics format contain feature codes assigned to various map features in a manner designed to facilitate automated production of base maps and special-purpose graphics at scales ranging from $1: 2,000,000$ to $1: 10,000,000$. Two capabilities are built into the feature coding scheme: (1) the size of features is encoded to permit selective exclusion of features based on the size appropriate for the map's output scale; and (2) the type of feature is encoded to permit grouping in various ways to produce logical sets of information.

The capability to select features according to size allows the user to produce, from a single data base, maps at various scales with appropriate levels of detail. For example, within the hydrography file, single line rivers, streams, and canals are coded according to length, and water bodies are coded according to length at their maximum dimension, both based on an interval scale. A map at 1:2,000,000 scale might appropriately include single line rivers and streams longer than $20 \mathrm{~km}$, canals longer than $1 \mathrm{~km}$, and water bodies longer than $2 \mathrm{~km}$ (fig. 2a), while a map of hydrography at $1: 5,000,000$ scale might appropriately include only rivers and streams exceeding 50 $\mathrm{km}$, canals exceeding $40 \mathrm{~km}$, and water bodies exceeding 4 $\mathrm{km}$ (fig. 2b). Finally, at a scale of 1:10,000,000, the user might choose to show only rivers and streams over $100 \mathrm{~km}$, canals over $80 \mathrm{~km}$, and water bodies over $10 \mathrm{~km}$ (fig. $2 \mathrm{c}$ ). The choice of breakpoints is, of course, a subjective task, and the limits chosen for these illustrations represent the preferences of a single user.

The capability to group features according to type into logical sets of information can be illustrated from the transporation file. Within the transportation overlay, there are currently over 30 distinct codes assigned to various types of roads and trails. Figure $3 a$ is a representation of a logical set made up of all Interstate and Federal and State limited access highways (ten distinct classification codes). The logical set represented by figure $3 \mathrm{~b}$ is made up of major U.S. and State primary non-limitedaccess highways (six distinct classification codes), and figure $3 \mathrm{c}$ is a representation of minor U.S., State, and other roads not depicted in figures $3 \mathrm{a}$ and $3 \mathrm{~b}$. Similar manipulations are possible with all files in the small-scale DLG data base, providing the user with the capability to produce a wide variety of map products from a single data source.

Because of the flexibility permitted by the detailed coding of features according to size and type, the smallscale DLG data base is expected to have extensive use. The USGS small-scale DLG data base represents the first full national coverage since World Data Base II and contains significantly more detail. Most of the data are current to 1980.

The technical specifications for the small-scale DLG data are described in detail in U.S. Geological Survey Circular 895-D (Domaratz and others, 1983).

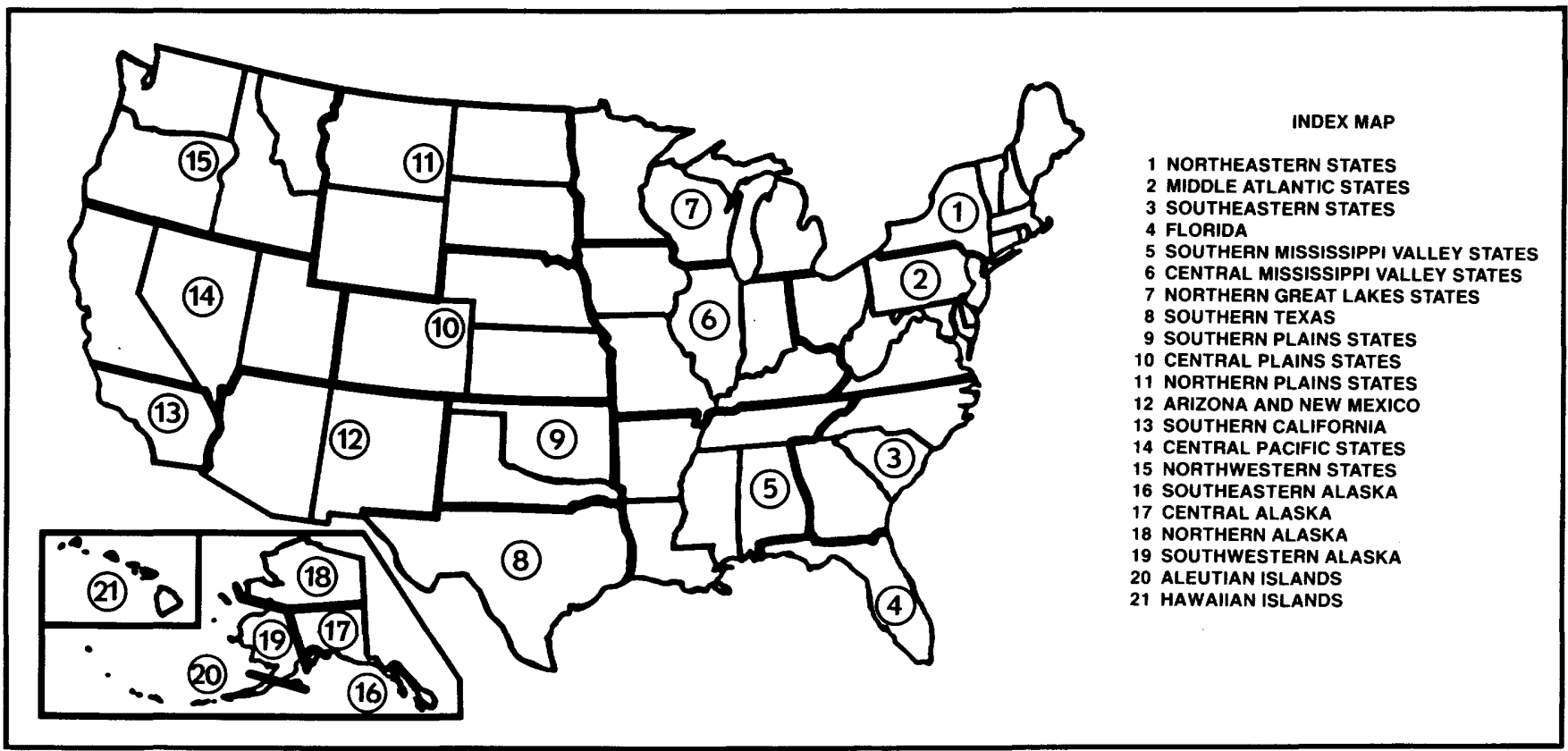

Figure 1. The small-scale DLG data base is divided into 21 multistate blocks to limit file size and to minimize edge-join problems in applications requiring several adjacent files. 


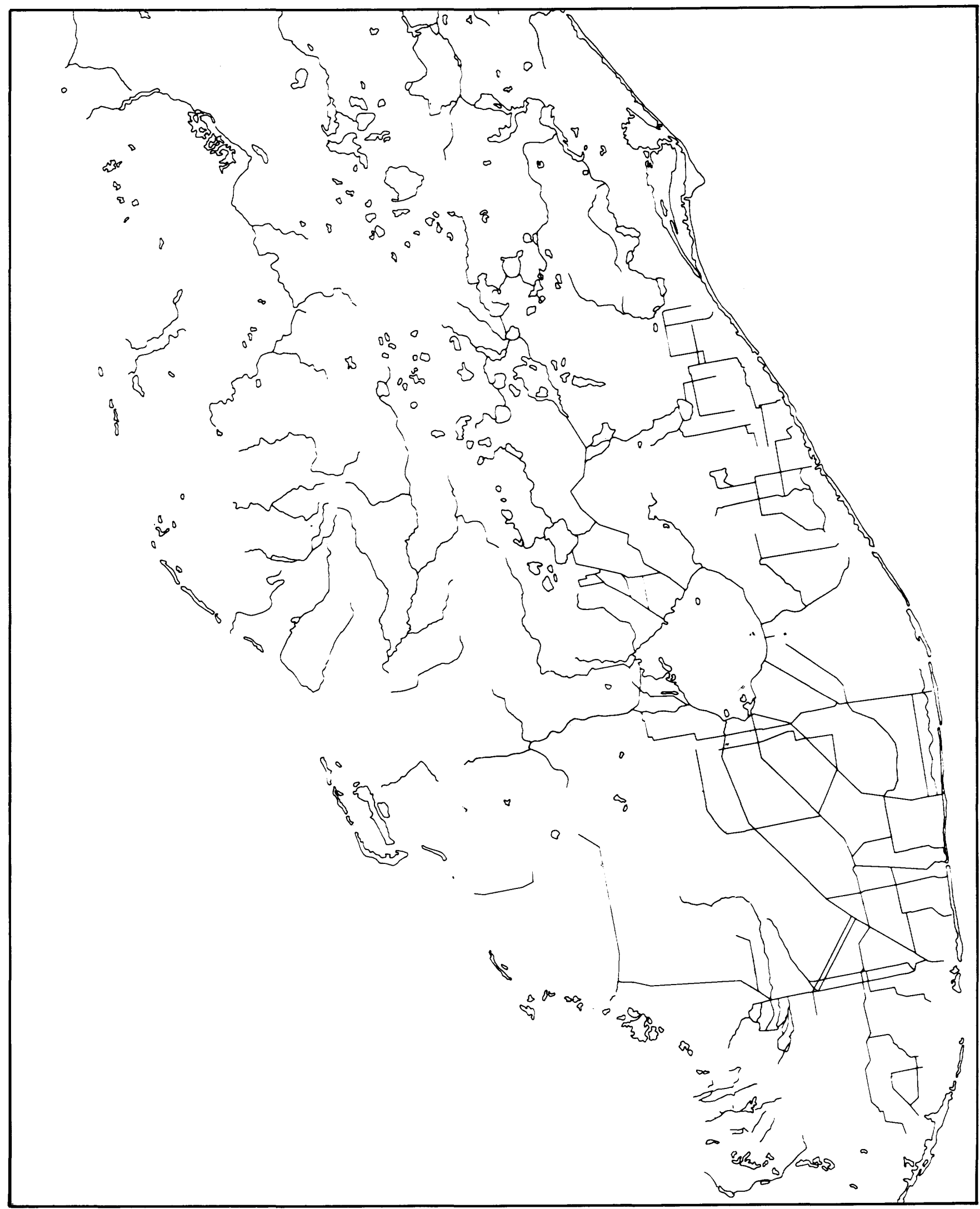

Figure 2a. Features in the 1:2,000,000-scale DLG data base are coded according to size in order to permit selective inclusion of features appropriate for the presentation scale. (2a) 1:2,000,000 scale, Central Florida-streams $>20$ $\mathrm{km}$, canals $>1 \mathrm{~km}$, water bodies $>2 \mathrm{~km}$. 


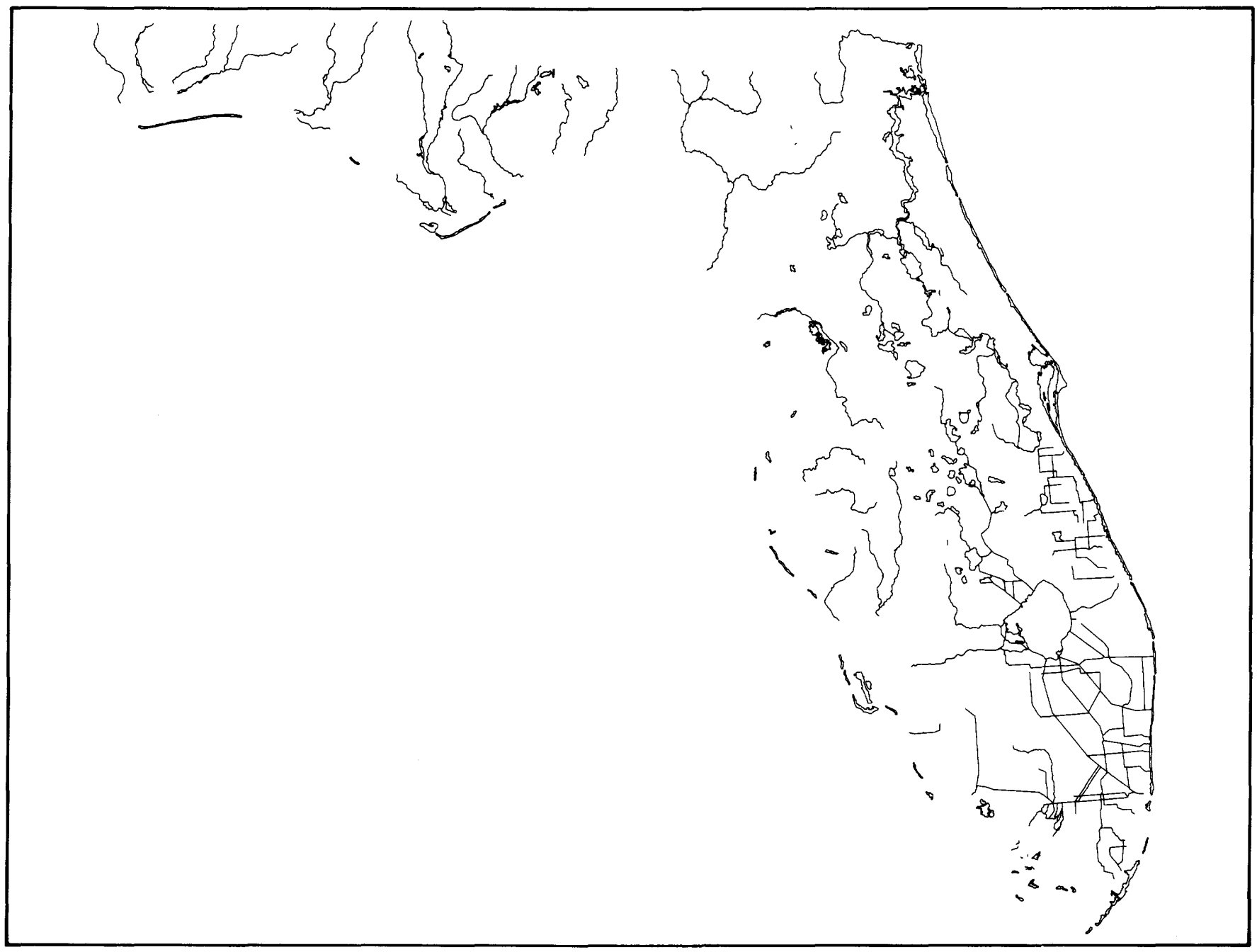

Figure 2b. 1:5,000,000 scale, Florida-streams $>50 \mathrm{~km}$, canals $>40 \mathrm{~km}$, water bodies $>4 \mathrm{~km}$.

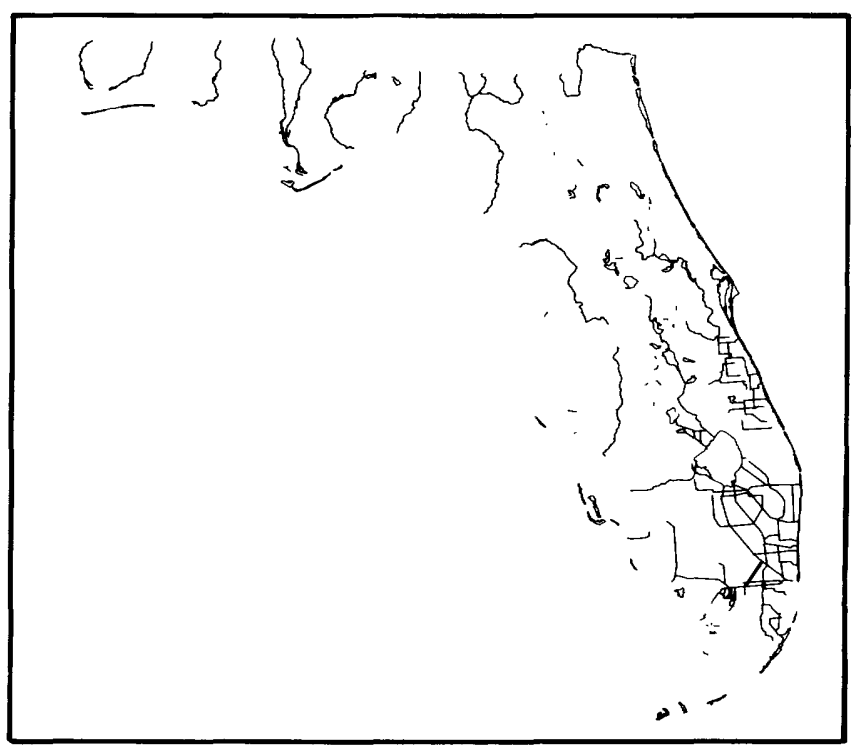

Figure 2c. $1: 10,000,000$ scale, Florida-streams $>$

$100 \mathrm{~km}$, canals $>80 \mathrm{~km}$, water bodies $>10 \mathrm{~km}$. 


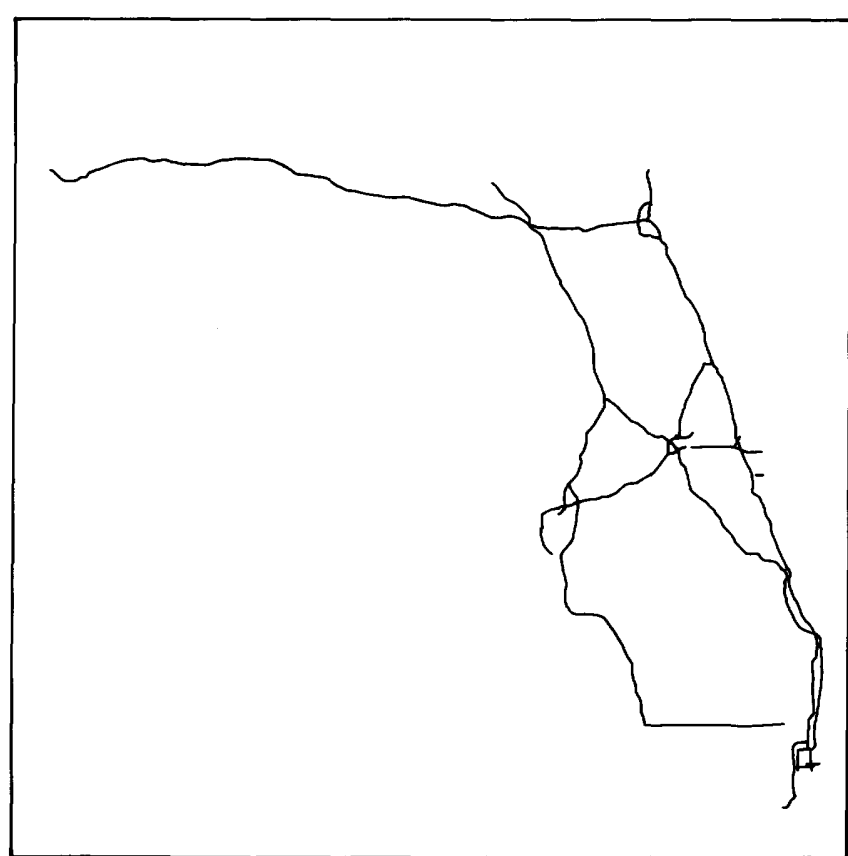

Figure 3a. Features in the 1:2,000,000-scale DLG data base are coded according to type in order to permit grouping of features into logical units of information for presentation. (3a) Florida - Interstate, and Federal and State limited access highways.

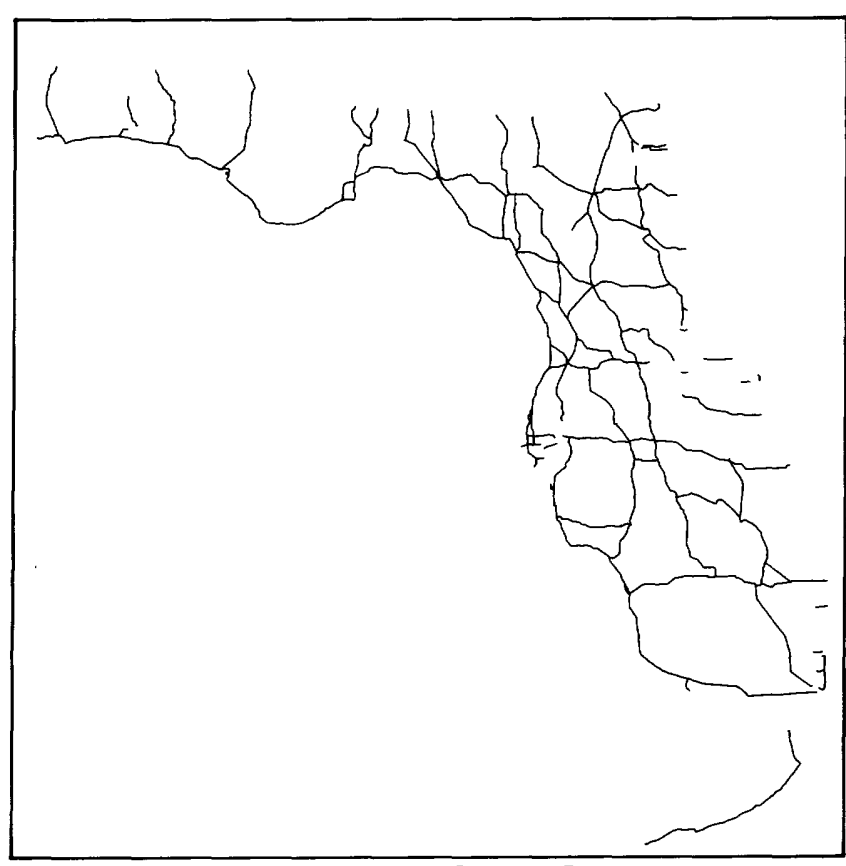

Figure 3b. Florida - Major U.S. and State primary nonlimited-access highways.

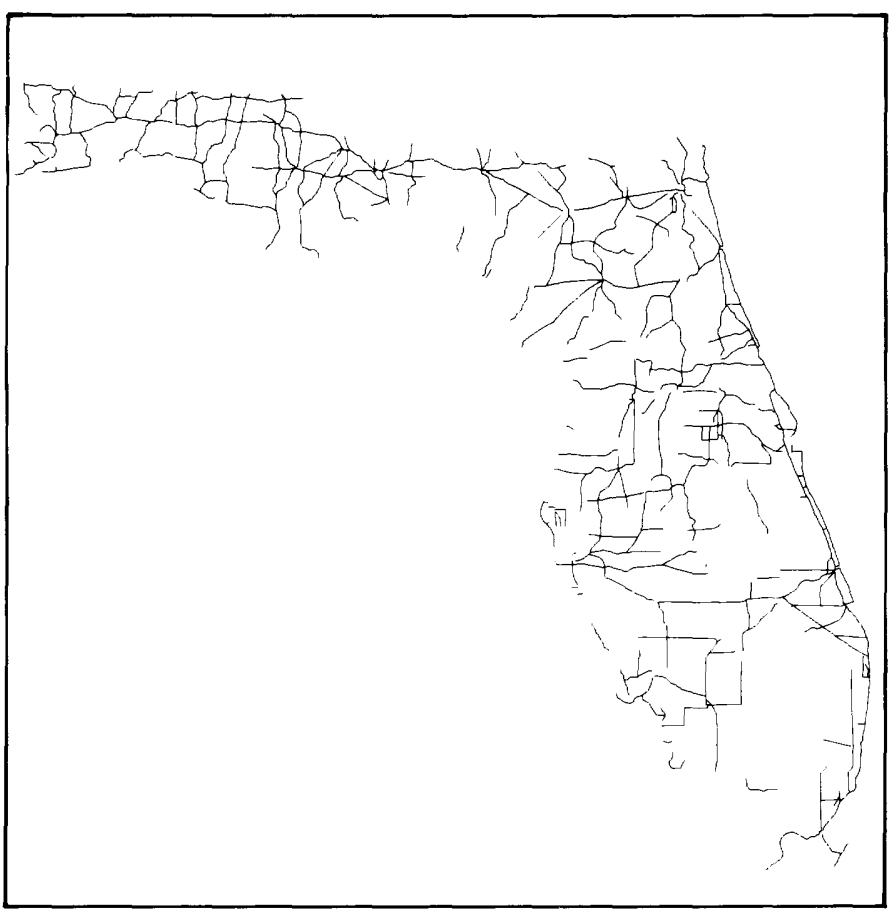

Figure 3c. Florida - Minor U.S., State, and other roads. 


\section{AVAILABILITY}

Most of the completed large-scale DLG's contain only boundary and U.S. Public Land Survey System files and geographic coverage is limited. A periodically revised index depicting the current status and availability of largescale DLG's is available.

Small-scale DLG's are available in the DLG-3 and special graphics format for all of the United States.

Questions about availability and ordering of all forms of DLG and related documentation should be addressed to:

U.S. Geological Survey

EROS Data Center

User Services Section

Sioux Falls, SD 57198

(605) 594-6151/FTS 784-7151

\section{SELECTED REFERENCES}

Allder, W.R., and Elassal, A. A., 1984, USGS Digital Cartographic Data Standards: Digital Line Graphs from 1:24,000-scale maps, U.S. Geological Survey Circular 895-C.

Allder, W.R. and others, 1984, USGS Digital Cartographic Data Standards: Digital Line Graph attribute coding standards, U.S. Geological Survey Circular 895-G.

Beck, F. J., and Plasker, J. R., 1979, USGS digital cartographic pilot projects: American Congress on Surveying and Mapping Annual Meeting, 39th, Washington, D.C., 1979, Proceedings, p. 300-305.

Domoratz, M. A. and others, 1983, USGS Digital Cartographic Data Standards: Digital Line Graphs from 1:2,000,000-scale maps, U.S. Geological Survey Circular 895-D.

Schmidt, W. E., 1981, Small-scale digital cartographic data and transportation planning: Computer Graphics in Transportation, Princeton University Conference, Princeton, N.J., 1981. [in press]

Stephens, M. J., 1980, The USGS 1:2,000,000-scale digital data base: American Congress on Surveying and Mapping Annual Meeting, 40th, St. Louis, Mo., 1980, p. 436-443. 


\section{Reduction of the Topographic Effect on Landsat Data}

\section{BACKGROUND}

Since the launch of Landsat 1 in July 1972, scientists have used multispectral scanner (MSS) data for inventories of the Earth's surface features. A basic assumption underlying the use of Landsat MSS image data for resource inventories is that similar cover types or conditions reflect electromagnetic energy in a similar fashion, thus permitting the use of spectral signatures (measurements of the amount of energy reflected in specific portions of the electromagnetic spectrum) in feature identification and mapping.

\section{THE PROBLEM}

A basic problem in the use of MSS data for land cover mapping lies in the fact that a single land cover type does not always exhibit a unique spectral signature. One of the primary reasons for this is the topographic effect. The topographic effect can be defined as the variation in the amount of electromagnetic energy reflected from inclined surfaces (such as hillsides) as compared to the energy reflected from horizontal surfaces (such as plains). Thus, an oak forest area found on a level plain, for example, will reflect less energy than it would if it occupied a hillside facing towards the Sun; the same oak forest found on a hillside facing away from the Sun will reflect less energy. Therefore, spectral signatures will vary for each cover type depending upon the landscape positions they occupy (fig. 4). This ultimately increases the likelihood that different land cover types will share the same spectral signature, increasing the risk of misinterpretation.

The Earth Resources Branch, National Aeronautics and Space Administration (NASA), has conducted extensive experimentation with methods that may mitigate solar illumination variations on Landsat multispectral images. The results of their research include a model that uses digital elevation data to calculate and apply a correction to the Landsat image that decreases the spectral variability caused by topographic effects. This process has been successfully tested in the Reward quadrangle area of Perry County, Pennsylvania (fig. 5).

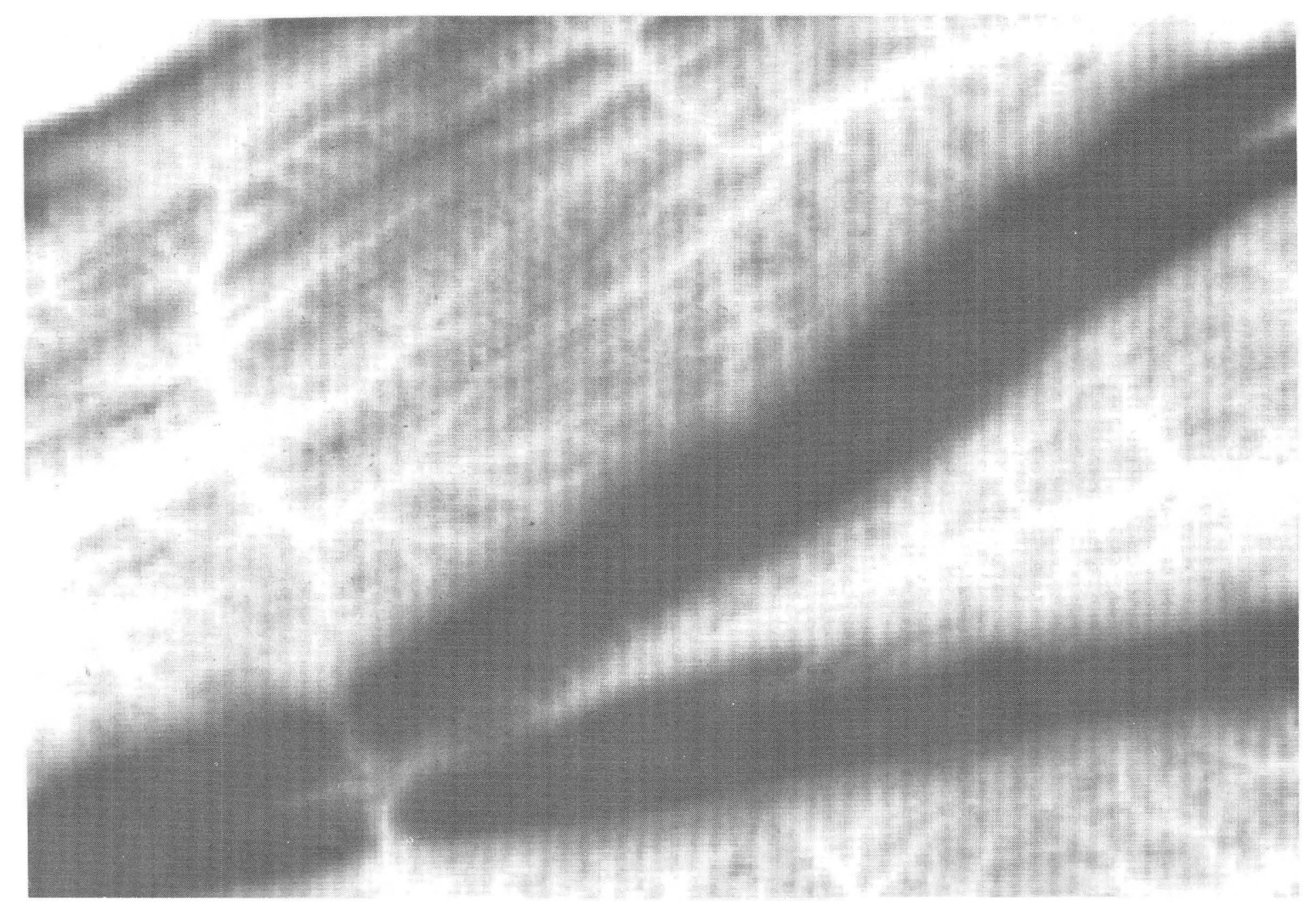

Figure 4. This Landsat MSS band 7 (reflected infrared energy) subscene of the Reward quadrangle in Pennsylvania illustrates the variability of the oak forest spectral signature. Notice the changes caused by the topographic effect, and compare with figure 10 . 


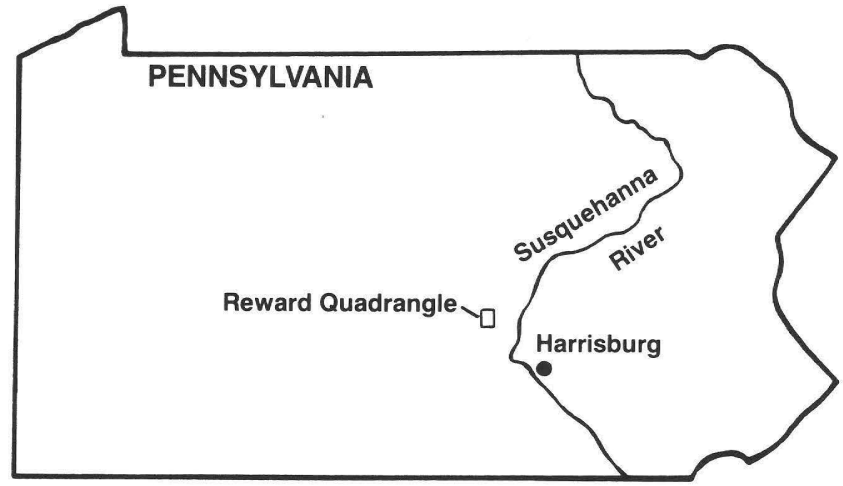

Figure 5. The Reward quadrangle is located in Perry County, Pennsylvania. This area consists of ridge and valley topography with a maximum elevation of 409 meters ( 1,342 feet). Much of the mountainous terrain is covered by a mixed oak woodland which includes white oak, red oak, chestnut oak, and black oak.

\section{DATA SOURCES}

\section{Topographic Data}

The solar illumination correction process needs very precise data describing the slope and aspect of land sur- faces. These data were calculated from a 7.5-minute digital elevation model covering the Reward quadrangle (fig. 6). The availability of the highly accurate elevation data, from which the slope and aspect files could be derived, was an essential requirement of the correction procedure.

The linear northeast to southwest ridge examined in this study was chosen for its constant slopes and aspects, and minimum differences between the two aspects in cover type, distribution, and density. These characteristics effectively isolated the topographic effect as the cause of variation in the spectral signature.

\section{Landsat Data}

The Landsat data used for the Reward quadrangle test were acquired July 19, 1976. The correction process was illustrated using the reflected infrared channels (bands 6 and 7 covering the $0.7-0.8$, and $0.8-1.1$ micrometer range of the electromagnetic spectrum respectively) of the multispectral scanner.

\section{MODELING PROCESS}

Several modeling techniques were initially analyzed by the NASA scientists. Most approaches used models

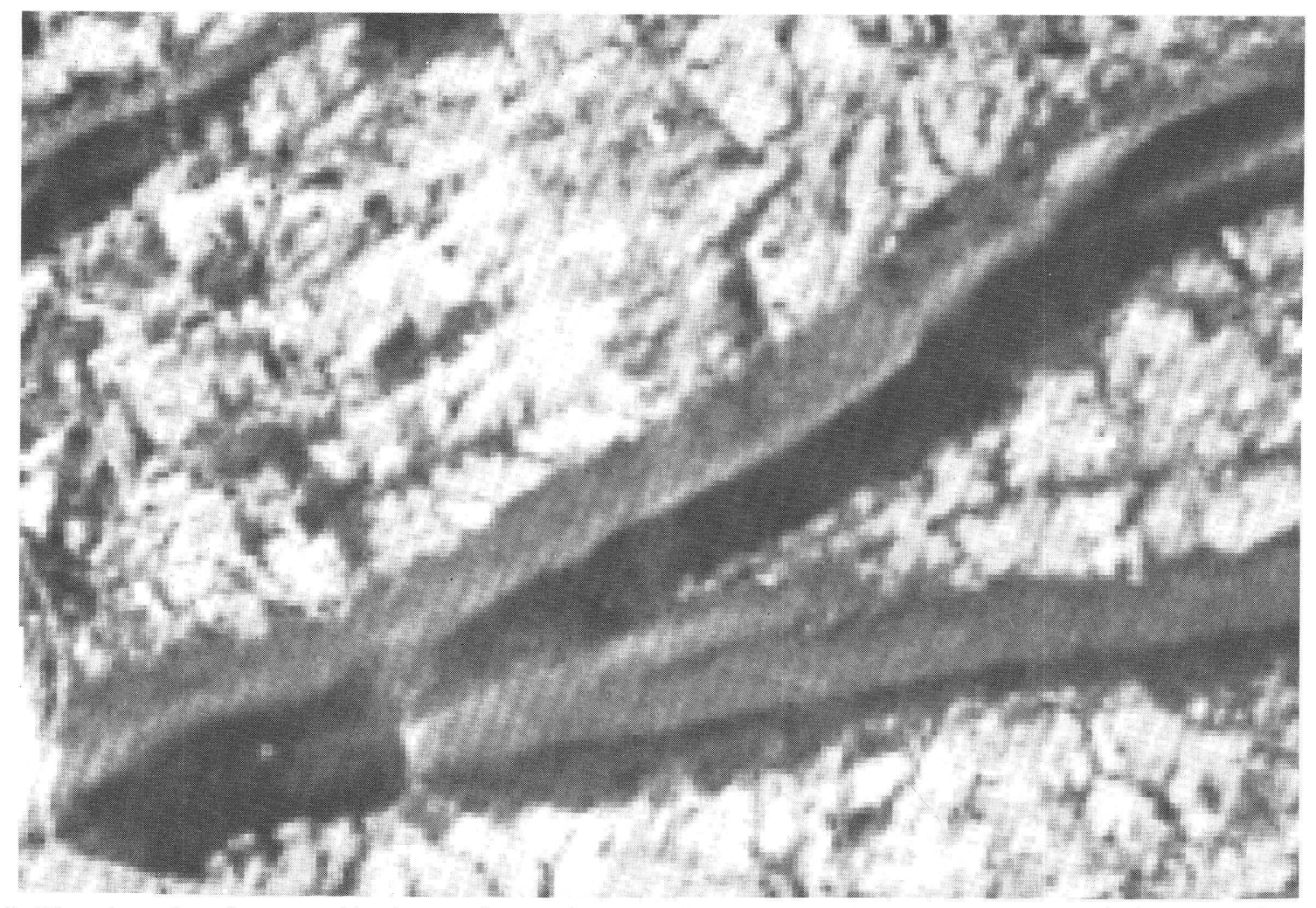

Figure 6. The elevation data used in the study was from the Reward quadrangle 7.5-minute digital elevation model. In this image, the dark tones represent low elevation while the light areas identify high elevations. 
that were based on the assumption that the solar energy was reflected from a Lambertian surface. A Lambertian surface reflects light equally in all directions. It was found, however, that results based on the Lambertian assumption were not optimal. A non-Lambertian model provided the best results.

The non-Lambertian model considered the angle of the incoming solar energy (incidence angle), the angle that the energy departs from the surface (exitance angle), and a factor known as Minnaert Constant. The Minnaert Constant provides a measure of the "Lambertianess" of a surface and is adjusted so that it represents true reflectance conditions of a surface. In the non-Lambertian model, the value chosen as the Minnaert Constant indicated that the surface reflectance angle was random rather than equal to the incidence angle.

The first step in the correction process was the calculation of the solar incidence angle for each land surface in the Reward quadrangle. This calculation required data on terrain slope and aspect, the solar elevation, and solar azimuth (figs. 7-9). The solar incidence angle data were in turn used in the following equation to correct solar illumination variations:

$$
\begin{aligned}
& \mathrm{L}=\mathrm{Ln}\left(\cos \mathrm{k}_{\mathrm{i}}\right)(\cos \mathrm{k}-1 \mathrm{e}) \\
& \text { where } \mathrm{L}=\text { Radiance (solar energy departing the } \\
& \quad \text { surface) } \\
& \qquad \begin{array}{c}
\mathrm{Ln}=\text { Radiance when } \mathrm{i}=\mathrm{e}=0 \\
\mathrm{i}=\text { Incidence angle } \\
\mathrm{e}=\text { Exitance angle } \\
\mathrm{k}=\text { Minnaert Constant }
\end{array}
\end{aligned}
$$

This equation is applied to each Landsat spectral channel individually in order to compensate for the topographic effect.

\section{RESULTS}

The application of the model reduced the overall spectral variability in band 6 by 86 percent. The ultimate result is corrected Landsat data where cover type data are altered to follow the basic assumption of each possessing a single spectral signature (fig. 10).

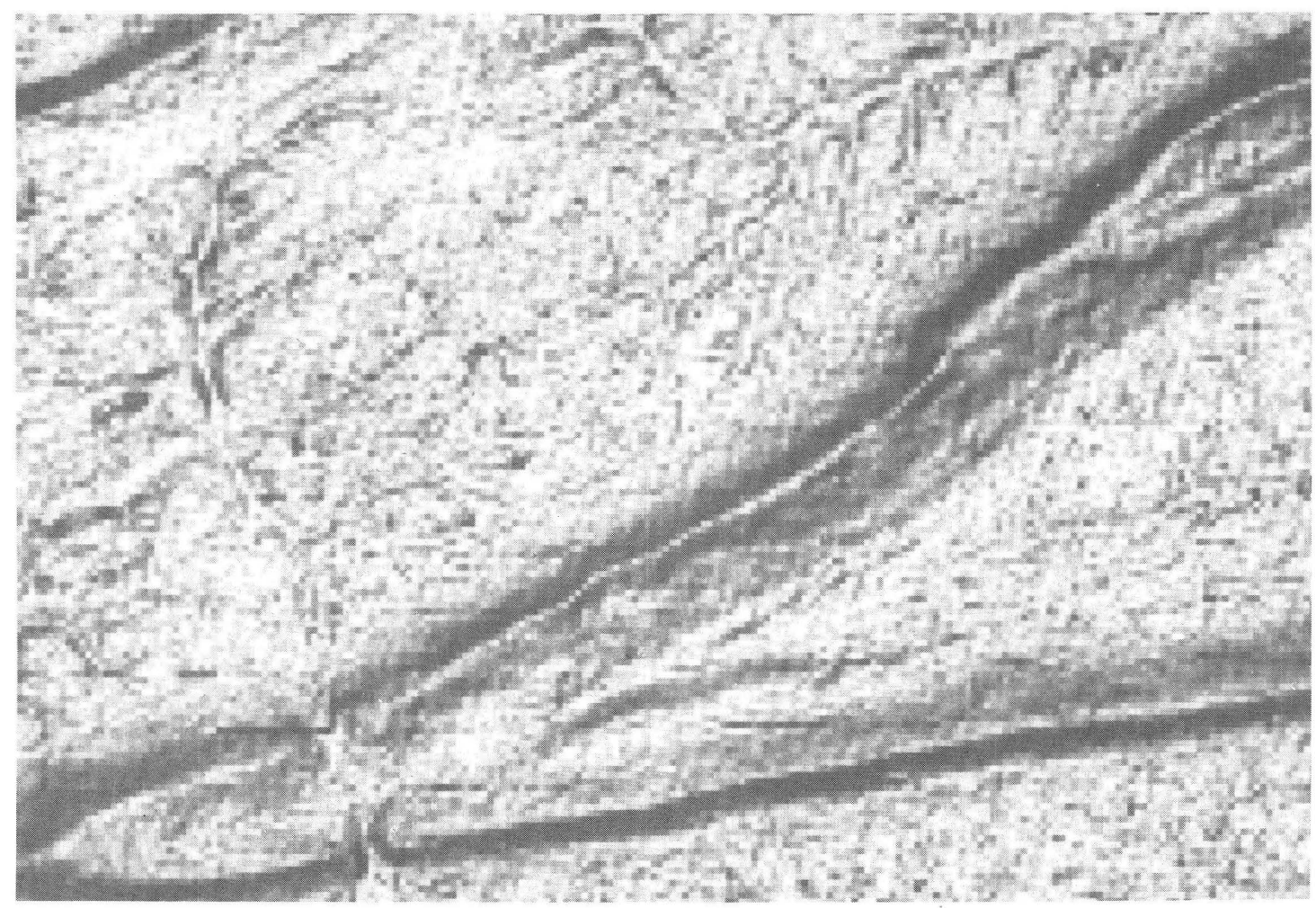

Figure 7. Slope angle data for Reward quadrangle are illustrated in this image in which dark tones are flatter slopes and light tones are steeper slopes. 


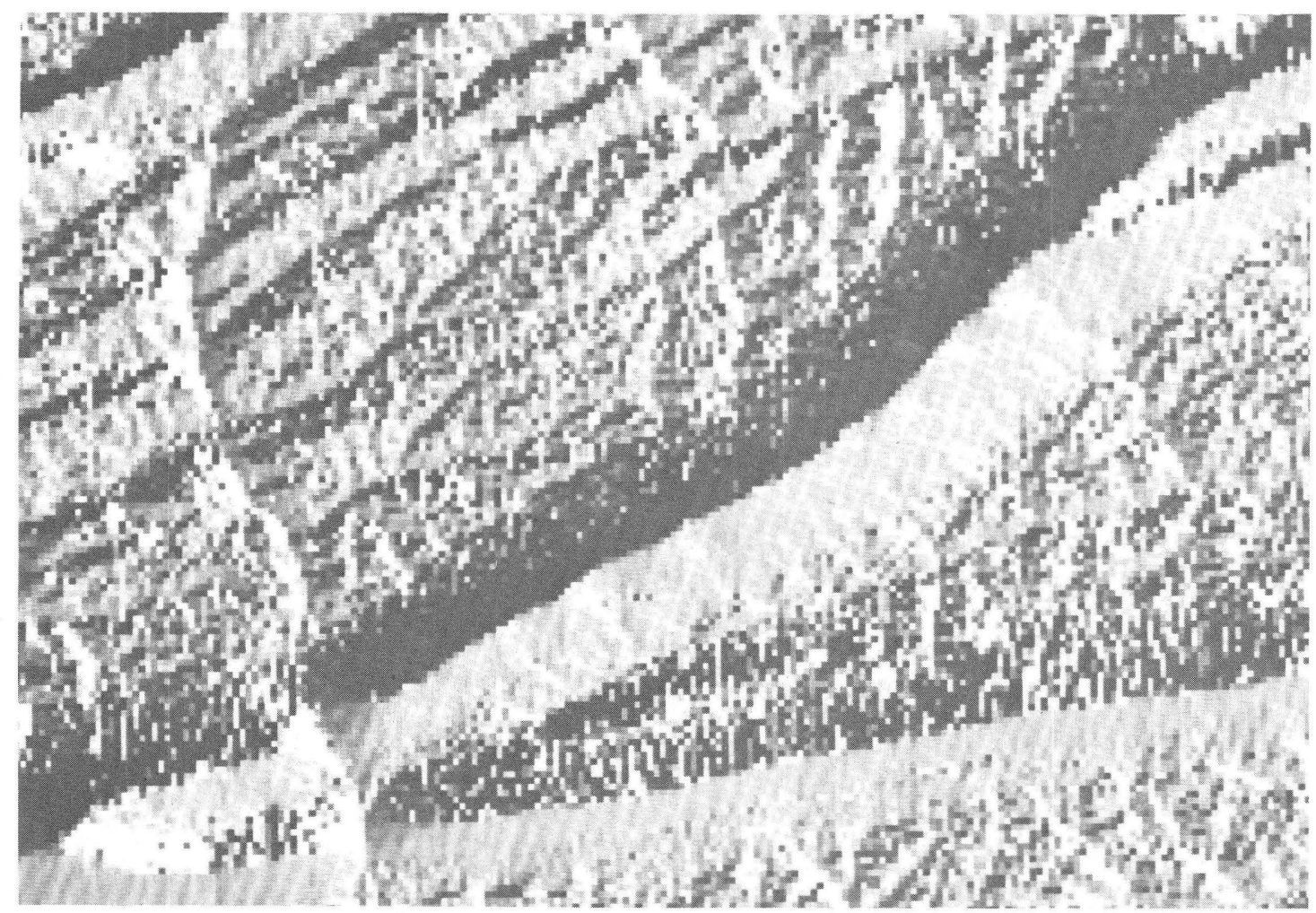

Figure 8. Aspect data for Reward quadrangle are illustrated here. Darkest tones indicate south aspects. Light tones indicate north aspects.

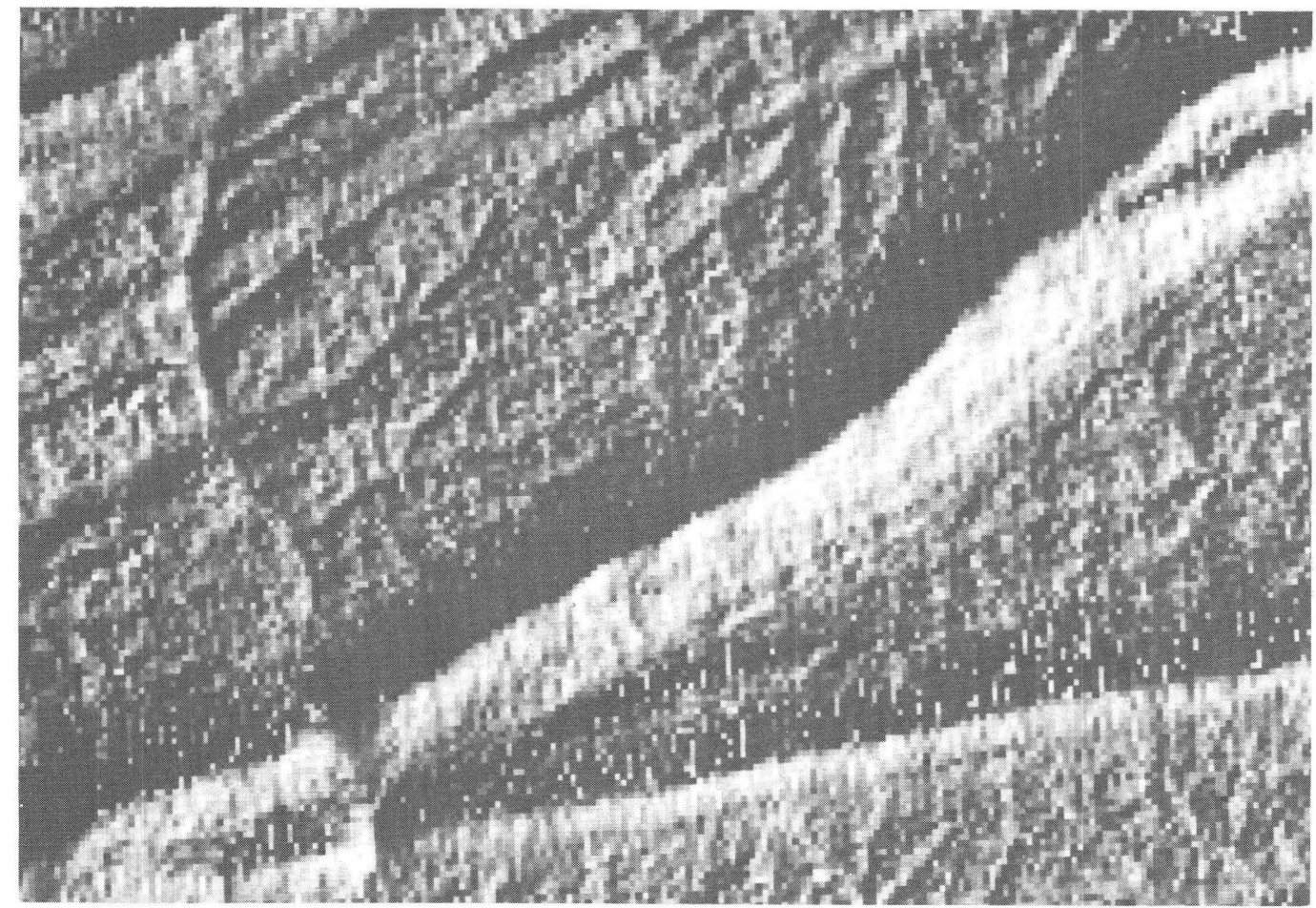

Figure 9. Solar incidence angle data for Reward quadrangle. Dark tones indicate small incidence angles (which correspond to directly illuminated surfaces). Light tones indicate large incidence angles (which correspond to shaded surfaces). Incidence angles are measured from a line perpendicular to the surface of the Earth. 


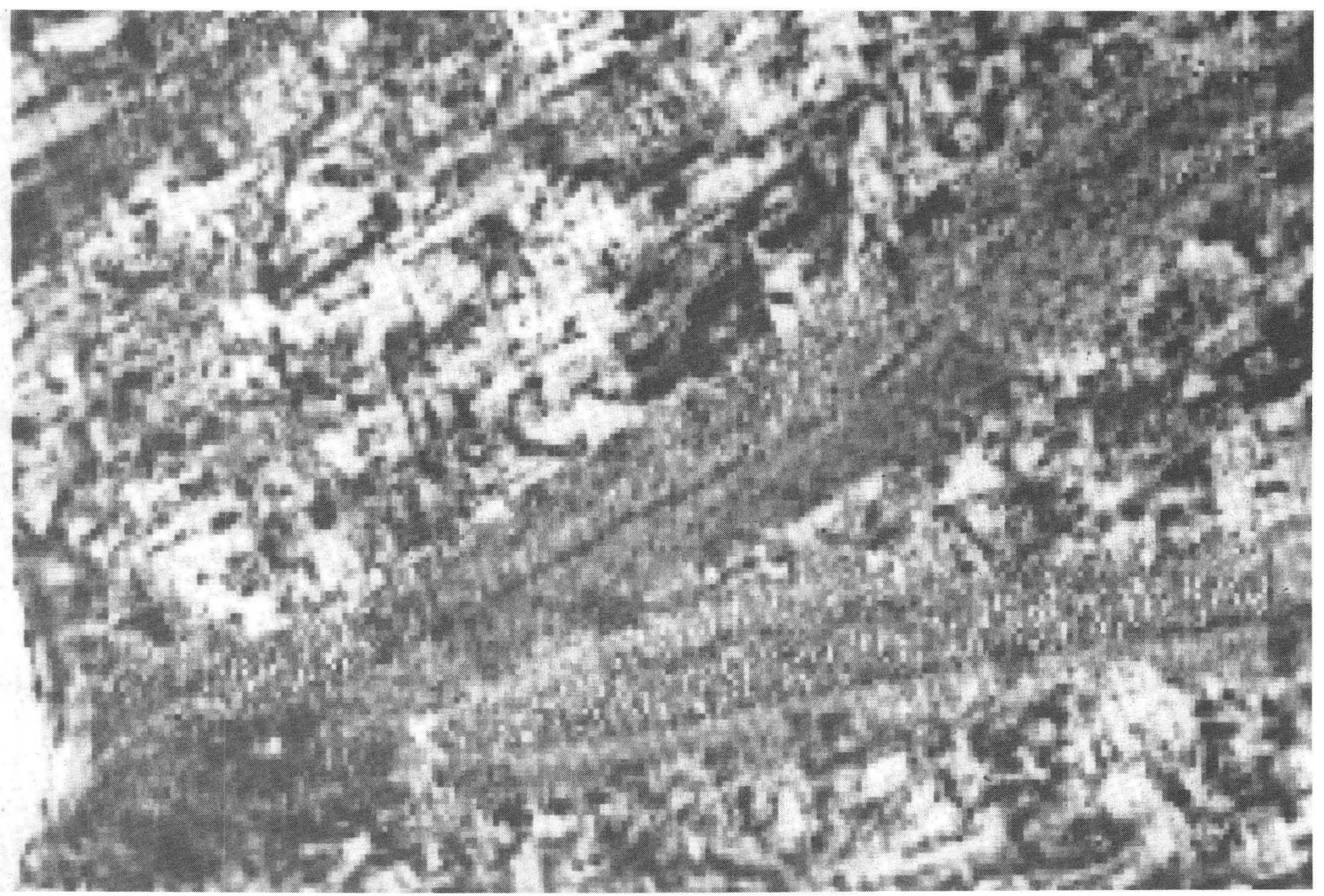

Figure 10. Corrected Landsat MSS band 6 (reflected infrared) data for the Reward quadrangle. Note the relatively uniform tones of the oak forest areas that indicate a reduction of spectral variability as compared with that evident in figure 4.

While more research is needed to refine the selection of Minnaert Constant values, the Reward quadrangle test does illustrate the success of the non-Lambertian model when used with precise DEM data.

\section{APPLICATION OF PRODUCTS}

The immediate benefit resulting from the NASA research is that the availability of a procedure for correcting solar illumination effects on the corrected spectral data should permit more accurate classification of land cover, more accurate inventory data, and hence dependable maps from which resource planning and management decision can be made. For more information, contact:

S. W. Wharton

Earth Resources Branch, Code 923

Goddard Space Flight Center

National Aeronautics and Space Administration

Greenbelt, Maryland 20771

\section{SELECTED REFERENCES}

Holben, B. N., and Justice, C. O., 1980, The topographic effect on spectral response from nadir-pointing sensors: Photogrammetric Engineering and Remote Sensing, v. 46, n. 9, p. 1191-1200.

Justice, C. O., and Holben, B. N., 1979, Examination of Lambertian and non-Lambertian models for simulating the topographic effect on remotely-sensed data: Goddard Space Flight Center, Greenbelt, Maryland, NASA TM 85290, $32 \mathrm{p}$.

Justice, C. O., Wharton, S. W., and Holben, B. N., 1981, Application of digital terrain data to quantify and reduce the topographic effect on Landsat data: International Journal of Remote Sensing, v. 2, n. 3, p. 213-230.

Minnaert, M., 1941, The reciprocity principle in lunar photogrammetry: Astrophysics Journal, v. 87, p. 159-170.

Smith, J. A., Lin, T. L., and Ranson, K. J., 1980, The Lambertian assumption and Landsat data: Photogrammetric Engineering and Remote Sensing, v. 46, n. 9, p. 1183-1189. 


\section{Forest Fire Behavior Prediction}

\section{BACKGROUND}

Every year forest fires take a devastating toll on our Nation's natural resources. Not only do wildfires have a significant economic impact through the loss of harvestable timber, they also cause the loss of human life, wildlife, and property as well as the destruction of the aesthetic value of wildlands. However, new legislation and advances in fire management technology have resulted in policies that direct fire managers to develop management plans for wildfire suppression. Both long-term, broadscale prevention plans for national forests and sitespecific suppression plans are now required. In order to develop these plans, U.S. Forest Service fire managers require an accurate and consistent method for predicting the behavior of forest fires.

The Northern Forest Fire Laboratory of the U.S. Forest Service has developed a mathematical model to provide fire managers with realistic estimates of fire behavior. If the model variables (fuel types, topography, and weather) accurately represent site-specific conditions, increased fire-fighting efficiency and decreased timber and other losses can be realized.

\section{THE PROBLEM}

Forest-fuels and digital topographic data needed for predicting fire behavior in national forests are generally available at only very low resolution for most areas. Few site-specific detailed data are available to provide the level of information necessary to make realistic estimates of fire behavior. In a cooperative project, the U.S. Forest Service and the EROS Data Center developed digital analysis techniques to provide the basic data needed to model forest fire behavior. The data were then incorporated into the Forest Service's fire behavior model. The specific objectives of the project were to:

- Develop a digital data base that provides site-specific information describing forest fuel types, topographic conditions, and weather conditions, and

- Produce a map using the mathematical fire behavior model displaying predicted fire behavior for a specific area.

The project methods were tested in the Lolo Creek area of the Lolo National Forest in western Montana (fig. 11).

\section{DATA SOURCES}

\section{Topographic Data}

High-resolution elevation data were required for virtually all aspects of the study. Specifically, topographic data were used to: (1) develop the fuel-type map, (2) extrapolate weather data collected at a single weather station, and (3) represent terrain conditions in the fire behavior model.

The topographic data needed throughout the study were supplied by 7.5-minute digital elevation models (DEM's) (fig. 12). The elevation values, registered to a map base, were used to develop slope and aspect data, and to improve the accuracy of fuel-type and weathercondition maps.

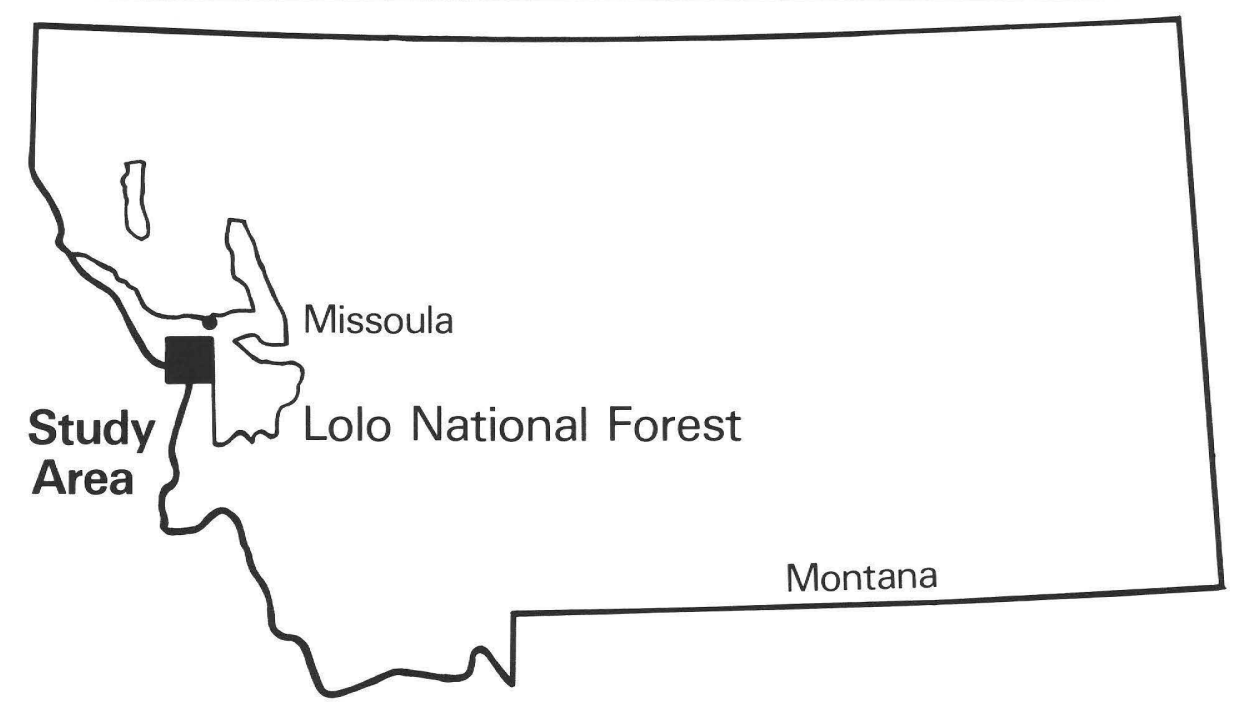

Figure 11. The Lolo Creek area $(1,180 \mathrm{~km})$ of the Lolo National Forest in the Bitterroot Mountains of western Montana was selected as the project study site. The forest vegetation includes ponderosa pine, Douglas-fir, western larch, subalpine fir, lodgepole pine, grand fir, and Englemann spruce. This diversity created a challenging environment for applying project techniques. 


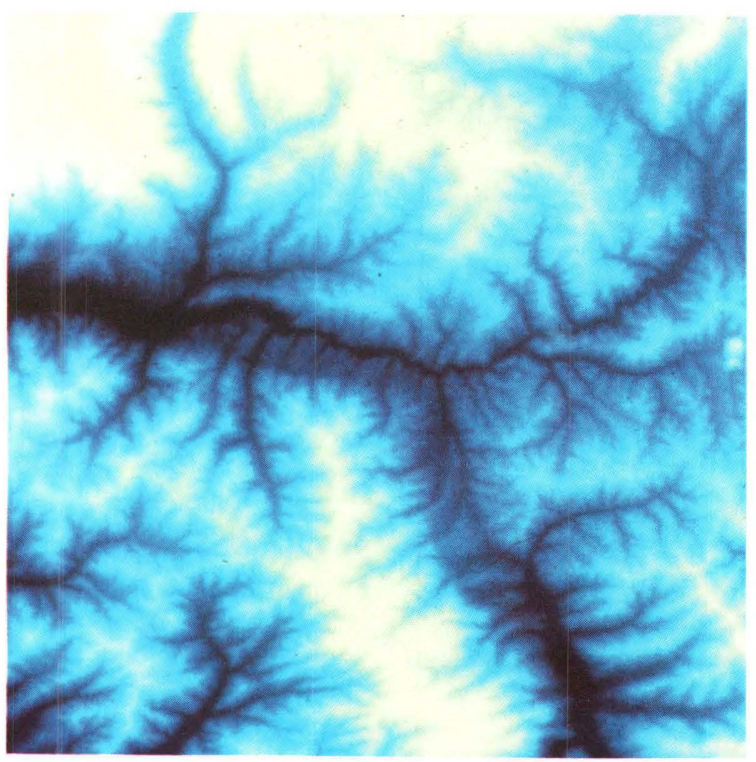

Figure 12. Slope and aspect were calculated from digital elevation data, mapped above. The highest elevations are displayed in light tones and the lowest in dark tones.

\section{Other Data}

In addition to topographic data, three other types of data were required:

Landsat Data-A July 1974 Landsat Computer-Compatible Tape (CCT) from the EROS Data Center was used in the development of a fuel-type map.

Road Network Data-U.S. Forest Service engineering maps were used to produce a road network map, needed both as a reference aid and for fire behavior modeling.

Weather Data-Daily weather observations, recorded at the USFS Missoula Fire Weather Station, were used in the fire behavior model.

\section{DATA ANALYSIS}

The initial analysis task involved the calculation of terrain slope and aspect. Digital elevation values at 60-meter intervals were compared with adjoining values to calculate average percent slope (fig. 13). The aspect or slope direction was then determined by comparing each elevation value with neighboring elevation values.

The second task was to divide the vegetation of the area into forest fuel classes. The classes, based on firerelated characteristics of the vegetation (fuel quantity, particle size, and fuel bed depth), were mapped by combining elevation, slope, aspect, and Landsat spectral data (fig. 14). The terrain variables permitted the consideration of the influence that the complex environmental factors

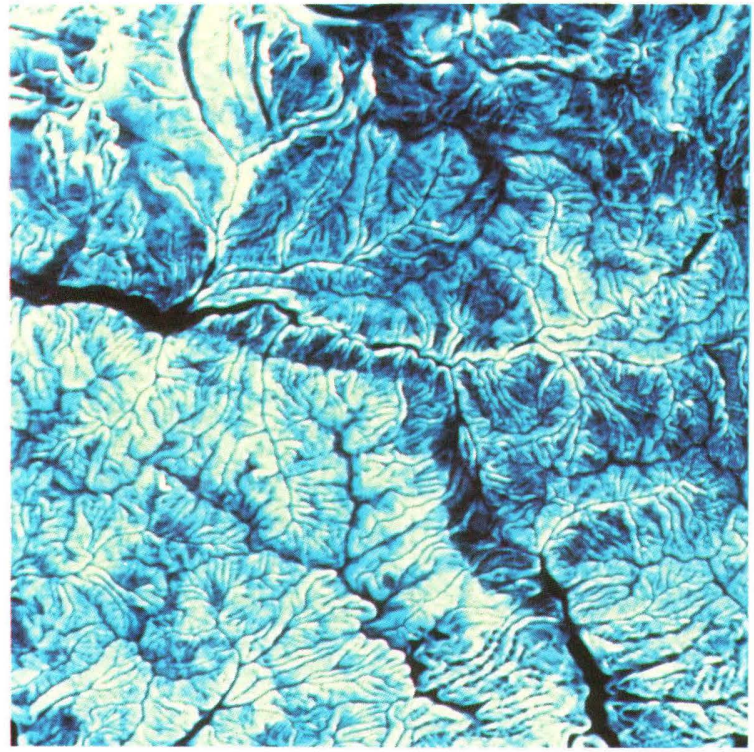

Figure 13. Calculated slopes mapped. Darkest tones represent the flattest slopes and the lightest tones represent the steepest slopes.

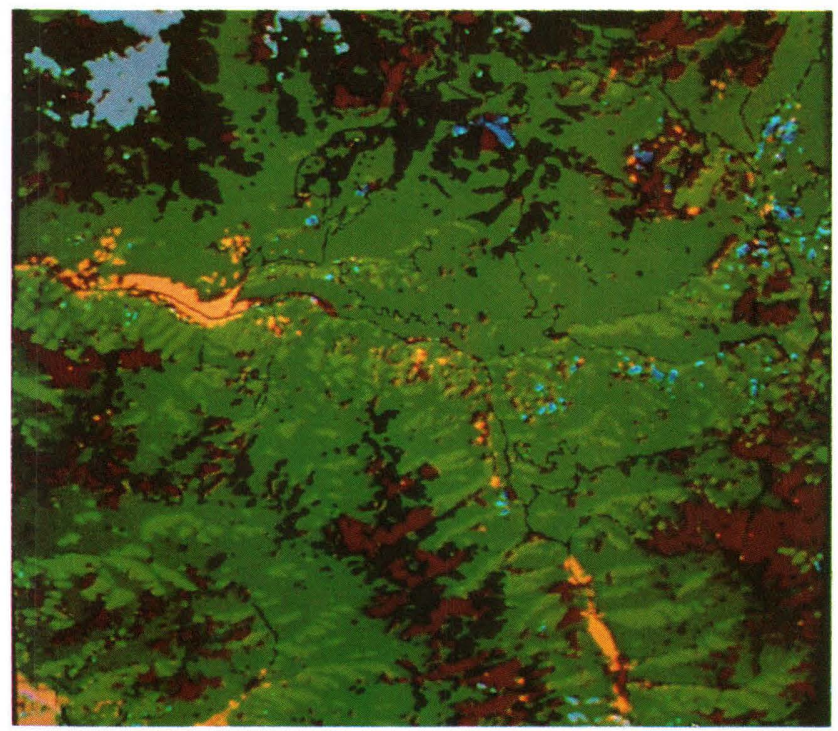

Figure 14. Forest fuel types.

Yellow - Perennial Grasses

Dark Green - Decadent Short Needle Conifers

Brown - Sagebrush and Grasses

Light Green - Open Pine Stands

Red - Clearcuts

Medium Green - Healthy Short Needle Conifers

White - Non-Vegetation

Tan - Agricultural Land

have on forest fire fuel classes.

The third task involved merging the topographic data with daily weather condition observations (wind speed, air 
temperature, relative humidity, and cloudiness) to produce a site-specific estimate of fuel moisture conditions. The topographic data were used to extrapolate weather conditions to the area around the recording station.

\section{FIRE BEHAVIOR MODELING}

The mathematical fire behavior model was developed by the U.S. Forest Service (Rothermel, 1972). This model used site-specific estimates of daily weather conditions, fire fuel types, and topographic characteristics to predict the following fire behavior components in the Lolo Creek area (fig. 15).

Flame Length - The length of the flame (in feet) produced in a forest fire.

Rate of Spread - The speed (in feet per minute) at which a fire would move.

Energy Release Rate - The amount of energy (in BTU's per square foot) released during a forest fire. These fire behavior components were then combined to identify fire potential classes that illustrate relative dayand site-specific fire dangers. The model, when used with digital cartographic data, provides a unique look at the role that topography, fuel types, and fuel moisture conditions have on regional fire behavior (fig. 16).

\section{APPLICATION OF PRODUCTS}

This study demonstrated techniques useful to the U.S. Forest Service for broad-scale fire prevention planning, monitoring active forest fires, assessing the damage

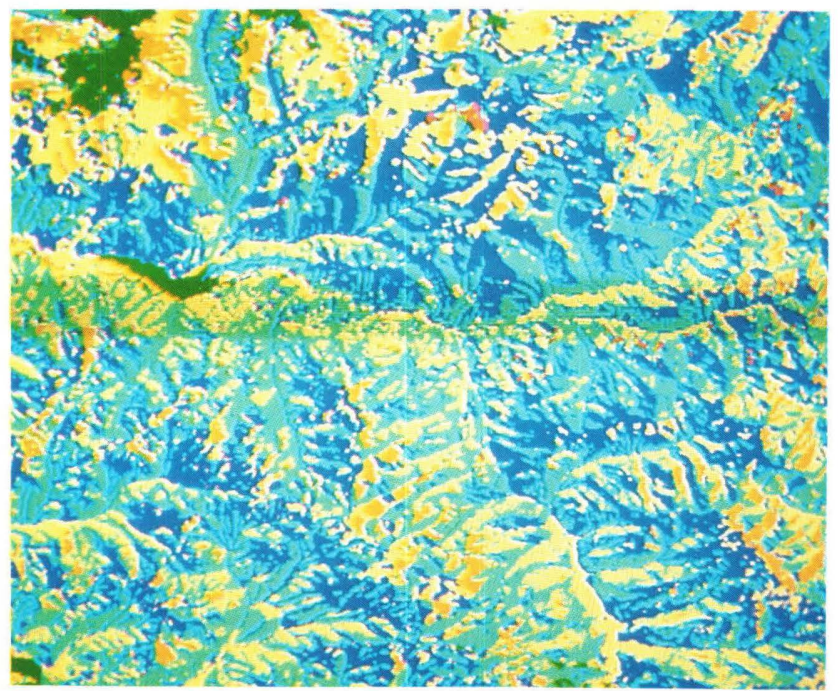

Figure 16. The modeling yielded three descriptive maps of specific fire behavior components and a composite map illustrating fire hazards in the Lolo Creek area on a typical August day. The blue colors on this Fire Hazards map represent the low fire hazards and the red colors represent the highest hazard areas.

potential of incipient fires, and other fire management activities. By using the model to simulate forest fires under a variety of weather conditions, a wide range of fire behavior patterns and planning regimes can be generated and evaluated.

In addition to their use in the fire behavior model, the fuel type, fuel moisture, and topographic data may enhance the capability of the lightning detection system now being tested by the Forest Service and the U.S.

FIRE POTENTIAL MODEL

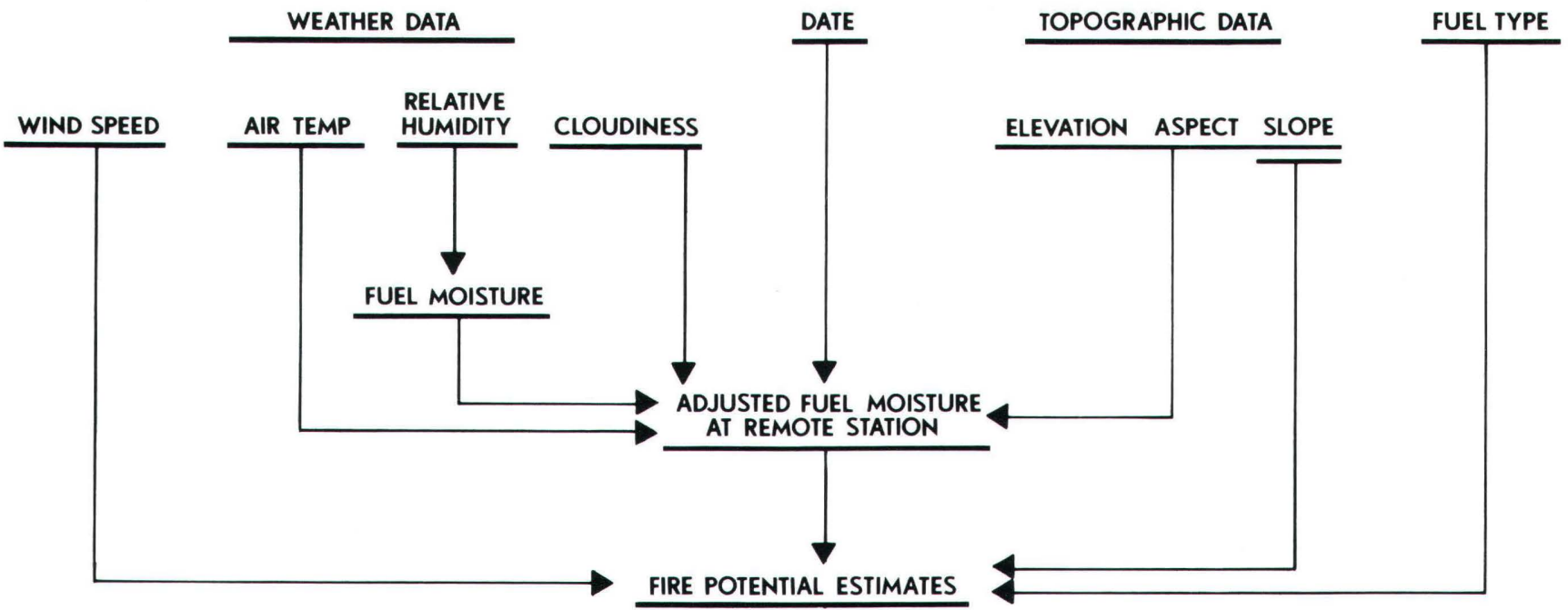

Figure 15. The USFS fire behavior model used site-specific data to predict the characteristics of a forest fire in the Lolo Creek area. 
Bureau of Land Management. This system, which currently can identify and locate cloud-to-ground lightning discharges, must ultimately assess the probability of a fire actually starting and what its potential behavior will be. By incorporating the data developed in this project with the lightning detection system, these evaluations may be provided.

\section{SELECTED REFERENCES}

Deeming, J. E., Burgan, R. E., and Cohen, J. D., 1977, The national fire-danger rating system 1978, in
Ogden, Utah, Intermountain Forest and Range Experiment Station, USFS General Technical Report, INT-39, $63 \mathrm{p}$.

Shasby, M. B., Burgan, R. E., and Johnson, G. R., 1981, Broad area forest fuels and topography mapping using digital Landsat and terrain data, in Machine Processing of Remotely Sensed Data, West Lafayette, Indiana, 1981, Proceedings: New York, Institute of Electrical and Electronics Engineers, p. 529-538.

Rothermel, R. C., 1972, A mathematical model for fire spread predictions in wildland fuels, in Ogden, Utah, Intermountain Forest and Range Experiment Station, USFS Research Paper INT-115, 40 p. 


\section{San Francisco Bay Area Earthquake Hazards Mapping}

\section{BACKGROUND}

The San Francisco Bay Area has a well-known record of seismic activity. Earthquakes are potentially a great hazard to the lives and properties in the Bay Area.

Primary effects of seismic activity, such as surface rupture and ground shaking, are frequently followed by landsliding, liquefaction (the changing of soil from a solid to a liquid condition), and occasionally by inundation by tsunamis (large, fast-moving sea waves caused by earthquakes) and by dam failure. These processes are all interrelated and their impacts are dependent on both the physical environment of the region and the location of people and buildings.

The key to minimizing earthquake damage lies in the ability to anticipate and plan for these effects. Much research has been done on the reaction of model sites to earthquake-related effects. This research provides a necessary foundation for other work, but it does not describe the variation and distribution of model sites over a specific geographic area. There is a definite need to tie the theoretical behavior shown in earthquake models to specific areas, and to portray this in a form useful to those people who make public and private land use decisions in the region.

\section{THE PROBLEM}

The Association of Bay Area Governments (ABAG), the comprehensive planning agency for the nine-county San Francisco region, is responsible for preparation of plans and information that maintain or improve the quality of life in the region. Earthquake preparedness assistance is one important area of ABAG's responsibilities, and it includes the collection and mapping of technical earthquake hazard data, earthquake legislation advocacy, determination of local government liability and insurance costs, the preparation of guides for elected officials, and the inclusion of seismic safety concerns in project reviews.

The mapping and presentation of technical information describing regional earthquake hazards is a key responsibility of ABAG's Bay Area Spatial Information System (BASIS). BASIS permits the analysis and presentation of complex earthquake data in a spatial format, which is useful in making earthquake hazard assessments for entire cities, for individual neighborhoods, or for individuals or private companies. BASIS contains a comprehensive earthquake data base that is being used to produce:

1. Basic earthquake hazards maps that explain potential hazards related to specific components of the earthquake problem, such as landslide susceptibility and tsunami hazard areas.

2. Composite earthquake hazard maps that summarize the total potential hazards for sites throughout the region.

In a cooperative project (Earthquake Mapping Project) with the USGS (Contract No. 14-08-0001-17751, -19108, and -19831), ABAG employed BASIS to produce several types of digital Earthquake files and resultant maps for San Mateo County (fig. 17). The project focused on developing an operational Earthquake hazard digital mapping capability and demonstrating some sample uses for researchers and local geologists and planners. The USGS developed much of the basic data and provided technical assistance in their use and interpretation. San Mateo County was chosen because both ABAG and USGS had more data available for that county than any other in the Bay Area. For additional information, contact:

Jeanne Perkins, Earthquake Project Manager

Association of Bay Area Governments

Hotel Claremont

Berkeley, California 94705

(415) 841-9730

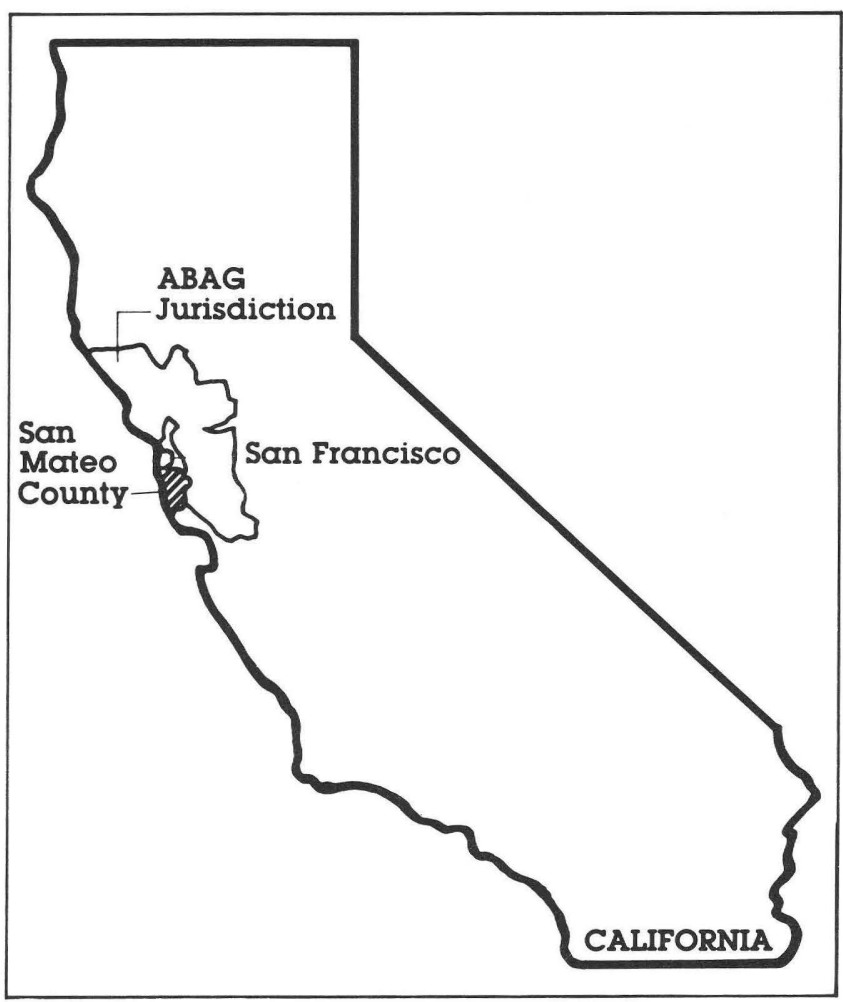

Figure 17. San Mateo County is an intensely urbanized area containing over one-half million residents. The danger of earthquake disaster is high due to the San Andreas Fault which extends through the county. 


\section{DATA SOURCES}

\section{Topographic Data}

High resolution topographic data were required to assist in the identification of the location and severity of earthquake-induced landslide susceptibility and overall earthquake hazards. The elevation values contained in 7.5-minute digital elevation models (DEM's) were used to calculate detailed slope data from which accurate maps displaying the maximum slopes throughout San Mateo County were made (fig. 18).

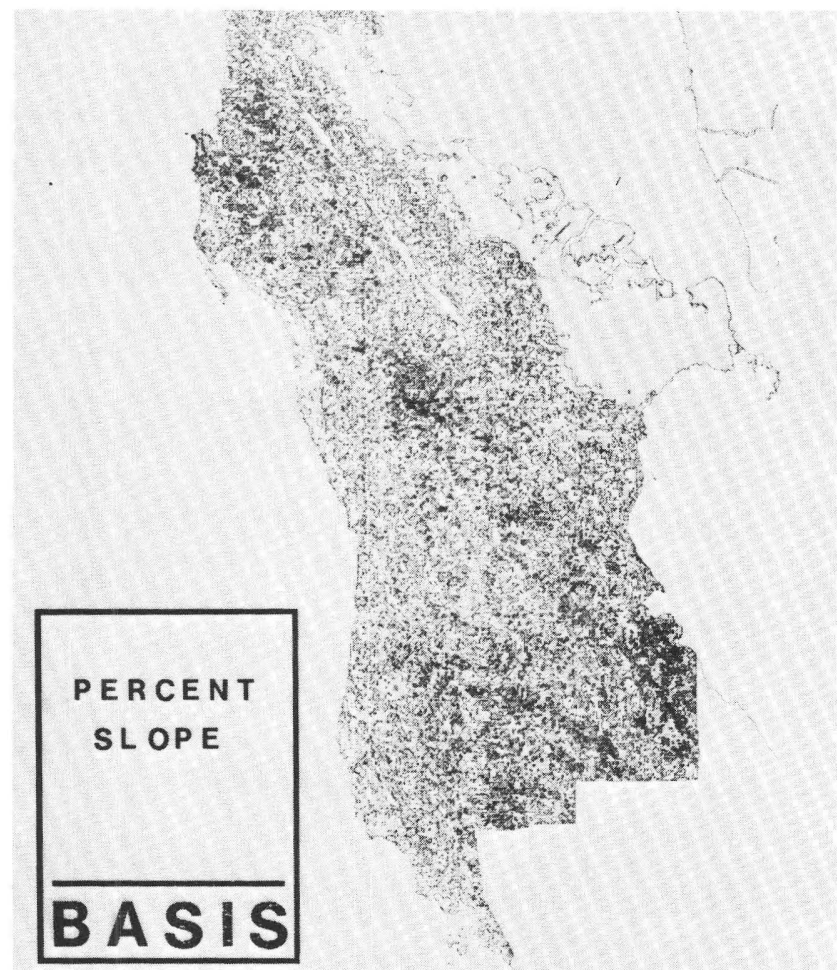

Figure 18. Digital elevation data were used to calculate this percent slope map for San Mateo County using ABAG's BASIS.

\section{Other Data}

Geology - U.S. Geological Survey (USGS) maps of surface geology were used in the identification of areas subject to ground shaking, liquefaction, and landslide problems.

Faults - USGS and California Geological Survey maps depicting major faults in the Bay Area were used to identify ground shaking, liquefaction, and surface rupture hazards.

Landslides - USGS records of historic landslide locations and their characteristics were used to assist in identifying liquefaction and earthquake-induced landslide hazards.

Tsunami Hazard Areas - USGS maps describing the areas and depth of potential tsunami inundation were used to assess composite earthquake hazards.
Dam Failure Hazard Areas - Maps produced by the California Office of Emergency Services were used to identify dams whose total failure would cause injury or loss of life.

\section{HAZARD MAPPING}

Six basic data files contained in BASIS were used to produce nine different earthquake hazard files, each depicting a specific component of the earthquake problem.

ABAG used the basic data files representing topography, geology, and historic landslides to assess regional earthquake-induced landslide susceptibilities. In the analysis process originally developed by USGS, percent slope and geologic data were compared to historic landslide information in order to rate the landsliding susceptibility of each slope class and geologic unit. Ratings were then combined to produce a four-category comprehensive earthquake-induced Landslide Susceptibility classification (fig. 19). Other hazard maps produced in the Earthquake Mapping Project are:

- Rainfall-Induced Landslide Hazards

- Maximum Ground Shaking Intensity

- Risk of Ground Shaking Drainage (for three different types of buildings)

- Liquefaction Susceptibility

- Liquefaction Potential

- Fault Surface Rupture

- Tsunami Hazard Areas

- Dam Failure Hazard Areas

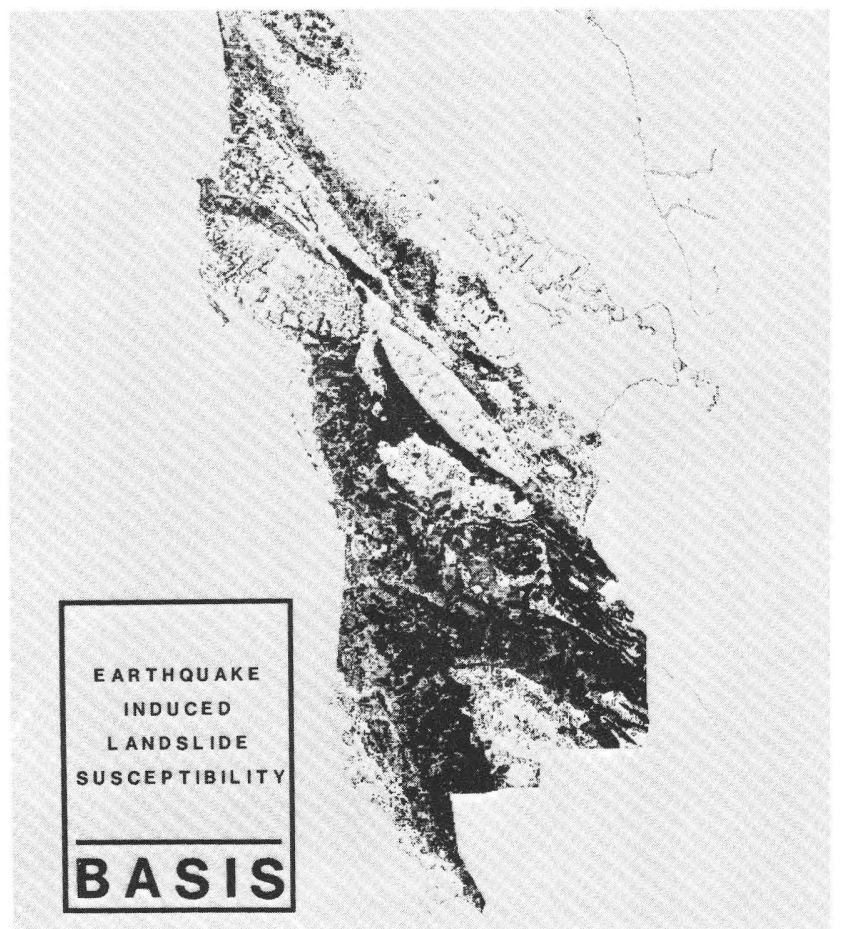

Figure 19. Earthquake-Induced Landslide Susceptibility map for San Mateo County (produced with BASIS). 
These earthquake hazard files were either used individually to describe specific characteristics of the earthquake problem, or composited to identify the combined earthquake risk.

\section{Composite Hazard Maps}

The individual hazard files are composited to produce additional files that represent the comprehensive, cumulative earthquake hazards or risks in a particular geographic location.

\section{Composite Maximum Earthquake Damage}

The maximum percent damage expected during an earthquake can be determined by adding the percent damage scores associated with the following individual hazard files (fig. 20):

- Earthquake-Induced Landslide Susceptibility

- Maximum Ground Shaking Intensity

- Fault Surface Rupture

- Liquefaction Potential

- Tsunami Hazard Areas

- Dam Failure Hazard Areas

Because the amount of damage is partially determined by the type of building affected, different assumptions regarding type of structures can be made.

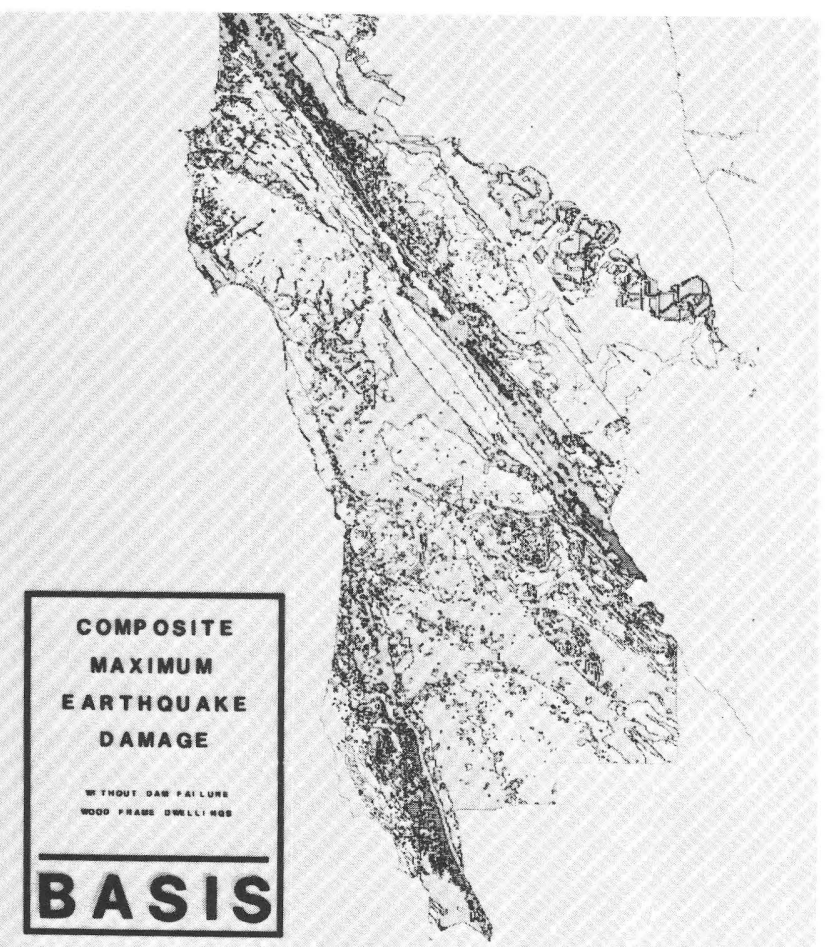

Figure 20. A map of Composite Maximum Earthquake Damage for San Mateo County. This example assumes that the area is uniformly covered by woodframe dwellings (produced with BASIS).

\section{Composite Risk of Earthquake Damage}

The risk of damage from an earthquake is estimated by compositing the individual hazard files. The expected damage is multiplied by the frequency with which earthquakes are expected to occur, and the resulting average annual damage cost is then discounted to its present value in order to permit a comparison with mitigation costs (fig. 21 ). The hazard files used to determine composite earthquake risks are:

- Earthquake-Induced Landslide Susceptibility

- Fault Surface Rupture

- Risk of Ground Shaking Damage

- Liquefaction Potential

- Tsunami Hazard Areas

The dam failure data were not used in measuring the risk of earthquake damage since the probability of dam breakage is low.

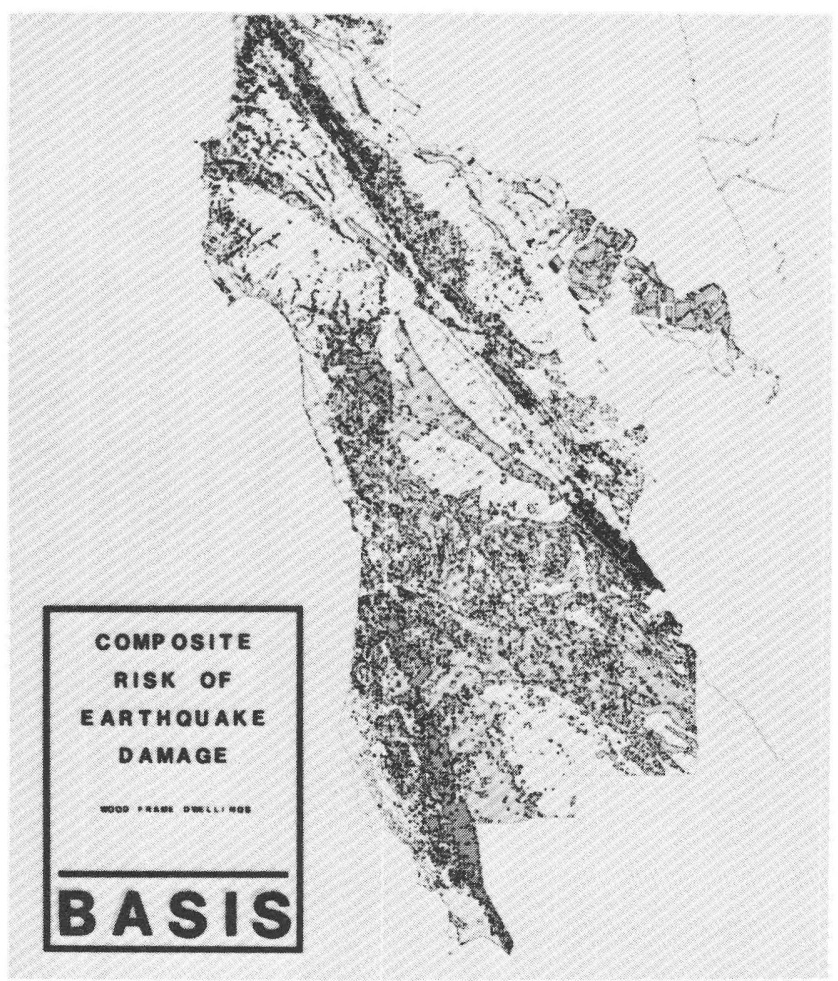

Figure 21. The Composite Risk map of Earthquake Damage identifies the statistical losses from earthquakes based on the frequency that this damage can be expected to occur for areas throughout San Mateo County (produced with BASIS).

\section{APPLICATION OF PRODUCTS}

The Earthquake Mapping Project illustrates the utility of digital cartographic data and computers for incorporating complex information into the planning and decision-making process. The files and maps produced in 
this project have thus far been applied to the following activities:

- reviewing projects proposing to use State and Federal funds, including highways, housing projects, and sewage treatment plants.

- seismic safety planning by local governments.

- environmental impact studies.

- supporting and advocating appropriate legislation at both the State and Federal level.

If additional funds become available, the detailed analysis and mapping already completed for San Mateo County will be completed for the remainder of the Bay Area. The technical approach used to evaluate the earthquake hazards throughout the Bay Area has directly contributed information that may ultimately result in the saving of many lives.

\section{SELECTED REFERENCES}

Association of Bay Area Governments, 1980, Earthquake map applications for automated environmental impact assessment: Berkeley, California, Working Paper-8, 15 p.

1980, Earthquake map applications for composite earthquake hazard mapping: Berkeley, California, Working Paper-9, 13 p. , 1980, Slope stability mapping: Berkeley, California, Working Paper-5, 13 p.

- 1980, A guide to ABAG's earthquake hazard mapping capability: Berkeley, California, $50 \mathrm{p}$.

, 1979, BASIS: The Bay Area spatial information system: Berkeley, California, $10 \mathrm{p}$.

Wilson, P. M., 1980, Earthquake hazards mapping in the San Francisco Bay region: Cambridge, Massachusetts, Harvard Computer Graphics Week 809, 21 p. 


\section{Preliminary Soils Mapping in Eastern Kentucky}

\section{BACKGROUND}

The highlands of eastern Kentucky are in the heart of Appalachia's coal producing region. Development of regional coal resources requires detailed information describing the physical characteristics of the land. Both the selection of mining sites and the evaluation of potential environmental impacts require detailed soils data. Because various soil bodies have different rates of erosion, varying engineering properties, and differing levels of productivity, a knowledge of the soils involved is important prior to any construction.

Unfortunately, soils mapping is not complete for the mountainous highlands. Less than 25 percent of the 30,000-square-kilometer Cumberland Plateau, for example, has been surveyed. Soil mapping is currently underway in this region but is not planned for completion until the 1990's.

\section{THE PROBLEM}

Because the need for soils data that satisfy the planning and regulatory activities in eastern Kentucky is current, surrogates to traditional soil survey maps are needed to fill the data gap.

The Lands Unsuitable for Mining Program of the Kentucky Department for Natural Resources and Environmental Protection has begun investigating alternative approaches for providing soils information. The large land area without soils data combined with the need for maps with detailed resolution suggested the use of digital data and computer-based analysis techniques. It became apparent that if appropriate data were available, the geographic overlay modeling capabilities of the Kentucky Natural Resources Information System (KNRIS) could be used to identify broad associations of soils. Thus, a project was initiated to assemble digital cartographic data related to geomorphology or terrain and to produce preliminary soils maps using geographic modeling techniques.

This project was conducted by personnel with the Lands Unsuitable for Mining Program and the Division of Conservation of the Kentucky Department for Natural Resources and Environmental Protection, with assistance from the department's KNRIS staff. For more information, contact:
Lands Unsuitable for Mining Program

Kentucky Department for Natural Resources and

Environmental Protection

14th Floor, Capitol Plaza Tower

Frankfort, Kentucky 40601

(502) $564-5174$

\section{DATA SOURCES}

\section{Topographic Data}

The form of individual soil bodies is closely related to topography, since it effects soil development. In particular, the steepness and direction of slopes influence the characteristics of each soil unit. As slopes become steeper, soil profile development is slowed. The slope direction (aspect) affects soil temperature, soil moisture, and surface vegetation. The combined effect of all topographic characteristics on soil conditions is significant.

A high-resolution digital elevation model of the Ogle 7.5-minute quadrangle was used for the soil modeling study (fig. 22). The elevation data served as the basis for percent slope and aspect calculations. The precision of the DEM was critical since minor topographic variations cause different soils conditions.

\section{Landform Data}

Landforms are important factors in defining unique soil bodies. Digital landform data (such as floodplain, terrace, toeslope) existing in KNRIS were used in the soil modeling process. These data had originally been manually interpreted from stereoscopic 1:24,000-scale aerial photographs, digitized, and incorporated into the KNRIS data base.

\section{SOILS MODELING AND MAPPING}

The aspect and percent slope data, developed using the DEM and the digital landform files were used in a composite model to delineate landform based soil units. Thus, the soil bodies are defined primarily on the basis of geomorphic soil forming factors (relief and parent material) and only indirectly consider the influence of climate, time, and organisms on soil formation.

The automated soil mapping involved three steps. First, the digital elevation data were converted to slope and aspect files using KNRIS-based algorithms. These files were used to produce a digital slope map containing seven slope categories that were consistent with Soil Conservation Service (SCS) soil survey percent slope classes (fig. 23). Percent slope was based on the steepest slope for 


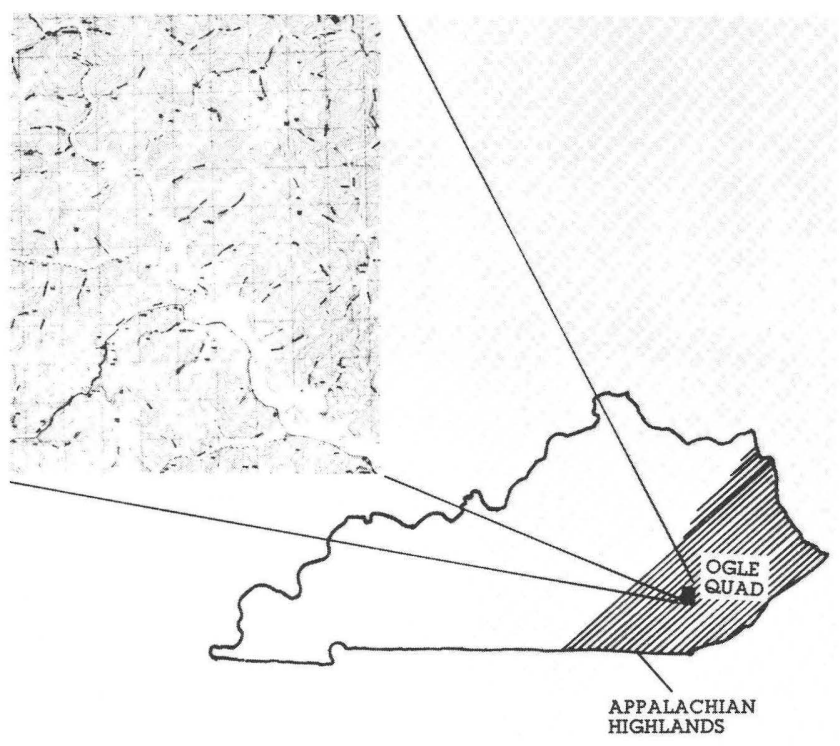

Figure 22. The area included in the USGS Ogle 7.5-minute quadrangle is typical of lands in the eastern Kentucky highlands. The area is in the rugged Cumberland Plateau which is characterized by highly dissected topography. Because of the presence of extractable coal resources, considerable interest exists to expand surface mining in the region.

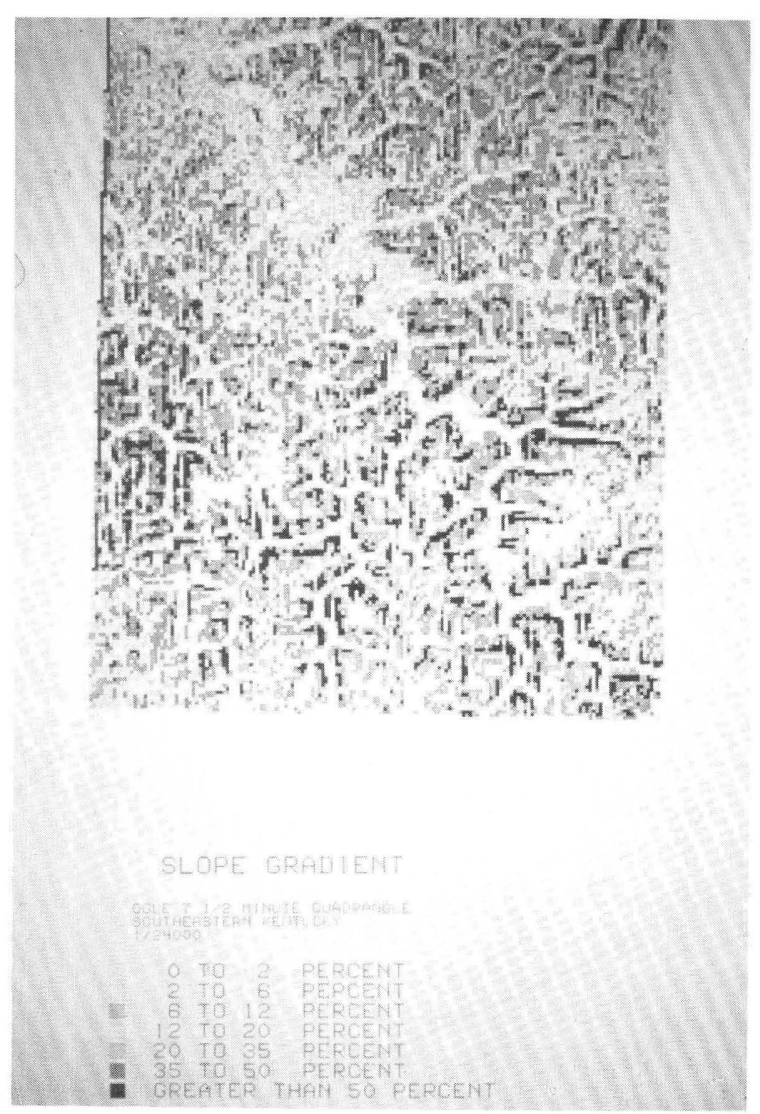

Figure 23. The percent slope file contains the maximum slopes existing throughout the Ogle 7.5-minute quadrangle. each 67-meter-square grid cell. The aspect calculations identified one of eight compass directions for each grid cell. The aspect data were then aggregated into "northslope" and "southslope" categories which are used by the SCS to map soil units in rugged areas of eastern Kentucky (fig. 24).

The definition of decision rules governing the soil modeling process was the second analysis step. This was done by examining the relationships between topography, landforms (fig. 25), and soil units in a surveyed area of Kentucky. Preliminary assumptions were evaluated in the field and the final soil model was defined.

The third and final task involved the actual soil modeling using an overlay analysis procedure. The geographically registered slope, aspect, and landform files were automatically composited, using the KNRIS computing system, to produce the desired seven-category preliminary soil map (fig. 26). The soil unit categories defined areas with unique combinations of landform, slope, and aspect conditions. Slope and landform conditions affect such factors as the amount of soil profile development and potential erosion rates. Aspect affects the amount and types of organic matter contributed to the soil body, soil moisture conditions, and soil temperatures.

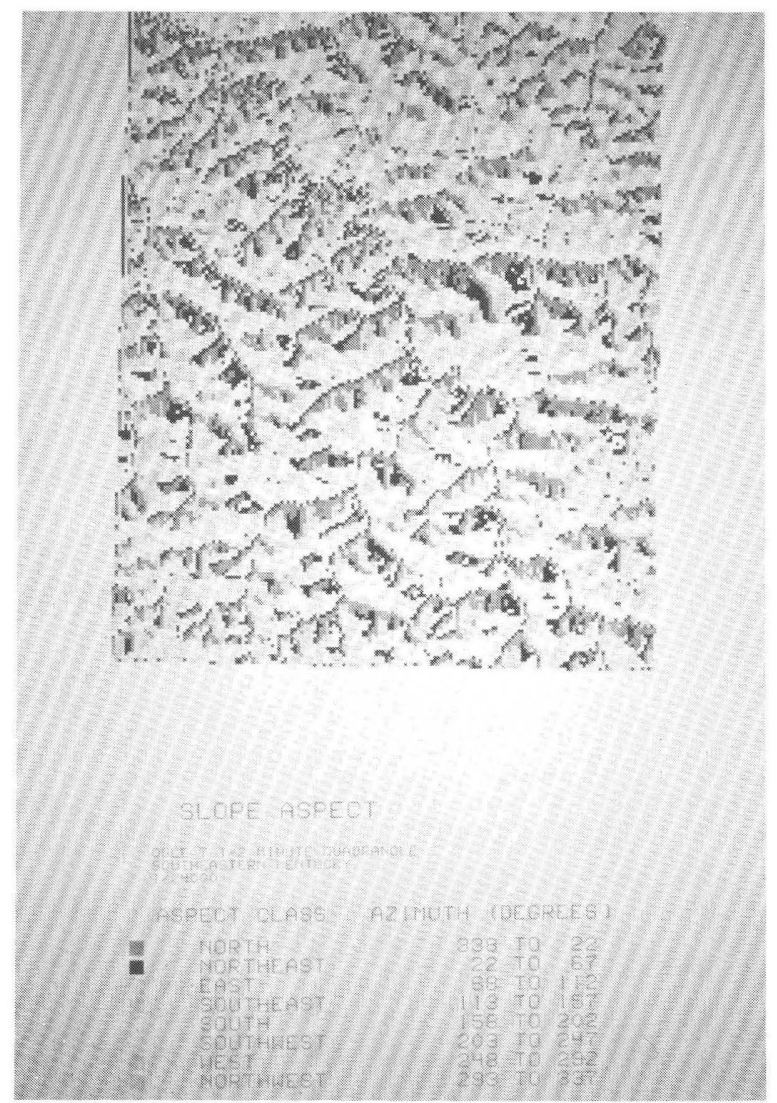

Figure 24. The aspect file contains the direction that each slope faces in the Ogle 7.5-minute quadrangle. 


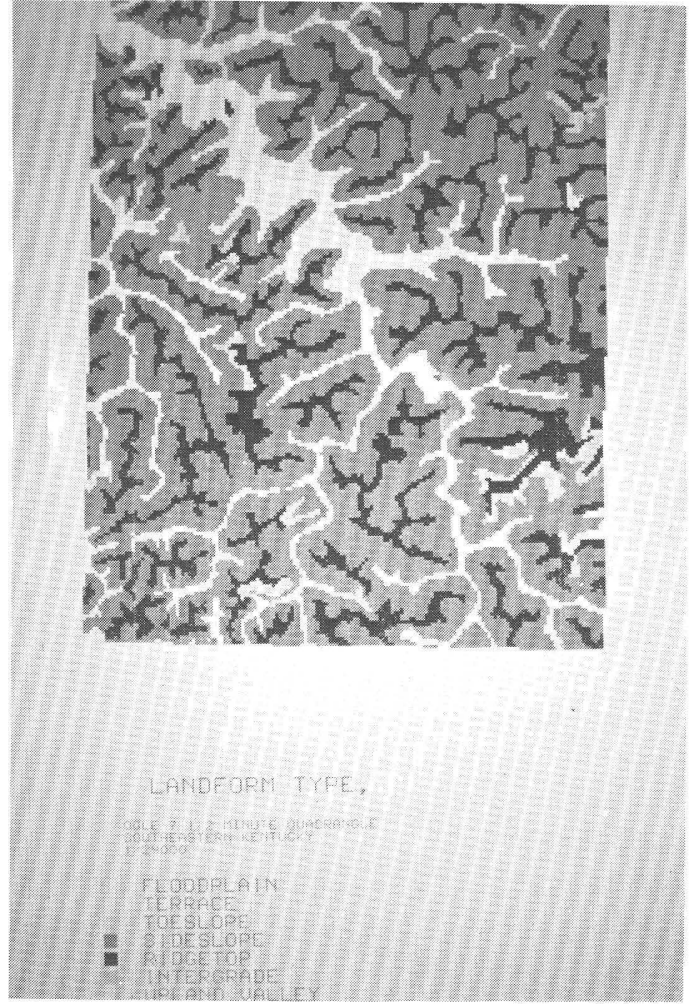

Figure 25. Primary landforms in the Ogle 7.5-minute quadrangle.

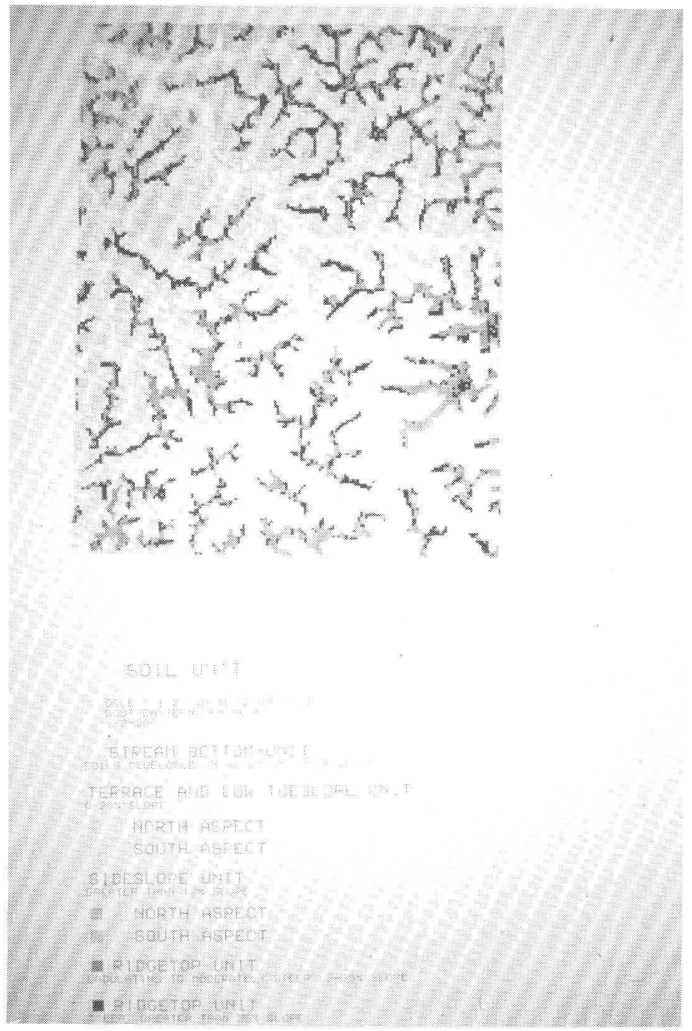

Figure 26. The soil map for the Ogle 7.5-minute quadrangle resulted from the compositing of slope, aspect, and landform data.
Thus, each of the seven soil units have unique erosion characteristics, productivity levels, and development suitabilities. In the absence of conventional soil survey maps, the preliminary soil maps provide a starting point from which soil use decisions can be made.

\section{APPLICATION OF PRODUCTS}

The preliminary soil maps and statistics produced using the automated soil modeling procedure have a variety of potential uses. As input to the planning process, they may be applied to problems such as:

- Land use conflicts between important agricultural lands and potential urban or surface mining developments.

- Coordinating planting and land acquisition activities in the Daniel Boone National Forest.

- Wildlife habitat modeling.

- Regional land capability or suitability development assessments.

The preliminary soils maps may also be useful tools for planning and conducting SCS field soil surveys. They may expedite initial phases of soil survey work such as terrain mapping and locating field transects. The preliminary soil maps may ultimately decrease the costs and efforts required to produce the detailed soil surveys, if significant correlations are found to exist between the preliminary soil units and field-verified soil characteristics.

The utility of the preliminary soil maps is obviously more limited than detailed SCS soil surveys. However, they do provide a low-cost alternative during the period before the SCS maps are available.

\section{SELECTED REFERENCES}

Croswell, Peter, 1981, Automated soil modeling with the Kentucky Natural Resources Information System (KNRIS): Frankfort, Kentucky, Kentucky Department for Natural Resources and Environmental Protection, $8 \mathrm{p}$. 


\section{Survey of Oregon Irrigation Development Potential}

\section{BACKGROUND}

The Columbia River system serves as the lifeline for the Pacific Northwest. The river supplies the region with food and fiber through irrigation, with electricity through hydroelectric plants, and provides transportation, recreation, and primary municipal and industrial water supplies. Dependence on the Columbia River system for these water uses obviously requires effective management so that no one use seriously interferes with the others. Water management decisions must be based on accurate information describing both present and future water use.

Irrigation is the largest consumptive use of Columbia River water, so it must be managed both to maximize agricultural benefits and to insure the wisest use of water and power supplies. Hydropower generation, in particular, is most adversely affected by irrigation development. The development of 4000 hectares (10,000 acres) of irrigation causes an average annual loss of $\$ 310,000$ (1976 dollars) of electrical energy. The exact amount of lost energy is dependent upon the characteristics of the land developed for irrigation agriculture. Future irrigation developments, therefore, must take place in areas where the loss of power revenues is more than compensated by the benefits derived from the new irrigation.

\section{THE PROBLEM}

The U.S. Army Corps of Engineers, North Pacific Division, has the responsibility for preparing a Columbia River system plan that maximizes the use of the region's resources. This plan must permit the development of lands having the greatest irrigation potential both in terms of land capability and efficient energy use. In order to prepare a plan that strikes a balance between irrigation growth and energy reduction, the Corps and the EROS Data Center designed techniques that provided the following information:

1. A potential-energy-costs map that illustrated power estimates for pumping irrigation water to sites throughout the study area.

2. An irrigation-development-potential map that identified land suitability for future irrigation.

The project methods were tested in the Umatilla River Basin of north-central Oregon (fig. 27) in order to determine their utility for supplying information used in the preparation of the Columbia River systems plan. The Corps assisted in the planning and review of the analysis, and assisted in the collection of supporting data. EROS completed the technical aspects of the project.

Two factors influenced the selection of the data and

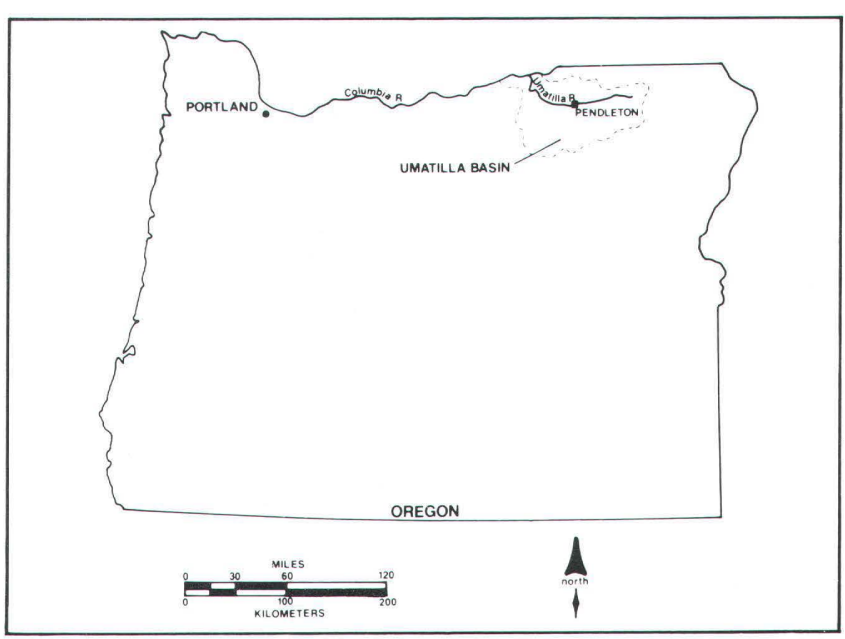

Figure 27. The study area included 400,000 hectares (one million acres) in the north portion of Oregon's Umatilla River Basin.

analysis techniques used in this study. First, the Corps of Engineers needed spatial or map-based information for its planning process. Second, the portion of the Umatilla Basin that was to be evaluated was too large (approximately 1 million acres), and the level of ground detail needed was too fine $(1 / 2$ hectare resolution) to be efficiently analyzed without the use of a digital computer. Therefore, an analysis process using digital cartographic data was selected for use in this project.

\section{DATA SOURCES}

\section{Topographic Data}

Solutions to both problems are partially based on the influence of topography. Energy requirements for irrigation are dependent on the distance water is lifted from its source to its point of use. Irrigation development potential of the land is partially based on the steepness of the landscape under consideration. As slopes become steeper, irrigation potential decreases due to increasing water runoff problems.

Digital terrain tapes (DTT) supplied the topographic data needed to prepare both maps. The data, when registered to a base map, provided elevation values for every acre in the study area (fig. 28). Computer analysis techniques can both convert the elevation data into the pump lift estimates needed to calculate energy requirements and transform them into the percent slope classes needed to determine irrigation suitability. Because the transformed data are also in digital form, they can readily be merged with other pertinent digital cartographic data to efficiently produce solutions to complex questions.

\section{Other Data}

In addition to topographic data, several other types 


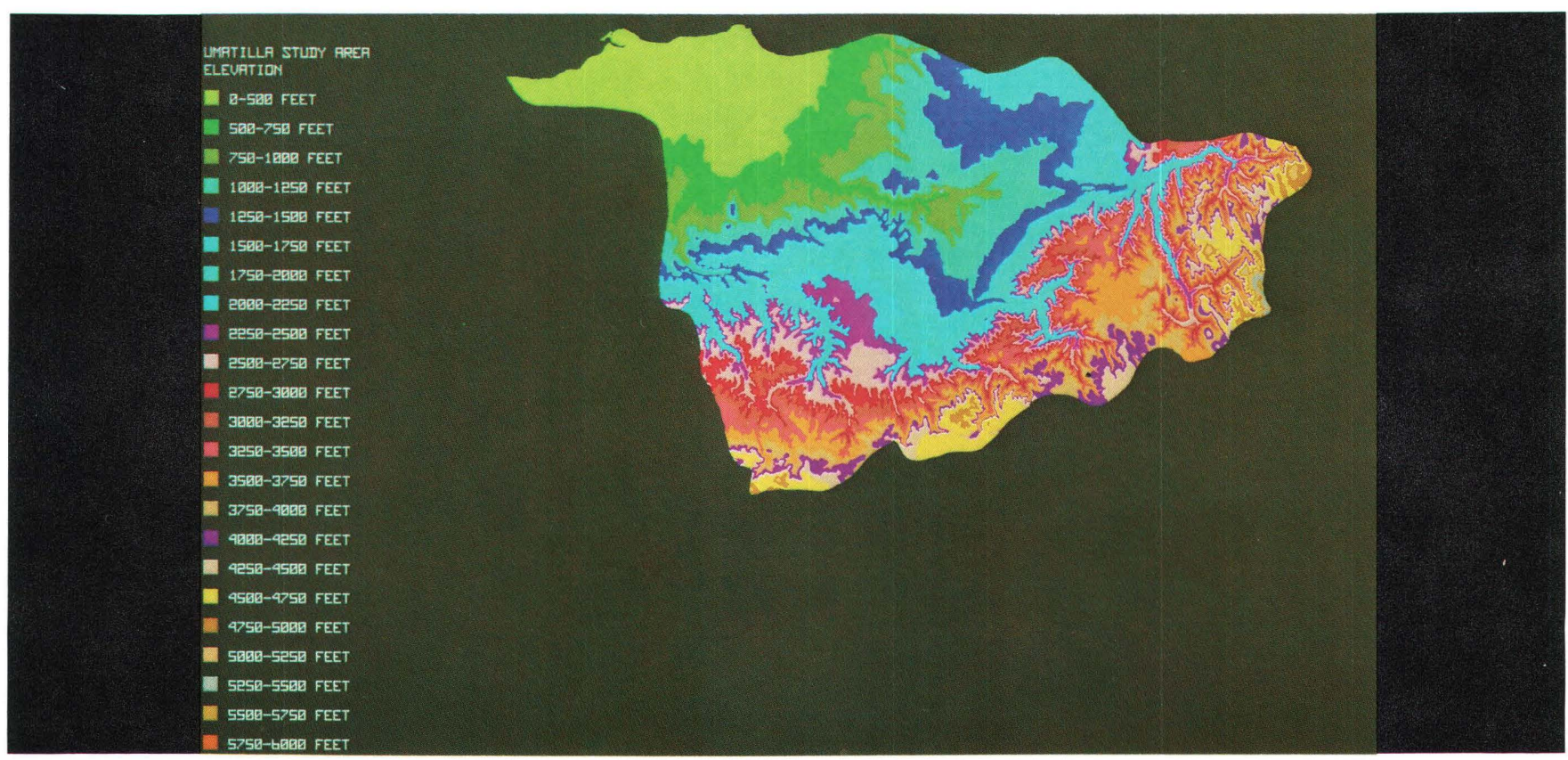

Figure 28. Digital elevation data for the Umatilla Basin provide a unique view of the region's topographic patterns. For example, the elevation data clearly identify the level tablelands that parallel the Columbia Basin to the north.

of data were required to accurately estimate energy requirements and determine irrigation potential.

Pumping Plant Data - Corps of Engineers records described the location and operating efficiency of pumping plants along the Columbia River.

Land Cover - A 1979 Landsat scene was interpreted to produce a land cover map.

Landownership - Both Corps of Engineers and USGS maps were used to identify landownership parcels.

Soil Survey Maps - USDA Soil Conservation Service detailed county soil surveys provided soil irrigability ratings.

These data, originally available in tabular and map formats, were digitized so that they could be used with the digital topographic data.

\section{ENERGY REQUIREMENTS MAPPING}

The amount of energy required for successful irrigation is dependent not only upon the lift and distance between the irrigated field and source of water, but also upon the type of crop being irrigated and the operating efficiency of the pump supplying the water. The Corps of Engineers traditionally has used an equation that considers these parameters to estimate energy needs in kilowatt hours per acre per year. The equation is as follows:

$$
\mathrm{KWH}=\frac{(1.024)(\text { Diversion })(\mathrm{TDH})}{\text { Epp }}
$$

Where, 1.024 - A constant that standardizes the equation.
Diversion - The amount of irrigation water required. ( 2.81 acre-feet per year in this area.)

TDH - The total dynamic head. This factor is the sum of the pump lift distance in feet, the friction loss per linear mile (at 11.12 feet per mile), and system operating pressure.

Epp - Efficiency of pumping plant supplying irrigation water ( 85 percent in this study).

The TDH component of the equation is critical since it represents the characteristics of the landscape. In the past, average vertical and linear distances between the source and point of use of the irrigation waters were used to estimate basin-wide energy requirements. In variable terrain, however, the average results will in fact vary significantly on a field-by-field basis. For assessing the energy impact of future development, the Corps needed more site-specific information.

Digital topographic data provided an efficient means for calculating pump-lift to lands throughout the Umatilla Basin. By identifying the elevation of the water source and the elevation of the point of use, the pump-lift in feet was quickly computed (fig. 29). The resulting lift data provided acre-by-acre estimates that were combined with friction-loss estimates (fig. 30) also developed with 1-acre detail, to produce the TDH portion of the energy equation. With TDH in a spatial format that accurately represents the landscape character, the remaining nonsite-specific variables (Diversion and Epp) can be included in the equation to produce the classification of potential energy requirements (fig. 31). 


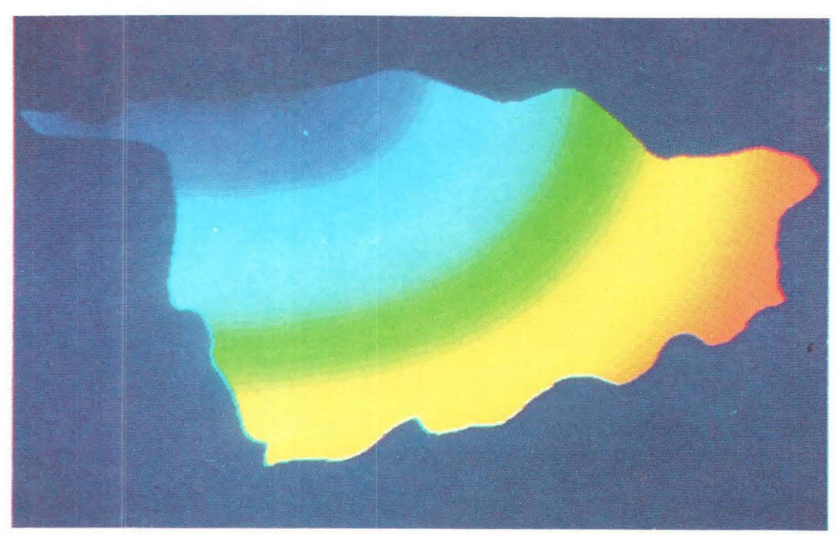

Figure 29. Pump lift distances in feet were calculated using the digital terrain data.

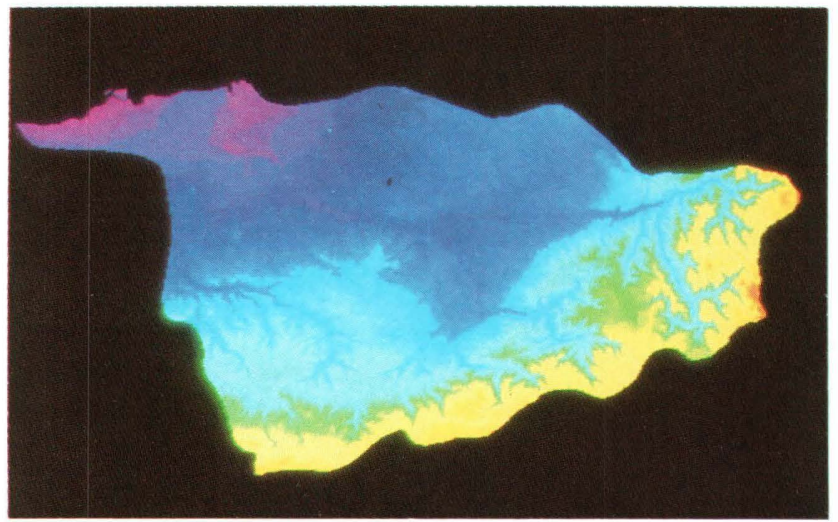

Figure 30. Friction loss was estimated by calculating the mileage from the pumping plants located along the Columbia River.

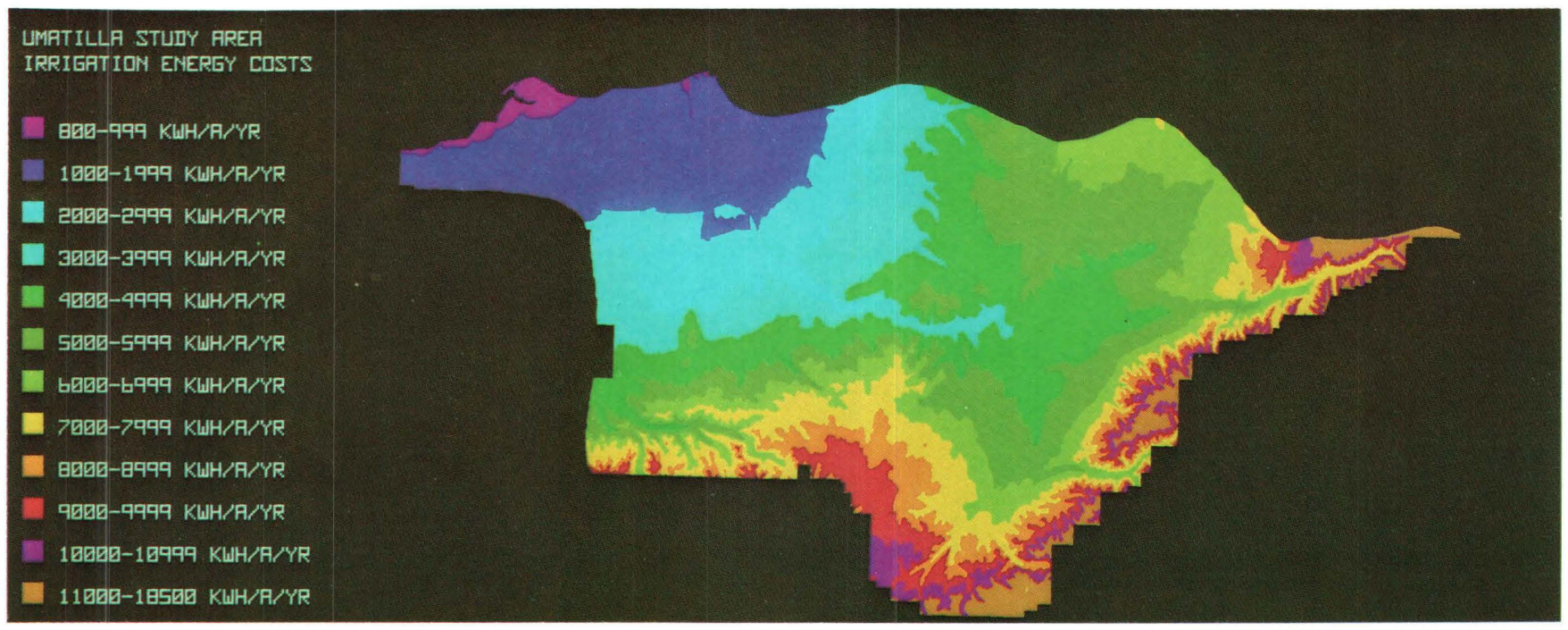

Figure 31. The potential energy requirements map provides an estimate of the energy required for irrigation development and an estimate of the lost power revenues as a result of the new irrigation. The map clearly illustrates the role of land position in determining energy costs.

\section{IRRIGATION POTENTIAL MAPPING}

To evaluate irrigation development potential for lands in the Umatilla Basin, a variety of physical characteristics of the landscape as well as potential energy requirements for future development must be considered (figs. 32-36). The physical factors that were identified as important were percent slope, soil irrigability, and existing land cover. The energy requirements data derived in the previously discussed phase of the project were to represent partial operating costs. One additional variable, landownership, was included since several areas in the basin had regulatory restrictions prohibiting irrigation development.

The five variables were first digitally composited to produce summary data describing irrigation development potential in the Umatilla Basin. The summary data

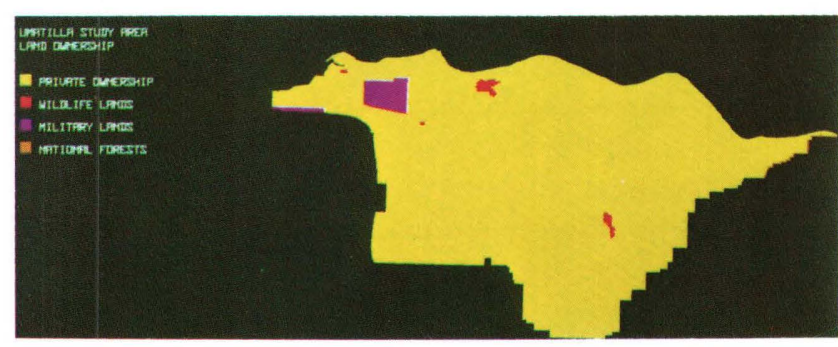

Figure 32. Land cover, interpreted from a 1979 Landsat scene, was used to identify lands that are already being irrigated, could be irrigated (dryland agriculture and rangeland), and cannot be irrigated (water bodies, wetlands, forests, and urban areas). 


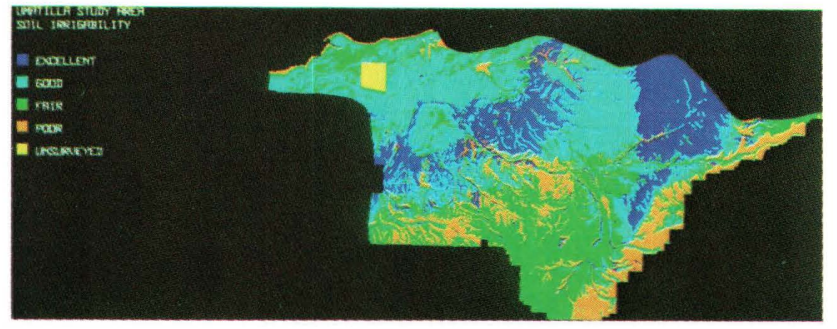

Figure 33. Soil irrigability was determined using county soil survey data prepared by the USDA's Soil Conservation Service. The irrigability ratings are based on the physical and chemical characteristics of each soil body.

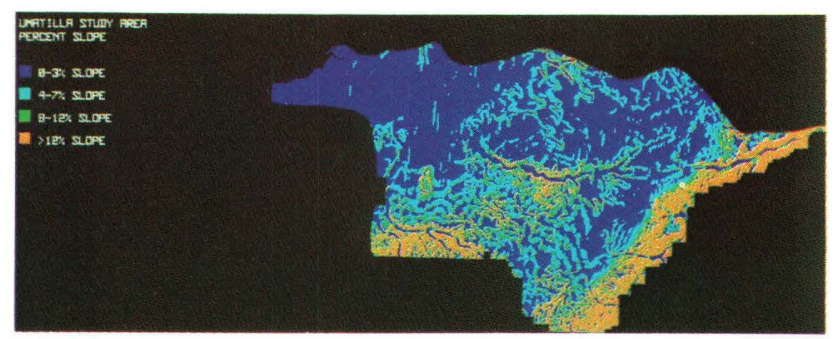

Figure 35. Digital terrain data were used to produce this percent slope classification. The slope data identify areas where land steepness limits irrigation development.

provides ratings of development potential based on the physical characteristics of the landscape, the economic impact of energy costs, and government restrictions prohibiting irrigation (fig. 37).

\section{APPLICATION OF PRODUCTS}

The map products of this study can be applied to a variety of planning problems. Of primary importance is their utility for evaluating assumptions used in the preparation of the Corps of Engineers Columbia River System Plan. The maps provide a baseline for measuring the validity of the irrigation development-hydropower generation balance strived for in the plan. Other applications of study results might include:

1. The potential-energy-costs map can be used to estimate energy impacts of new irrigation developments. By locating possible development areas on the energy map, both the developer's energy costs and the amount of lost hydropower can be estimated.

2. The irrigation-development-potential map can be used to identify lands that offer the greatest return on investment. Both private and government developers can benefit from this knowledge.

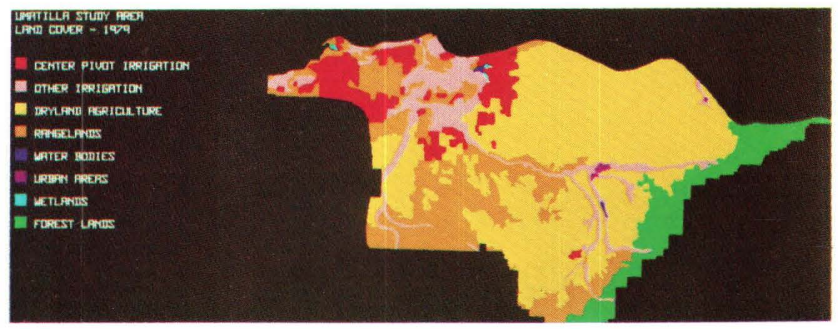

Figure 34. Land ownership, produced using several sources of data, identifies land areas with administrative regulations prohibiting irrigation development.

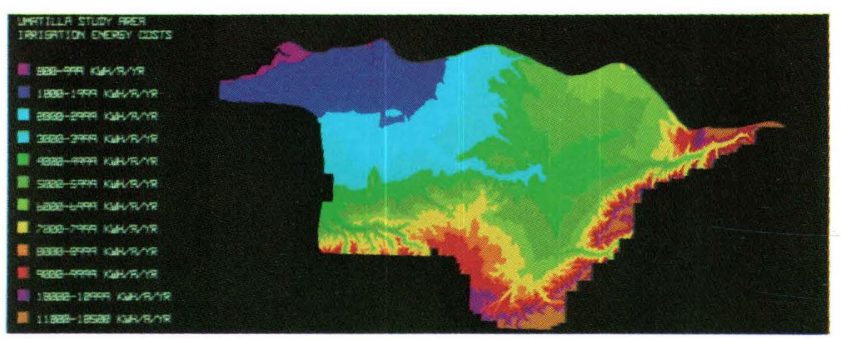

Figure 36. Energy requirements are also based on terrain data.

Whereas the maps produced in this study will never replace detailed on-site surveys of irrigability, they do provide a starting point for planning future regional uses of land, water, and power resources. From this starting point, more cost-effective field studies will be possible, and more resource-efficient water development decisions can be made.

\section{SELECTED REFERENCES}

Johnson, G. E., Vining, R. F., and Loveland, T. R., 1980, Remote sensing applied to irrigation engineering: Proceedings of the 1st International Conference on Computing in Civil Engineering, New York, N.Y., p. 545-560.

Loveland, T. R., and Johnson, G. E., 1982, The role of remotely sensed and other spatial data in predictive modeling: the Umatilla, Oregon example, in William T. Pecora Symposium, 7th, Sioux Falls, South Dakota, 1981, Proceedings: American Society of Photogrammetry, p. 442-454. 


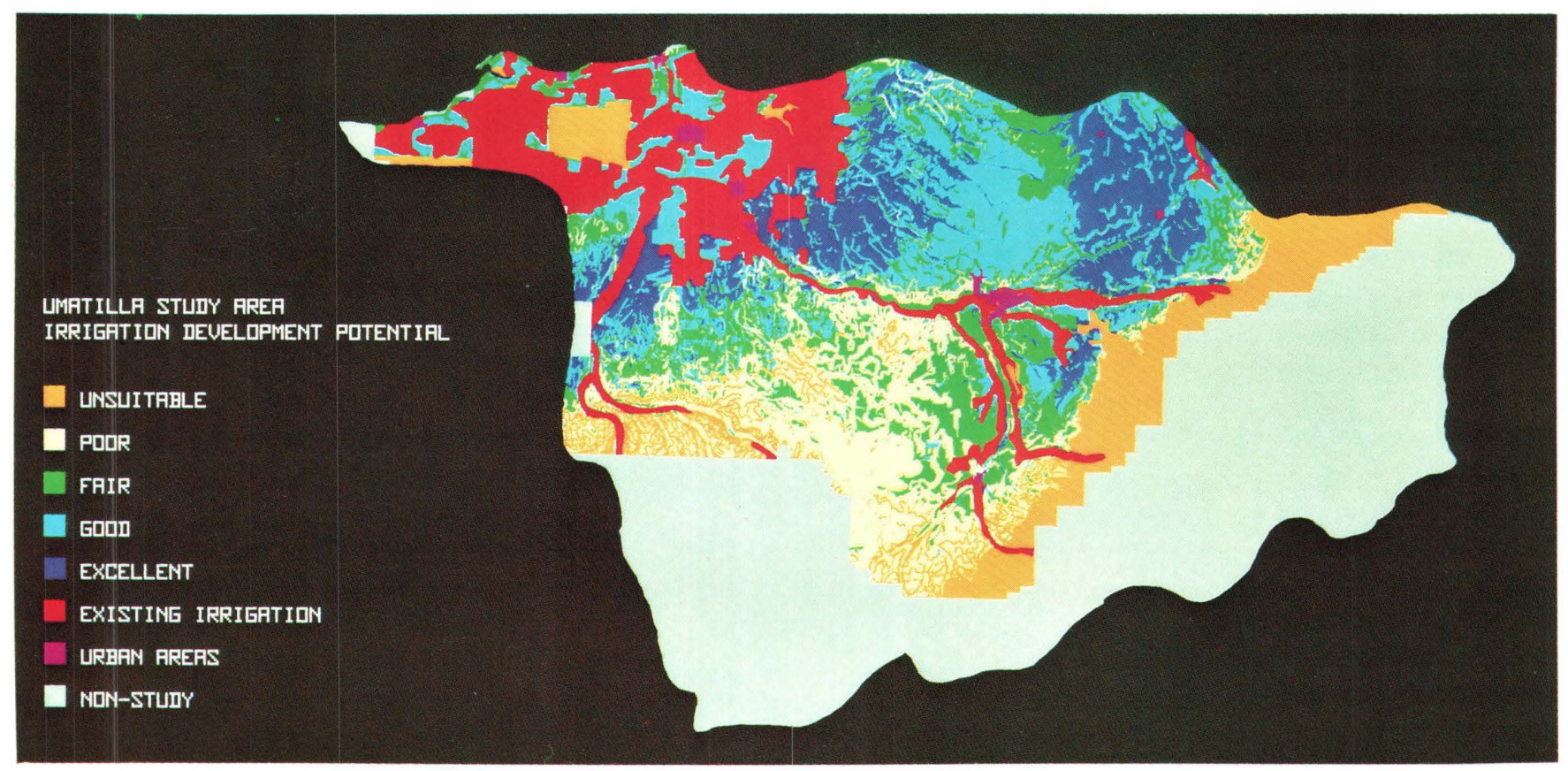

Figure 37. The Irrigation Development Potential Map represents the cumulative impact that energy requirements, slope, soils, land cover, and land ownership have on irrigation development. 


\section{Arizona Rangeland Management}

\section{BACKGROUND}

The U.S. Bureau of Land Management (BLM) is responsible for the administration of nearly 80 million hectares of public lands in the continental United States. The agency must manage all resources found on these lands so that the greatest public benefit is realized. The many uses of public lands, including livestock grazing, timber production, minerals development, fish and wildlife habitat, and outdoor recreation, require proper planning in order to insure long-term benefits.

As pressures for increased access and use of public lands mount, timely resource information is needed. This need was further recognized when the 94th Congress passed the "Federal Land Policy and Management Act of 1976" which stated:

"The Secretary [of the Interior] shall prepare and maintain on a continuing basis an inventory of all public lands and their resource and other values, giving priority to areas of critical environmental concern. This inventory shall be kept current so as to reflect changes in conditions and to identify new and emerging resource and other values." (Public Law 94-579, Title II Section 201(a), 43 USC 1711, October 21, 1976.)

Because of the need for natural resource data, the BLM has updated its traditional inventory procedures so that it can apply the most efficient data collection methods.

\section{THE PROBLEM}

The BLM needs resource inventory and evaluation procedures that permit not only the collection of baseline data, but also the efficient analysis of complex planning problems related to multiple uses of the public lands. Because of the tremendous land area that must be managed, new technologies must be adopted if timely information are to be gathered efficiently. The BLM and the Earth Resources Observation Systems (EROS) Data Center undertook a cooperative project to evaluate the suitability of remote sensing and geographic data base technologies for resource mapping and analysis. Remote sensing would provide the inventory data, and these, plus related resource data, would be stored in a computerized geographic data base and manipulated to produce the required maps and information. The specific objectives of the project were:

(1) to develop procedures for inventorying and mapping vegetation resources found on BLM lands.

(2) to develop procedures for combining several types of resource data to produce rangeland and wildlife management opportunity maps.

The methods developed in the project were tested in the BLM Grand Wash Planning Unit in northwest Arizona (fig. 38).

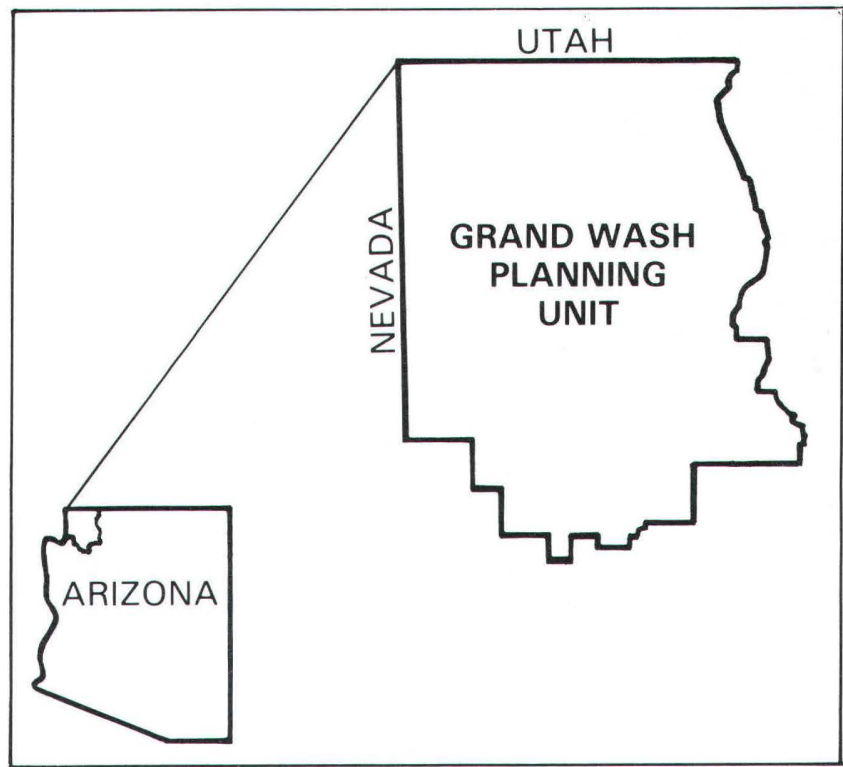

Figure 38. The BLM Grand Wash Planning Unit encompasses approximately 750,000 hectares in northwest Arizona. Broad, arid rangeland valleys dominate the area. Several tree-covered mountainous regions lie within the planning unit. The elevation ranges from 300 to over 2000 meters.

The Grand Wash Planning Unit rangeland management project was a part of the Arizona Vegetation Resource Inventory (AVRI) project. Bureau of Land Management personnel representing the Scientific Systems Division (Denver, Colorado), the Arizona State Office (Phoenix, Arizona), and the Arizona Strip District (St. George, Utah) provided expertise related to both inventory sampling procedures and rangeland management practices. The EROS Data Center provided the majority of the remote sensing and geographic data analysis expertise.

\section{DATA SOURCES}

\section{Topographic Data}

Digital terrain tape (DTT) elevation data and derived slope and aspect data were used throughout the project (fig. 39). Topographic data played an important role in improving the vegetation map of the Grand Wash Planning Unit area, and topographic factors were also used, with other data, to identify rangeland management opportunities, wildlife habitats, and grazing suitabilities. 


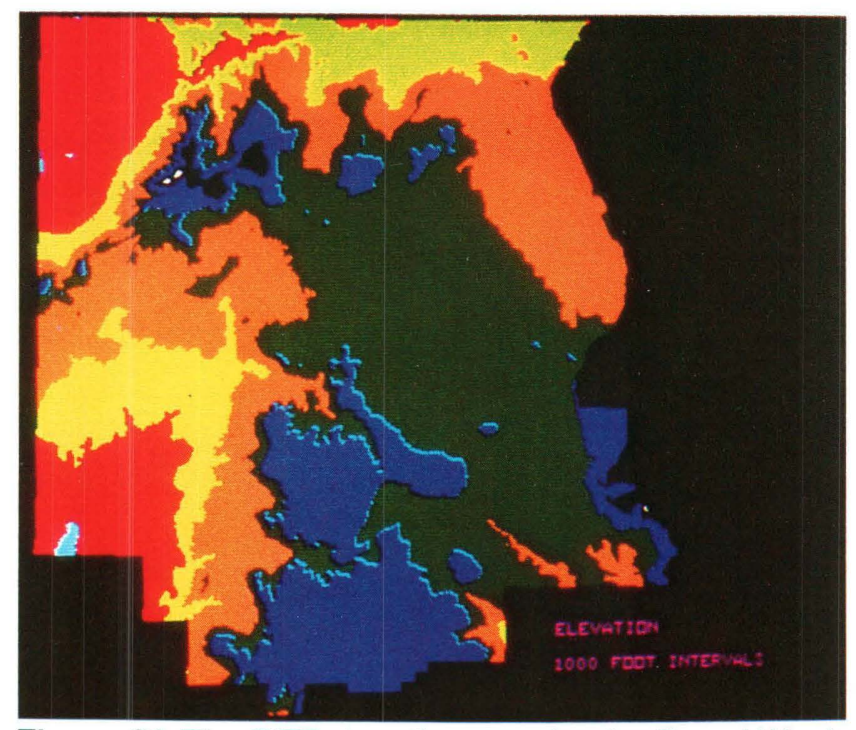

Figure 39. The DTT elevation map for the Grand Wash Planning Unit.

\section{Other Data}

Landsat - A Landsat Computer-Compatible Tape (CCT) was used in the vegetation inventory phase of the project. Road Network - BLM road maps were used to produce selected management opportunity maps, although they first had to be converted to a digital format so that all project data could be analyzed collectively.

Field Data - Reference data collected in the field describing vegetation resources were converted to a digital form and used to precisely define the characteristics of the vegetation map.

\section{VEGETATION MAPPING}

A comprehensive inventory of vegetation resources was needed in order to provide a baseline from which future vegetation changes could be measured. The inven- tory data were also required to assist in identifying rangeland management opportunities.

The initial task was the development of a detailed vegetation map for the Grand Wash Planning Unit. The vegetation mapping originally done using only the Landsat data yielded 54 percent accuracy, so were too inaccurate to be useful. However, by combining the Landsat data with elevation values supplied by the DTT, a more accurate and useful vegetation map was created, as the elevation data permitted the inclusion of information on the distributional characteristics of specific plant communities. For example, a Landsat class identified as Mohave desert shrub vegetation was initially mapped at elevations from 365 to 2000 meters. However, in the field, it was found that this vegetation type seldom occurs at elevations above 1500 meters. Therefore, the areas classified as Mohave desert shrub above 1500 meters were reassigned to another vegetation category. The final vegetation map accuracy improved from 54 percent when only Landsat data were used, to 73 percent when both Landsat and elevation data were used (fig. 40).

\section{RANGELAND MANAGEMENT OPPORTUNITIES}

The final vegetation map, which provided useful information on the distribution of plant communities in the Grand Wash Planning Unit was used with other mapbased data to produce a series of management opportunity maps. The flexibility of the digital data base (vegetation, topography, and road network) permitted efficient generation of maps describing range conditions, public use options, and wildlife habitat.

\section{Sagebrush Treatment Areas}

Sagebrush is unpalatable to livestock and competes with and eventually forces out desirable feed plants. Burning is a common treatment in areas dominated by
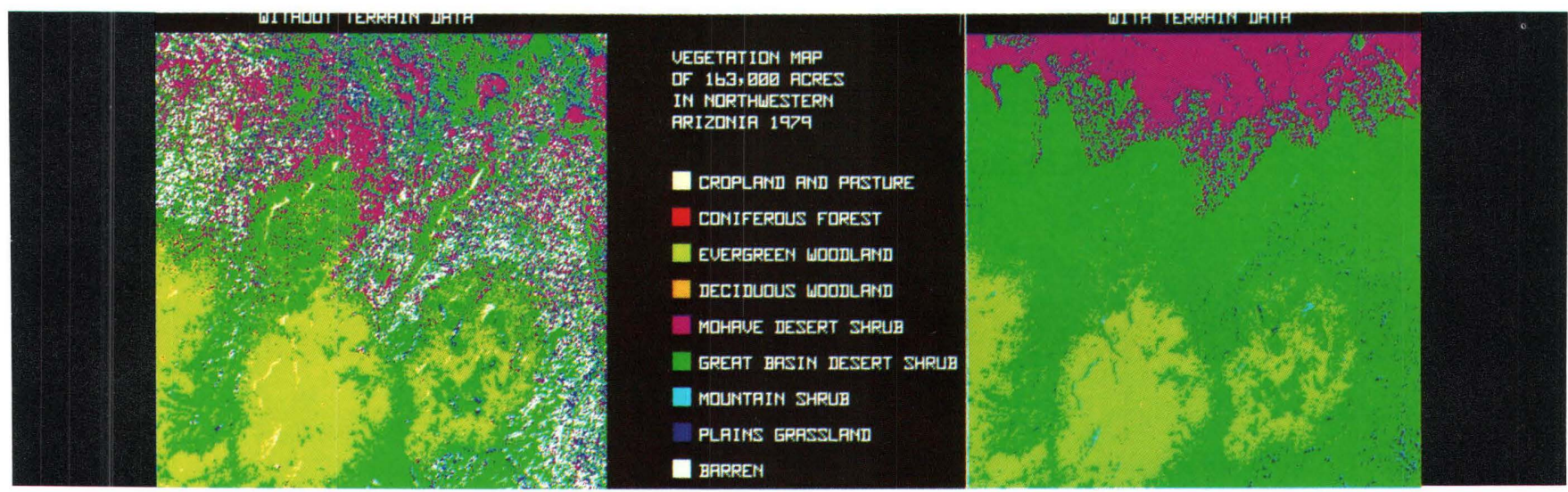

Figure 40. The use of topographic data with Landsat data to classify vegetation improved the accuracy of the vegetation map from 54 percent using only Landsat data to 73 percent. 
sagebrush since it destroys seeds and permits the regrowth of beneficial plant species. However, burning has adverse impacts because a burned area is susceptible to serious soil erosion. Based on these considerations, a composite map was created using vegetation, slope, and elevation data to show the location of sagebrush (using the vegetation and elevation maps) and define (using slope data) treatment areas with low soil erosion potential (fig. 41).

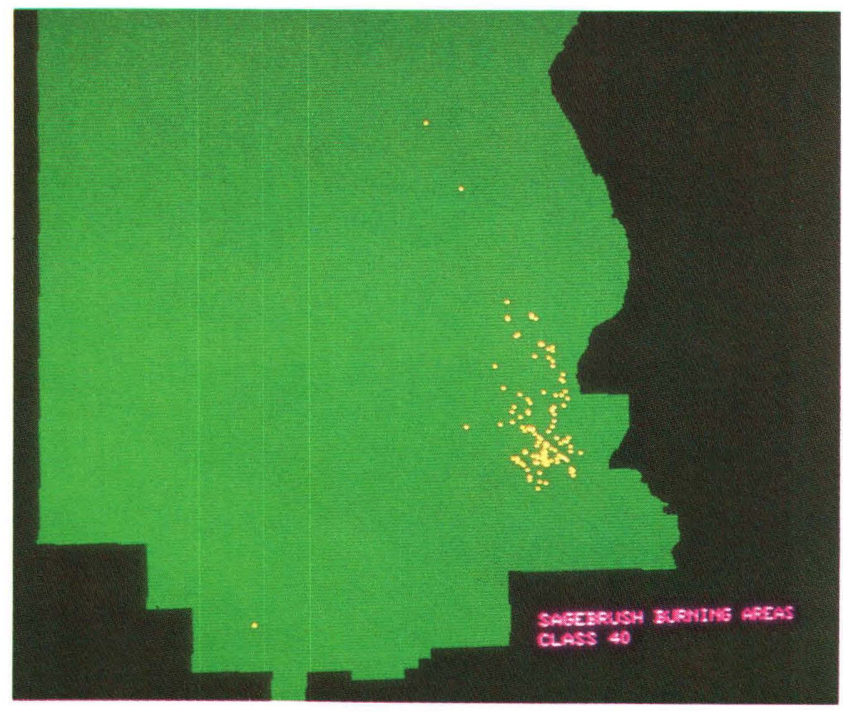

Figure 41. This Sagebrush Treatment Areas map was produced using vegetation, slope, and elevation data. Treatment areas are displayed in yellow.

\section{Pinyon-Juniper Cutting Areas}

The BLM has a program designed to make the PinyonJuniper vegetation, commonly cut for use as firewood by local residents, available to the public. A composite map that identifies areas where cutting can be done with a minimal impact on other resources, was created based on vegetation, elevation, slope, and road access (fig. 42.). Areas dominated by Pinyon-Juniper vegetation, with elevations between 1,500 and 1,800 meters, with slopes under 15 percent, and that lie within $0.8 \mathrm{~km}$ of a road were identified as Pinyon-Juniper cutting areas for issuance of permits.

\section{Potential Antelope Habitat}

Maps showing major habitat areas for antelope were needed to assist in preparing wildlife habitat management plans. By locating areas that could potentially carry significant antelope populations, the BLM can develop habitat management or species reestablishment plans that recognize the carrying capacity of the rangelands. The Potential Antelope Habitat composite map (fig. 43) was created by identifying areas with Great Basin desert shrub and Plains grassland vegetation, elevations between 1200 and 1800 meters and slopes under 20 percent.

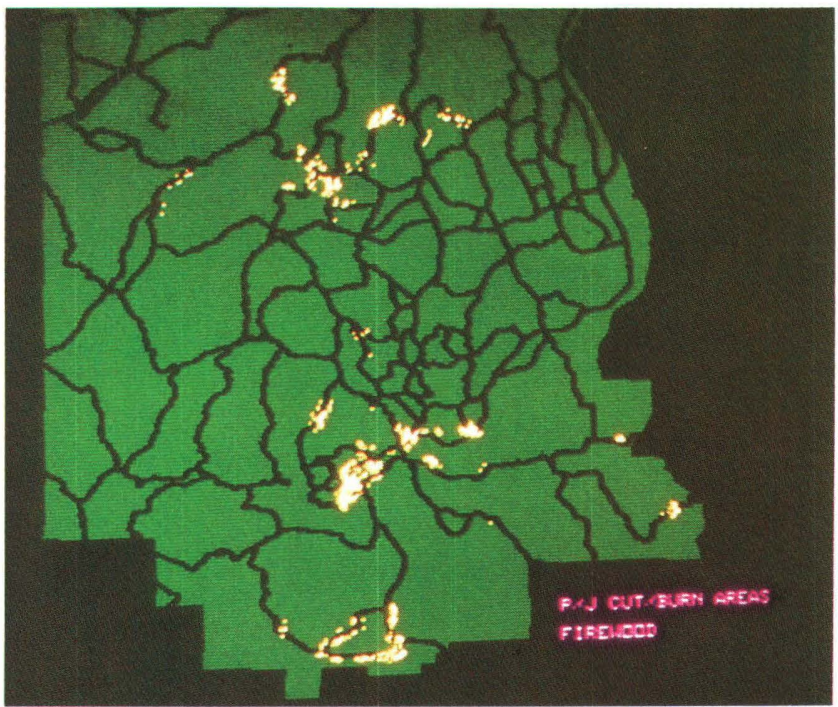

Figure 42. Pinyon-Juniper Cutting Areas, shown in yellow, were identified using vegetation, elevation, slope, and road network data.

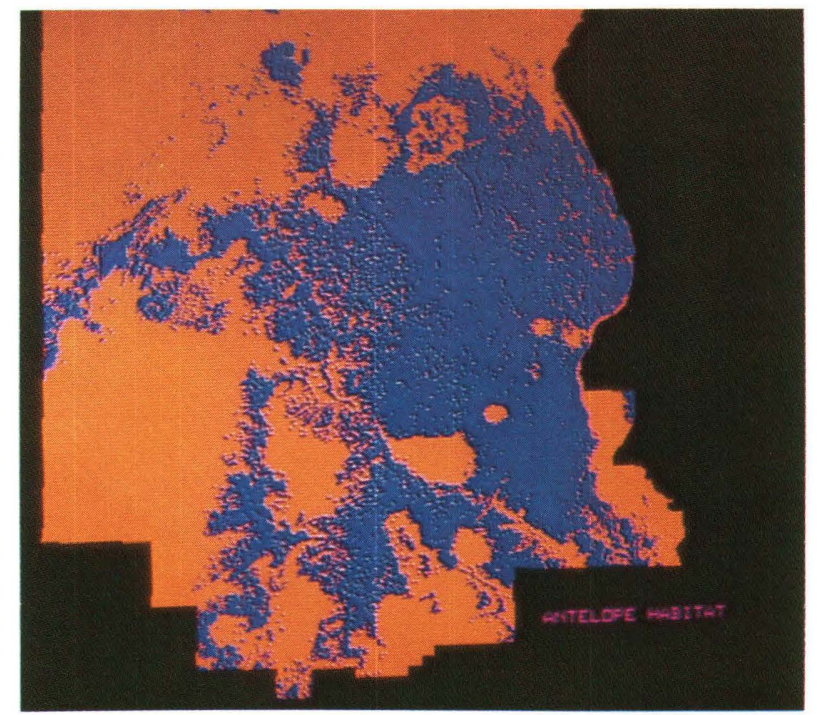

Figure 43. This Potential Antelope Habitat composite map was developed using vegetation, elevation, and slope data. Prime habitat is represented in blue.

\section{Other Management Opportunity Maps}

Six additional composite maps were produced using specific combinations of topographic, vegetation, and road network data. They were:

- Blackbrush Treatment Areas

- Pinyon-Juniper Burning Areas

- Mule Deer Spring/Fall Range

- Mule Deer Summer Range

- Mule Deer Winter Range

- Bighorn Desert Sheep Habitat 


\section{APPLICATION OF PRODUCTS}

The map products of the Grand Wash project were immediately applied to BLM planning and management activities. Both the vegetation map and the management opportunity maps have been used for land use planning, environmental analysis, and resource management. Specifically:

- Tree cutting permits are being granted using the Pinyon-Juniper Cutting Areas map.

- Habitat management plans have been prepared using the Potential Antelope Habitat map.

- The vegetation inventory map is being used for daily rangeland planning and analysis.

The digital data used in this project provide a flexible, powerful tool for range managers.

\section{SELECTED REFERENCES}

Bonner, W. G., Jr., 1978, Information requirements for natural resource inventories, in National Computer Conference, Anaheim, California, June 1978, Proceedings: Montvale, New Jersey, American Federation of Processing Societies, p. 87-91.

Ramey, George, Moore, Ken, Walker, L. D., and Wolfe, Cub, 1980, Executive summary - Arizona vegetation resource inventory and mapping project (Phase 2 ASVT Project) Final Report: Phoenix, Arizona, U.S. Bureau of Land Management, $16 \mathrm{p}$.

Rohde, W. G., and Miller, W. A., 1981, AVRI Arizona vegetation resource inventory final report: Unpublished report, Sioux Falls, SD, USGS EROS Data Center, 80 p. 


\section{South Carolina Coastal Zone Management}

\section{BACKGROUND}

The South Carolina coastal zone is comprised of approximately 200,000 hectares along a 320 kilometer coastline. This fragile natural resource is important as a fishery and as wildlife habitat; in addition, the region's aesthetic qualities have contributed to increased tourism and second-home ownerships. The developments associated with the recreational growth are of special concern. Orderly growth, that balances economic development while still preserving the ecological integrity of the coastal zone, is desired by State officials.

The enactment of Public Law 92-583, the Coastal Zone Management Act of 1972, by the U.S. Congress provided the framework needed by coastal States such as South Carolina to develop long-term management plans for orderly growth in the coastal zone. PL 92-583 required States to prepare a coastal zone management plan and enforcement procedures that identify:

1. Coastal zone boundaries

2. Permissible uses

3. Areas of particular concern

4. Areas of preservation

5. Areas of priority uses

6. Organizational structures

These components can be efficiently developed only if adequate information describing the coastal resources is available. Therefore, South Carolina initiated a program that would collect data relating to coastal resources and present it in a manner conducive to planning and management activities.

\section{THE PROBLEM}

The South Carolina Coastal Council was given the responsibility to establish an information system that provided the baseline data needed to evaluate coastal zone problems. Because of the large area involved, and because geographic data describing the location and characteristics of coastal resources were required, it was determined that a computer-based geographic information system would be the most effective tool for coastal zone planning and management. To minimize expenditures, it was decided that whenever possible, existing sources of data would be utilized.

The University of South Carolina's (USC) Computer Services Division, with program coordination provided by the State Division of Research and Statistical Services, Office of Geographical Statistics, was selected to develop and house the information system. Their initial objective was to produce maps and accompanying area statistics describing land use and wetland conditions in the coastal counties (fig. 44). Maps of general land use and land cover, and land use and detailed wetlands within the critical area of the coastal zone were needed.

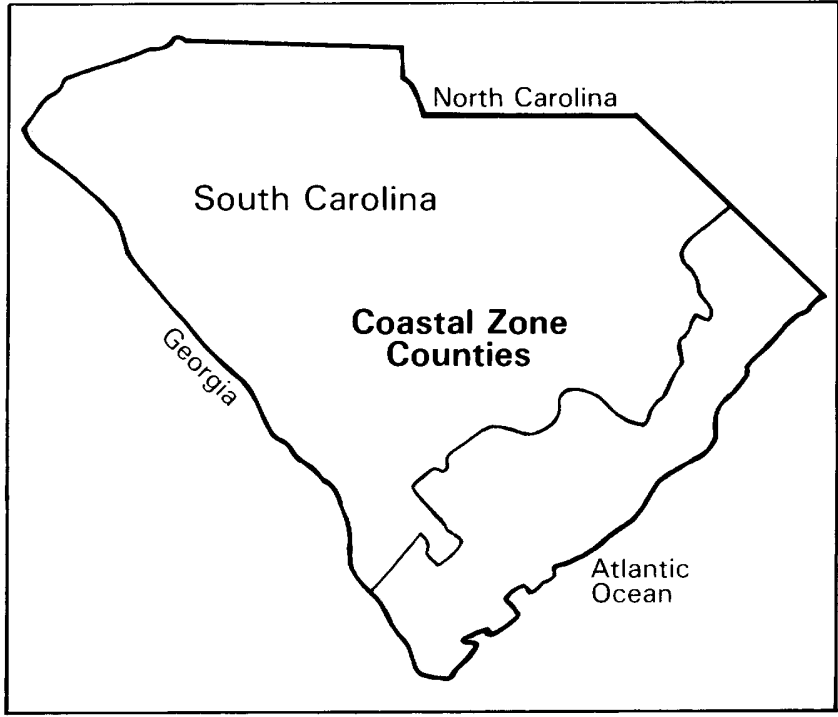

Figure 44. Eight counties comprise the South Carolina Coastal Zone. This 200,000 hectare region is primarily forested, but has significant areas of marshes and open water.

Under the direction of the University's Computer Services Division, the Geographic Information Retrieval and Analysis System (GIRAS) developed by the U.S. Geological Survey was used to produce the maps.

The South Carolina coastal mapping program involved several State agencies. Overall responsibility for the definition and utilization of the program's information resources belongs to the South Carolina Coastal Council; the software system maintenance and information production tasks are handled by the University of South Carolina Computer Services Division; and system direction and policies are the responsibility of the State Division of Research and Statistical Services, Office of Geographical Statistics. The U.S. Geological Survey provided technical assistance in the installation and use of the Geographic Information Retrieval and Analysis System (GIRAS).

This case study is based on materials prepared by the coastal mapping project's major investigator, Dr. David J. Cowen. For more information, contact:
Dr. David J. Cowen
Department of Geography
University of South Carolina
Columbia, SC 29621
(802) $777-6803$ 


\section{DATA SOURCES}

\section{Land Use and Land Cover}

Land use and land cover data describing the location and types of land uses and cover types in South Carolina's eight coastal counties were needed for understanding the relationships between developed and natural areas. Accurate land use and land cover maps and statistics would provide insight into potential conflicts that might currently exist or arise with future development.

Land use and land cover data, produced by the U.S. Geological Survey were selected as the source of the baseline land use information (fig. 45). The USGS maps provided complete coverage of the eight coastal counties and thus served as an excellent tool for preparing the land use component of the South Carolina Coastal Zone Management Plan. The data were particularly useful because 40 percent of the coastal zone land use data were available in a digital form.

\section{Other Data}

Detailed wetlands data (information showing locations of salt marshes, brackish marshes, freshwater marshes, etc.) were needed to thoroughly understand the fragile environmental conditions of the coastal zone. Under the Coastal Council's direction, extensive field surveys and interpretations of low-altitude color-infrared aerial photographs were used to produce these data, which were then digitized so that they could be used in conjunction with other digital geographic data.

\section{COASTAL ZONE MAPPING}

The mapping of land uses in the eight coastal counties was completed in two stages. In the initial stage, the USC Computer Services Division used USGS land use and land cover data to produce a Level I land use and land cover map which displayed: (1) urban or built-up lands, (2) agricultural lands, (3) rangeland, (4) forest land, (5) water, (6) wetlands, and (7) barren lands. The map was produced by first digitizing the land use and land cover maps that were not already in a computer-compatible format, then merging these data with the existing digital files, and finally using the automated mapping capabilities of GIRAS to produce color separates of the land use and land cover categories. The separates were then combined to produce a four-color land use map. Area statistics for each land use and land cover category were also generated. Thus, a recent and unbiased inventory map of general land uses in the eight coastal counties was produced.

The second mapping stage consisted of increasing the information contained in the Level I map by subdividing the general wetlands category into the detailed wetlands categories mapped by the South Carolina Coastal Coun-

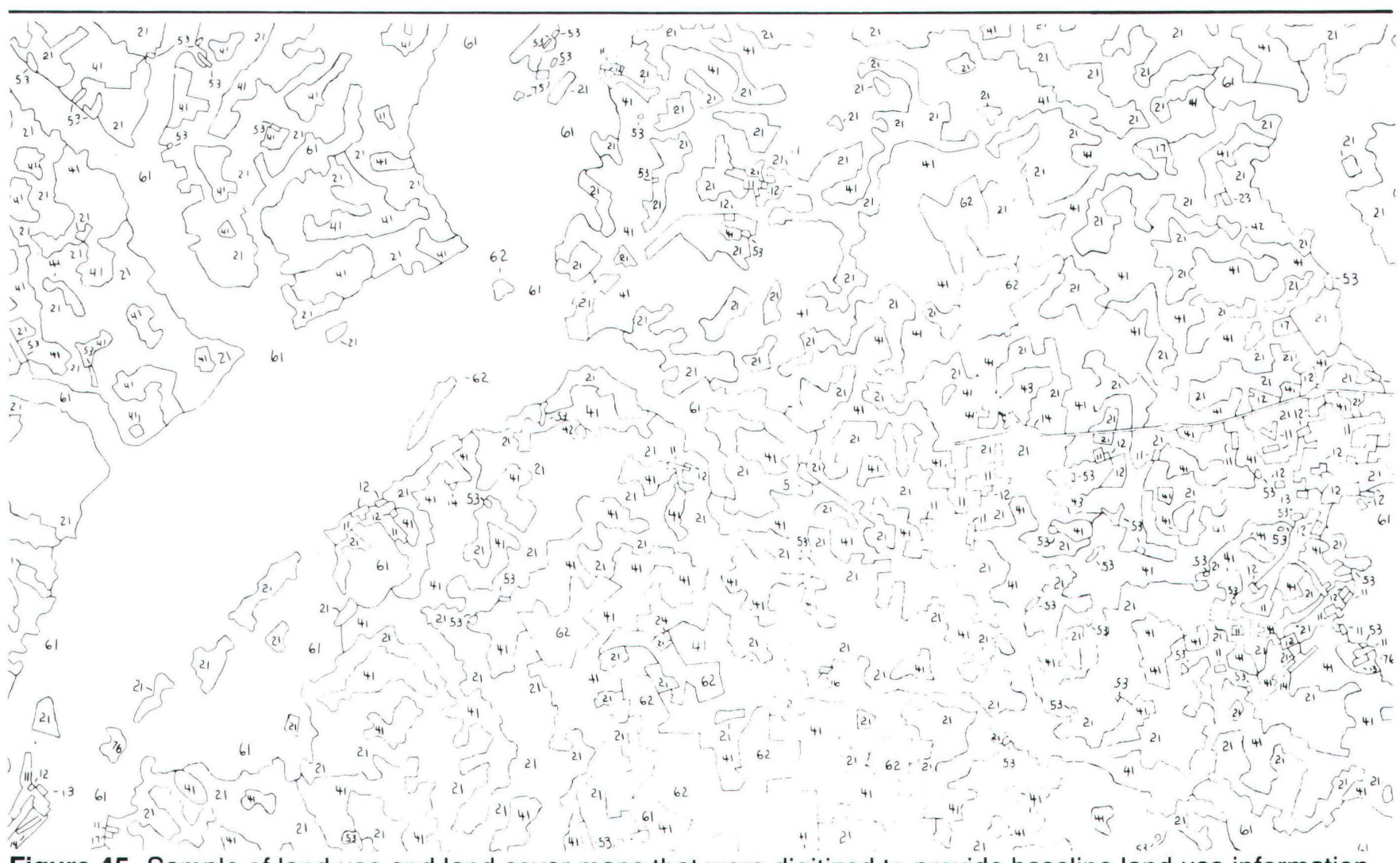

Figure 45. Sample of land use and land cover maps that were digitized to provide baseline land use information. 
cil. In addition, critical areas of the coastal zone were defined. The result was a map displaying the Council's detailed wetlands categories and the USGS's general land use classes and accompanying area statistics summarizing category acreages for both the critical and noncritical areas of each of the eight South Carolina coastal counties (fig. 46). This final product is an innovative combination of the basic USGS land use and land cover data with data collected by local agencies. By augmenting existing data with the detailed, locally collected data required in the planning process, a cost-effective approach was designed to meet South Carolina's information requirements.

\section{APPLICATION OF PRODUCTS}

The South Carolina Coastal Zone land use and land cover maps provided the Coastal Council with information that was used to prepare components of the management plan required by the Coastal Zone Management Act of 1972. The maps and statistics are also valuable tools for carrying out the directives of South Carolina's Coastal Zone Management Act of 1977 (Code of Laws of South Carolina, 1976, v. 16, chapter 391980 Supplement). Specific requirements of the State Act that can use the land use maps include:

(1) Comprehensive coastal zone management planning;
(2) Examining, modifying, improving, or denying applications for permits for activities.

(3) Managing and regulating all activities within estuaries and marine sanctuaries.

(4) Establishing, controlling, and administering pipeline corridors and the location of pipelines in critical areas;

(5) Directing and coordinating the beach and coastal shore erosion control activities.

The flexibility of the coastal mapping program, best illustrated by the ability to combine data from a variety of existing sources, provides a useful tool for managing both current and future problems facing South Carolina's coastal zone.

\section{SELECTED REFERENCES}

Cowen, D. J., Crosley, Powel, and Holland, Michael, 1979, Automated mapping of South Carolina's coastal zone: Proceedings of the American Congress on Surveying and Mapping, Washington, D.C., p. 247-253.

Cowen, D. J., Walters, George, Feinberg, Kenneth, Holland, Michael, and Vang, Alfred, 1979, The evolution of the South Carolina coastal mapping program, in Computer Mapping in Education, Research

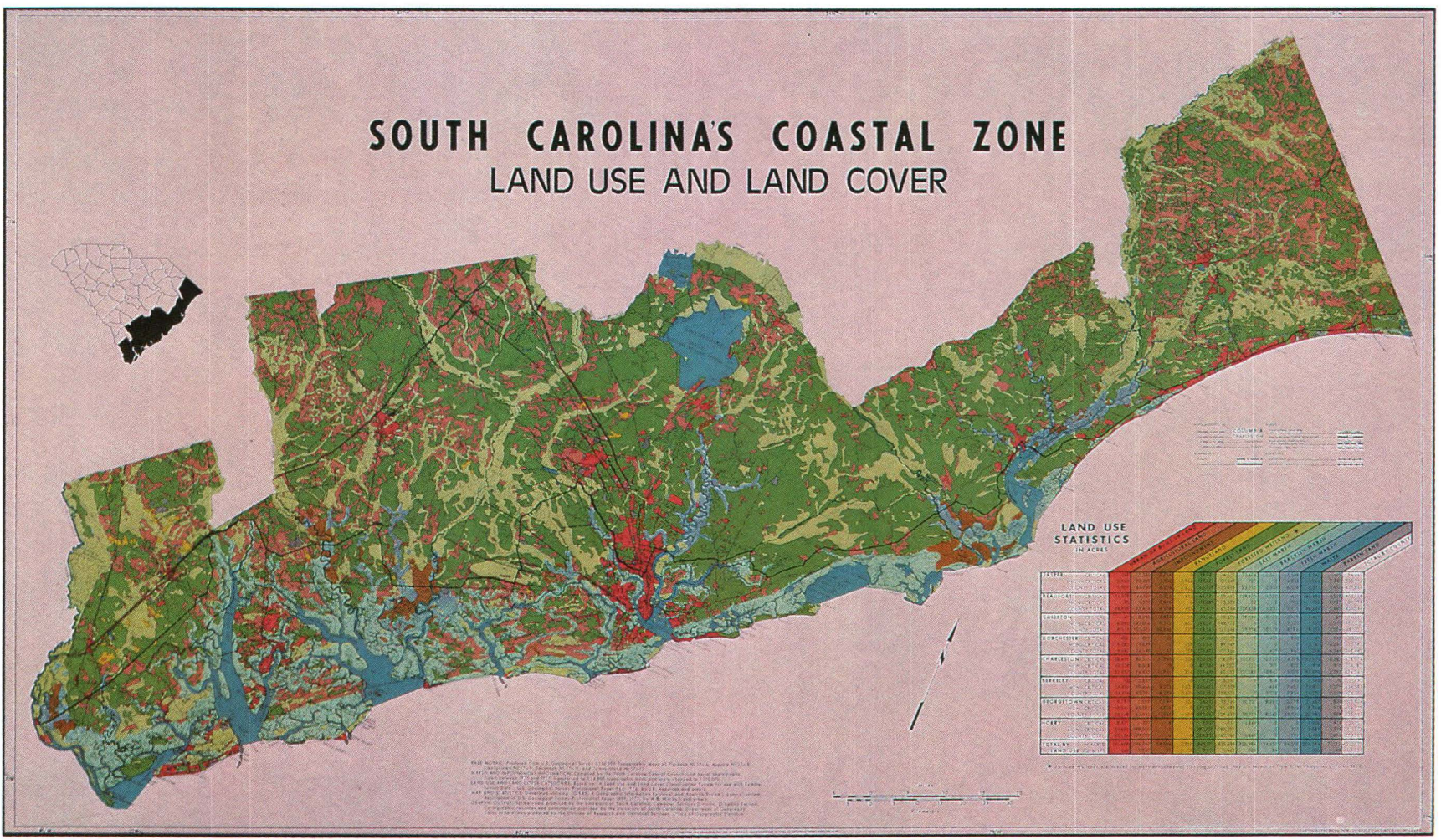

Figure 46. South Carolina Coastal Zone land use map produced using both USGS and Coastal Council land use and land cover data identifies both the uses of the coast's critical zone and provides a detailed summary of acreage statistics. 
and Mapping, Cambridge, Massachusetts, Harvard Laboratory for Computer Graphics and Spatial Analysis, p. 29-36.

Cowen, D. J., Vang, A. H., and Waddell, J. M., Jr., 1980, The South Carolina geographical information system: the role of the State and the University in system implementation, in Urban, Regional, and State Government Applications of Computer Map- ping, Cambridge, Massachusetts, Harvard Laboratory for Computer Graphics and Spatial Analysis, p. 48-58.

Mitchell, W. B., Guptill, S. C., Anderson, K. E., Fegeas, R. G., and Hallam, C. A., 1977, GIRAS - A geographic information retrieval and analysis system for handling land use and land cover data: U.S. Geological Survey Professional Paper 1059, p. 16. 


\section{Environmental Assessment of a Nuclear Power Plant Accident- The Three Mile Island Example}

\section{BACKGROUND}

A nuclear accident occurred in late March 1979 at the Three Mile Island thermal nuclear power plant on the Susquehanna River, 10 miles southeast of Pennsylvania's State capital, Harrisburg. Although the plant is located in an area dominated by forests, agricultural land, and open water, it is at the center of a triangle formed by populous metropolitan centers at Harrisburg, York and Lancaster (fig. 47).

The incident raised questions regarding the need for and availability of data upon which disaster assessments and evacuation plans could be made. When an accident occurs, a cartographic data base must already exist if politicians, planners, utility company personnel, and involved laymen can be expected to quickly implement the most desirable course of action. A variety of data types could be maintained in this data base, including land use and land cover, topography, hydrology, landownership, transportation, and population distribution, keyed to census statistical tracts and local political units. When population data are combined with land use and transportation information, different evacuation plans can be developed which take into account the daily patterns of movement of various segments of the population (for example, school children, urban workers, and farmers).

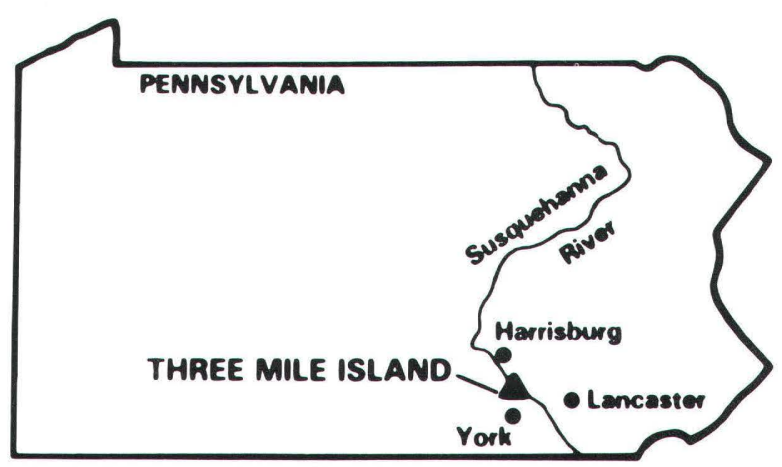

Figure 47. Three Mile Island is located on the Susquehanna River in eastern Pennsylvania. It lies in the middle of a triangle formed by the cities of York, Harrisburg, and Lancaster.

\section{THE PROBLEM}

A comprehensive data base of natural and cultural resource information did not exist in a readily accessible format at the time of the Three Mile Island accident. When hearings were held by the Atomic Safety and Licensing Board of the Nuclear Regulatory Commission following the accident, a request for preparation of relevant map products was made to the U.S. Geological Survey. In response to this request, two types of digital cartographic products were produced using the USGS Geographic Information Retrieval and Analysis System (GIRAS):

(1) computer-plotted maps of land use and land cover, with census tracts, for 20 - and 50 -mile radius areas.

(2) population density maps for 20- and 50-mile radius areas.

\section{DATA SOURCES}

\section{Land Use and Land Cover}

Regional land use and land cover patterns are important input to determining the types of impacts which would result from a nuclear accident. Land use data can provide a means to determine whether the affected area is predominantly populated, agricultural, or undeveloped. This information, when combined with other data (such as radiation released and wind speed and direction) can assist officials in predicting the magnitude of the impacts on area residents.

The land use and land cover data were contained in a statewide digital data base that was developed as part of a cooperative effort between the Pennsylvania Department of Environmental Resources and the U.S. Geological Survey. The Geological Survey compiled the data as part of its land use and land cover mapping program. Nineteen categories were mapped in the Three Mile Island area.

This data base was maintained on GIRAS, which can be used to perform computer mapping as well as to correlate land use area measurements with census and other data, to update data sets, and to retrieve and analyze data.

\section{Census Areas}

U.S. Bureau of the Census data, which identify census area boundaries, were needed to assess the demographic characteristics of the impacted region. Census County Subdivision boundaries were available in digital form through the USGS land use and land cover data analysis program.

\section{Population}

Census Bureau population estimates for 1977 were used to determine population density. 


\section{IMPACT MAPPING}

The initial analysis produced a map displaying the land use and land cover and census tracts of the Three Mile Island region (fig. 48). The digital nature of the data allowed the use of the automated mapping capabilities of GIRAS, which is designed to accept digitized input, provide comprehensive editing facilities, produce cartographic and statistical output, permit retrieval and analysis of data, and exercise data-base management tasks. For this application, the data were plotted on base maps that covered areas within $32 \mathrm{~km}$ and $80 \mathrm{~km}$ of the Three Mile Island facility. The final maps have the radius information displayed in 5-mile increments.

The presentation of land use, census, and radius data on one map provides a unique tool for identifying the affected areas. For example, by comparing the demographic characteristics of census tracts in the residential land uses areas, it is possible to estimate the number of people who might be affected. The consideration of cropland and pasture locations in relationship to the distance from the power plant permits an assessment of the extent to which food supplies might be affected by a nuclear accident.
The second map displayed 1977 population density estimates by Census County Subdivision, with 5-mile radius increments. It was produced by calculating the population densities for the region and using the GIRAS automated mapping capabilities to plot the data (fig. 49).

\section{POTENTIAL APPLICATIONS OF PRODUCTS}

The set of maps produced for the Three Mile Island area is a prototype demonstration of a working atlas for hazard mitigation and emergency response. It could be used to plan for different scenarios of potential disasters, or as a basis for reacting to an actual disaster such as might have occurred at Three Mile Island in 1979. For example, if wind patterns and other meteorological phenomena are known, then fallout patterns from radiation leaks can be plotted and their impact on human populations and agricultural resources can be assessed. The land use and population density information can be manipulated to portray the movement of various segments of the population during a typical day. In this way, the impacts of

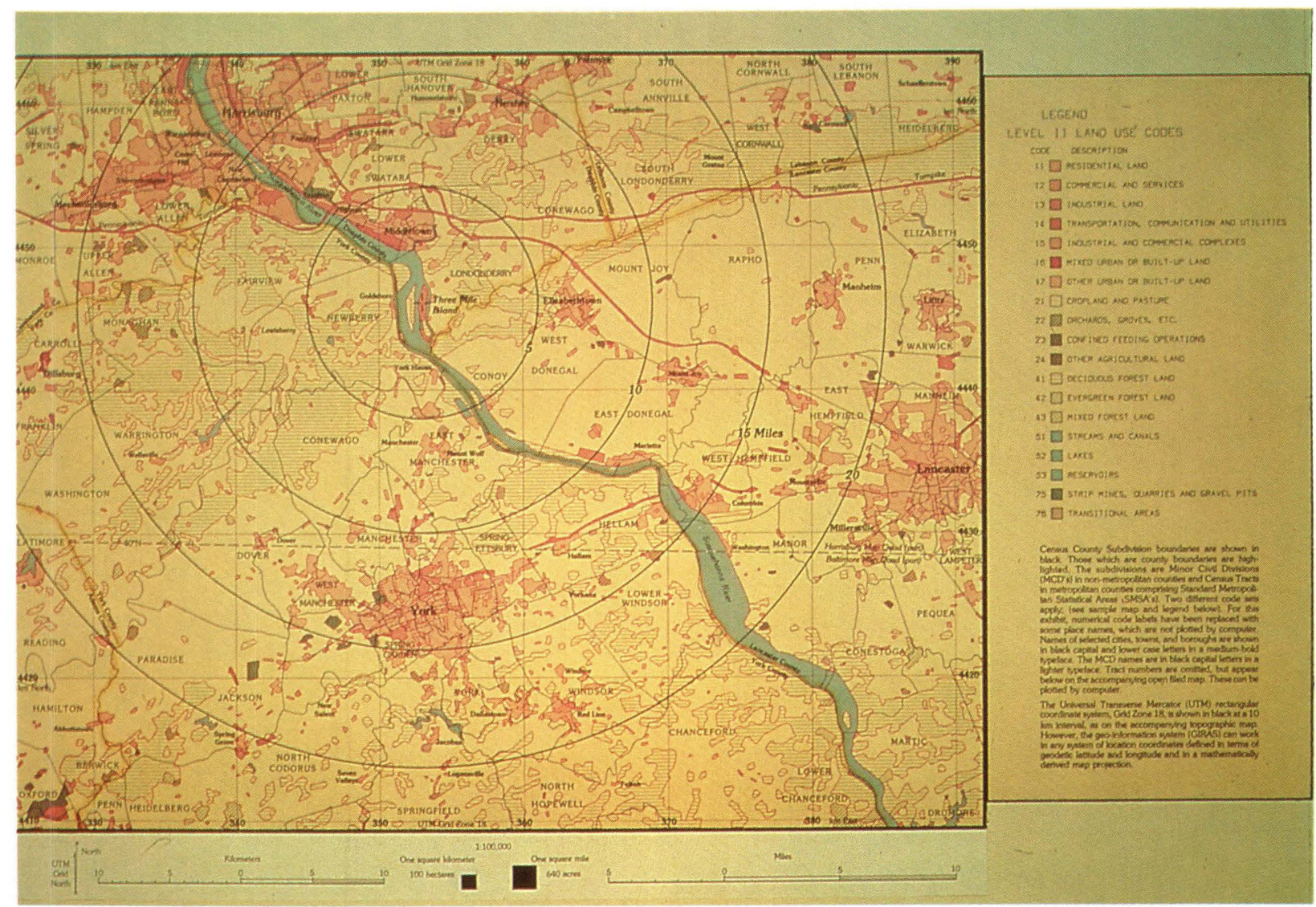

Figure 48. Land use and land cover and census tract map area around Three Mile Island (original scale 1:100,000). Nineteen categories of land use and land cover have been mapped. Census county subdivision boundaries are shown by black lines and upper case lettering. 


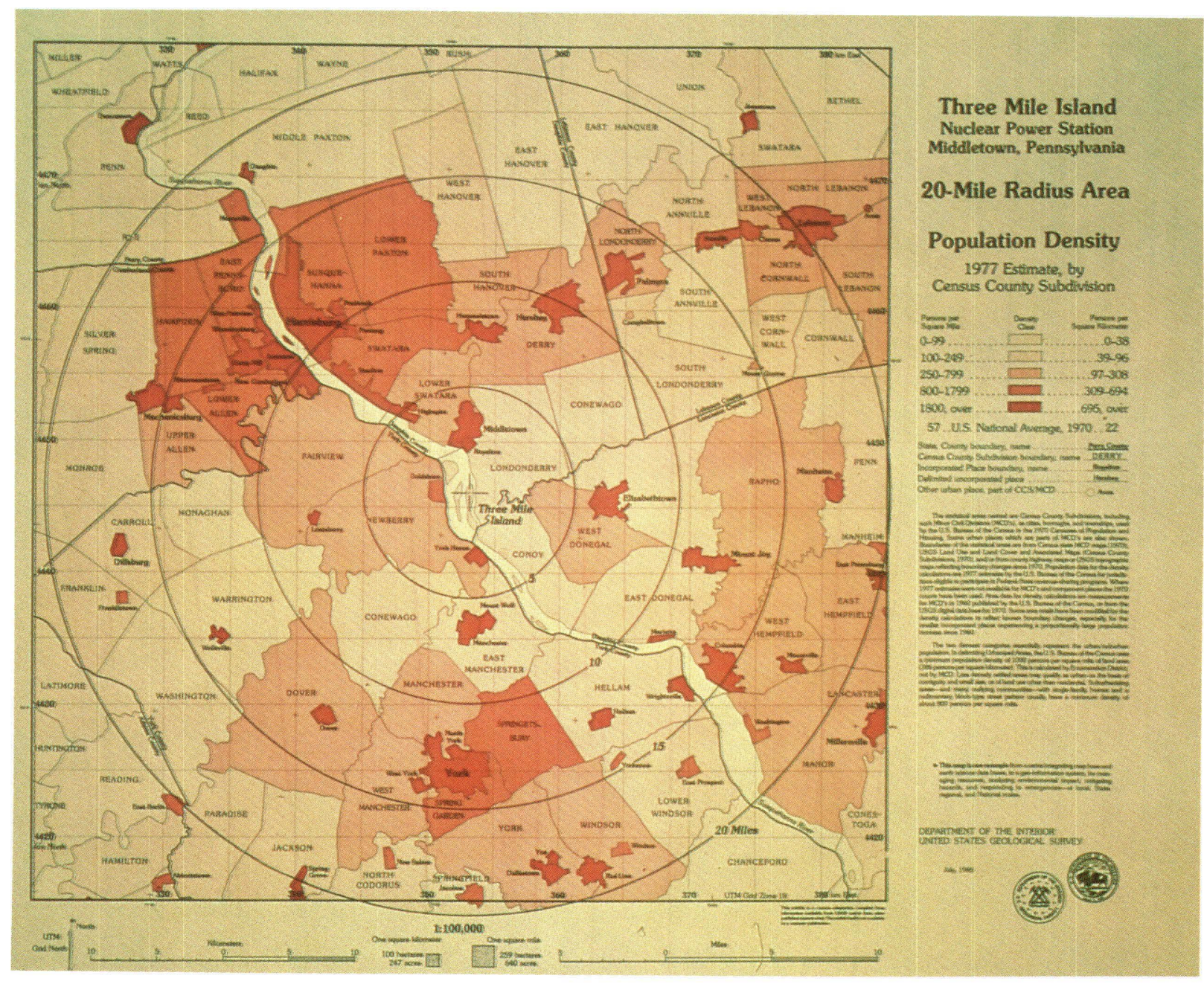

Figure 49. Population density for a 20-mile radius area around Three Mile Island (original scale 1:100,000). The two densest categories represent most of the urban/suburban population

fallout can be made more time-and-location specific, and response to a disaster can be more effective.

This data base would be useful for planning evacuation routes and other emergency response actions. Population distributions can be correlated with patterns of radiation dispersion to identify transportation routes which would be most effectively used as evacuation routes. Those routes which do not have adequate capacity, or would pass through areas of excessively high radiation, could be identified and avoided. The data base of land use, population, and associated transportation networks would also be appropriate for identifying sites for fallout shelters and host areas for relocation of the affected population.

Because much of the information needed for such a data base is customarily used in the power plant site selection process, and thus would already be available upon completion of construction of the nuclear power plant, it would be logical to maintain and update it in a data base for disaster impact assessment and planning purposes. Computer-based geographic information systems are available to facilitate data entry, storage, manipulation, update, monitoring, and display.

The map series discussed here was designed and produced by James R. Wray, Robin Fegeas, and Bruce Wright, Office of Geographic and Cartographic Research, U.S. Geological Survey, to meet the needs of agencies that were assessing the implications of the Three Mile Island accident for future power plant disaster planning. For further details, contact:

Office of Geographic and Cartographic Research National Mapping Division

U.S. Geological Survey

521 National Center

Reston, Virginia 22092

(703) 860-7796 